\title{
The Jena Diversity-Dynamic Global Vegetation Model (JeDi-DGVM): a diverse approach to representing terrestrial biogeography and biogeochemistry based on plant functional trade-offs
}

\author{
R. Pavlick ${ }^{1,2}$, D. T. Drewry ${ }^{1,3}$, K. Bohn ${ }^{1}$, B. Reu ${ }^{1,4}$, and A. Kleidon ${ }^{1}$ \\ ${ }^{1}$ Max Planck Institute for Biogeochemistry, Jena, Germany \\ ${ }^{2}$ International Max Planck Research School on Earth System Modelling, Hamburg, Germany \\ ${ }^{3}$ Jet Propulsion Laboratory, California Institute of Technology, Pasadena, California, USA \\ ${ }^{4}$ Institute of Biology, University of Leipzig, Leipzig, Germany
}

Correspondence to: R. Pavlick (rpavlick@bgc-jena.mpg.de)

Received: 26 March 2012 - Published in Biogeosciences Discuss.: 17 April 2012

Revised: 4 April 2013 - Accepted: 15 May 2013 - Published: 21 June 2013

\begin{abstract}
.
Terrestrial biosphere models typically abstract the immense diversity of vegetation forms and functioning into a relatively small set of predefined semi-empirical plant functional types (PFTs). There is growing evidence, however, from the field ecology community as well as from modelling studies that current PFT schemes may not adequately represent the observed variations in plant functional traits and their effect on ecosystem functioning. In this paper, we introduce the Jena Diversity-Dynamic Global Vegetation Model (JeDiDGVM) as a new approach to terrestrial biosphere modelling with a richer representation of functional diversity than traditional modelling approaches based on a small number of fixed PFTs.

JeDi-DGVM simulates the performance of a large number of randomly generated plant growth strategies, each defined by a set of 15 trait parameters which characterize various aspects of plant functioning including carbon allocation, ecophysiology and phenology. Each trait parameter is involved in one or more functional trade-offs. These trade-offs ultimately determine whether a strategy is able to survive under the climatic conditions in a given model grid cell and its performance relative to the other strategies. The biogeochemical fluxes and land surface properties of the individual strategies are aggregated to the grid-cell scale using a mass-based weighting scheme.
\end{abstract}

We evaluate the simulated global biogeochemical patterns against a variety of field and satellite-based observations following a protocol established by the Carbon-Land Model Intercomparison Project. The land surface fluxes and vegetation structural properties are reasonably well simulated by JeDi-DGVM, and compare favourably with other state-ofthe-art global vegetation models. We also evaluate the simulated patterns of functional diversity and the sensitivity of the JeDi-DGVM modelling approach to the number of sampled strategies. Altogether, the results demonstrate the parsimonious and flexible nature of a functional trade-off approach to global vegetation modelling, i.e. it can provide more types of testable outputs than standard PFT-based approaches and with fewer inputs.

The approach implemented here in JeDi-DGVM sets the foundation for future applications that will explore the impacts of explicitly resolving diverse plant communities, allowing for a more flexible temporal and spatial representation of the structure and function of the terrestrial biosphere. 


\section{Introduction}

Human activities are altering the terrestrial biosphere at a large scale and an alarming rate (Millennium Ecosystem Assessment, 2005). The risks associated with these activities have led to the development of terrestrial biosphere models (TBMs; e.g. Foley et al., 1996; Friend et al., 1997; Woodward et al., 1998; Cox, 2001; Sitch et al., 2003). These mechanistic, process-based, numerical models simulate the large-scale dynamics of terrestrial ecosystems and have proven useful for testing hypotheses and making predictions regarding the responses of ecosystem structure and functioning to past and future environmental changes (Quillet et al., 2010). TBMs have also been embedded within comprehensive earth system models (ESMs) to capture biogeochemical and biogeophysical feedbacks between the terrestrial biosphere and the physical climate system (Levis , 2010). Intercomparison studies (Friedlingstein et al., 2006; Sitch et al., 2008), however, have revealed considerable divergence among the results of these models with respect to the fate of the terrestrial biosphere and its function as a driver of the global carbon cycle under projected scenarios of climate change. This divergence may be, at least in part, due to their coarse and differing treatment of plant functional diversity (Sitch et al., 2008; Harrison et al., 2010; R. Fisher et al., 2010).

For reasons of computational efficiency as well as a lack of sufficient data and theory, TBMs typically abstract the immense functional diversity of the over 300000 documented plant species to a small number (typically between 4 and 20) of discrete plant functional types (PFTs; Kattge et al., 2011) which are defined a priori before any simulations are run. In the context of TBMs, PFTs represent broad biogeographical, morphological, and phenological aggregations (e.g. tropical broadleaf evergreen forest or boreal needleleaf deciduous forest) within which parameter values are held spatially and temporally constant and responses to physical and biotic factors are assumed to be similar (Prentice et al., 2007). They have typically been classified subjectively using expert knowledge, and their occurrence within a given model grid cell is based, either directly or indirectly, on semiempirical bioclimatic limits, such as minimum or maximum annual temperature (e.g. Box, 1996; Bonan et al., 2002; Sitch et al., 2003). Inductive approaches have also been proposed wherein PFTs are objectively classified by applying statistical techniques to large datasets of vegetation traits and climatic variables (e.g. Chapin et al., 1996; Wang and Price, 2007). Some TBMs known as dynamic global vegetation models (DGVMs) allow the distribution of PFTs to evolve dynamically in response to changes in climate. Regardless of approach, the PFT schemes used by current TBMs, and in particular those used by DGVMs, have been criticized as ad hoc and as ignoring much of our growing knowledge of comparative plant ecology (Harrison et al., 2010).

In fact, the field ecology community has shown that for many plant traits there is a large amount of variation within
PFTs, and that for several important traits there is greater variation within PFTs than between PFTs (Wright et al., 2005; Reich et al., 2007; Kattge et al., 2011). This trait variation may play an important role for many ecosystem functions (Díaz and Cabido, 2001; Westoby et al., 2002; Ackerly and Cornwell, 2007) and for ecosystem resilience to environmental change (Díaz et al., 2006). Recent model-data assimilation studies using eddy covariance fluxes (Groenendijk et al., 2011) as well as other field and satellite-based observations (Alton, 2011) provide confirmation that current PFT schemes are insufficient for representing the full variability of vegetation parameters necessary to accurately represent carbon cycle processes. A more theoretical study by Kleidon et al. (2007) demonstrated that using a small number of discrete vegetation classes in a coupled climate-vegetation model can lead to potentially unrealistic multiple steadystates when compared with a more continuous representation of vegetation. Others have contended that DGVMs may overestimate the negative effects of climate change by not accounting for potential shifts in ecosystem compositions towards species with traits more suited to the new conditions (Purves and Pacala, 2008; Tilman et al., 2006). For example, some coupled climate-vegetation models (e.g. Cox et al., 2000) project an alarming dieback of the Amazon rainforest under plausible scenarios of continuing anthropogenic greenhouse gas emissions. The coarse representation of functional diversity in these models provided by current PFT schemes could be leading to an overestimation of the strength and abruptness of this response (R. Fisher et al., 2010). Likewise, DGVMs might underestimate the positive effects of environmental changes on ecosystem performance, e.g. by ignoring warm-adapted species in typically temperature-limited regions (Loehle, 1998). Therefore, while PFTs have been and will likely continue to be useful for many modelling applications, going forward we will need new approaches that allow for a richer representation of functional diversity in DGVMs.

Many approaches have been proposed to meet the challenge of improving the representation of functional diversity in DGVMs (e.g. Wright et al., 2005; Reich et al., 2007; Kattge et al., 2009; Harrison et al., 2010; Verheijen et al., 2012). However, so far, most of these have applied empirical relationships between observed plant traits and environmental (primarily climatic) factors. The utility of such correlational approaches for predicting the effects of global change on the terrestrial biosphere may be limited, as climate model projections point towards the possibility of novel climates without modern or palaeo-analogues (Jackson and Williams, 2004; Williams and Jackson, 2007). Other modellers have introduced schemes in which PFT parameters adapt to environmental conditions, e.g. with adaptive parameters related to leaf nitrogen (Zaehle and Friend, 2010), allocation (Friedlingstein et al., 1999) and phenology (Scheiter and Higgins, 2009). However, despite some interesting proposals (e.g. Falster et al., 2010; Van Bodegom et al., 2011), so far no DGVM has sought to mechanistically represent the 
full range of functional trait diversity within plant communities (i.e. at the subgrid scale) using a trait-based trade-off approach. Such approaches have enabled significant progress in modelling the biogeographical and biogeochemical patterns of global marine ecosystems (Bruggeman and Kooijman, 2007; Litchman et al., 2007; Follows et al., 2007; Dutkiewicz et al., 2009; Follows and Dutkiewicz, 2011).

Here, we introduce our prototype for a new class of vegetation models that mechanistically resolve subgrid-scale trait variability using functional trade-offs, the Jena DiversityDGVM (hereafter JeDi-DGVM). Just as the first generation of PFT-based DGVMs were built upon earlier PFT-based equilibrium biogeography models, JeDi-DGVM builds upon an equilibrium biogeography model (Kleidon and Mooney, 2000, hereafter KM2000) based on the concept of functional trade-offs and environmental filtering. JeDi-DGVM and KM2000 were inspired by the hypothesis "Everything is everywhere, but the environment selects" (Baas-Becking, 1934; O’Malley, 2007). This nearly century-old idea from marine microbiology postulates that all species (or in the case of JeDi-DGVM, combinations of trait parameter values) are, at least latently, present in all places, and that the relative abundances of those species are determined by the local environment based on selection pressures. Rather than simulating a handful of PFTs, JeDi-DGVM simulates the performance of a large number of plant growth strategies, which are defined by a vector of 15 functional trait parameters. The trait parameter values determine plant behaviour in terms of carbon allocation, ecophysiology, and phenology and are randomly selected from their complete theoretical or observed ranges. JeDi-DGVM is constructed such that each trait parameter is involved in one or more functional trade-offs (Bloom et al., 1985; Smith and Huston, 1989; Hall et al., 1992; Westoby and Wright, 2006). These trade-offs ultimately determine which growth strategies are able to survive under the climatic conditions in a given grid cell, as well as their relative biomasses.

KM2000 demonstrated that this bottom-up plant functional trade-off approach is capable of reproducing the broad geographic distribution of plant species richness. More recently, their trade-off approach has provided mechanistic insight into other biogeographical phenomena including the global patterns of present-day biomes (Reu et al., 2010), community evenness and relative abundance distributions (Kleidon et al., 2009), as well as possible mechanisms for biome shifts and biodiversity changes under scenarios of global warming (Reu et al., 2011). JeDi-DGVM extends the KM2000 modelling approach to a population-based model capable of representing the large-scale dynamics of terrestrial vegetation and associated biogeochemical fluxes by aggregating the fluxes from the many individual growth strategies following the "biomass-ratio" hypothesis (Grime, 1998).

In the following section, we describe the novel features of the JeDi-DGVM including mechanistic trait filtering via environmental selection and how the resulting fluxes and land surface properties associated with many plant growth strategies are aggregated to the ecosystem scale. More detailed descriptions of the model equations and parameters are provided in Appendices A-C. Then, we evaluate the simulated patterns of terrestrial biogeochemical fluxes and associated land surface properties against a variety of field and satellite-based observations. To highlight the unique capabilities of JeDi-DGVM, we also evaluate the simulated patterns of functional diversity and the sensitivity of the mechanistic trait-filtering approach to the number of sampled plant growth strategies. Finally, we discuss the current limitations of the JeDi-DGVM, as well as some potential improvements and applications, before we close with a summary and conclusion.

\section{The Jena Diversity-Dynamic Global Vegetation Model}

JeDi-DGVM consists of a plant growth module that is tightly coupled to a land surface module. Both components contain parameterizations of ecophysiological and land surface processes that are common to many current global vegetation and land surface models. The main novelties in the vegetation component are (i) an explicit representation of trade-offs that are associated with a diverse set of plant growth strategies, (ii) the inclusion of the whole trait space for testing their relative fitness, and (iii) the aggregation of properties and fluxes from the individual growth strategies to grid-scale structure and function based based on their relative abundances. The following overview of the model focuses on describing the novel combination of these components and how they are implemented in the model, while the full description with the detailed parameterizations is provided in Appendices AC. A schematic diagram of the JeDi-DGVM modelling approach is shown in Fig. 1.

\subsection{Representation of trade-offs}

When we speak of terrestrial vegetation, we speak of a large number of plants of different species that differ to some extent in how they grow and respond to the environment. In fact, in a given environment there are potentially many different strategies by which individual plant species could grow and cope with the environment, with some ways being more beneficial to growth and reproductive success than other ways. Some plant species, for instance, grow and reproduce rapidly, such as grasses, while others, such as trees, grow slowly and it takes them a long time to reproduce. Some species allocate a greater fraction of their assimilates to leaves, enhancing their ability to capture incoming sunlight, while others allocate more to root growth, increasing their access to soil moisture. Some species react quickly to changes in environmental conditions, thereby potentially exploiting more of the beneficial conditions for growth, while others 


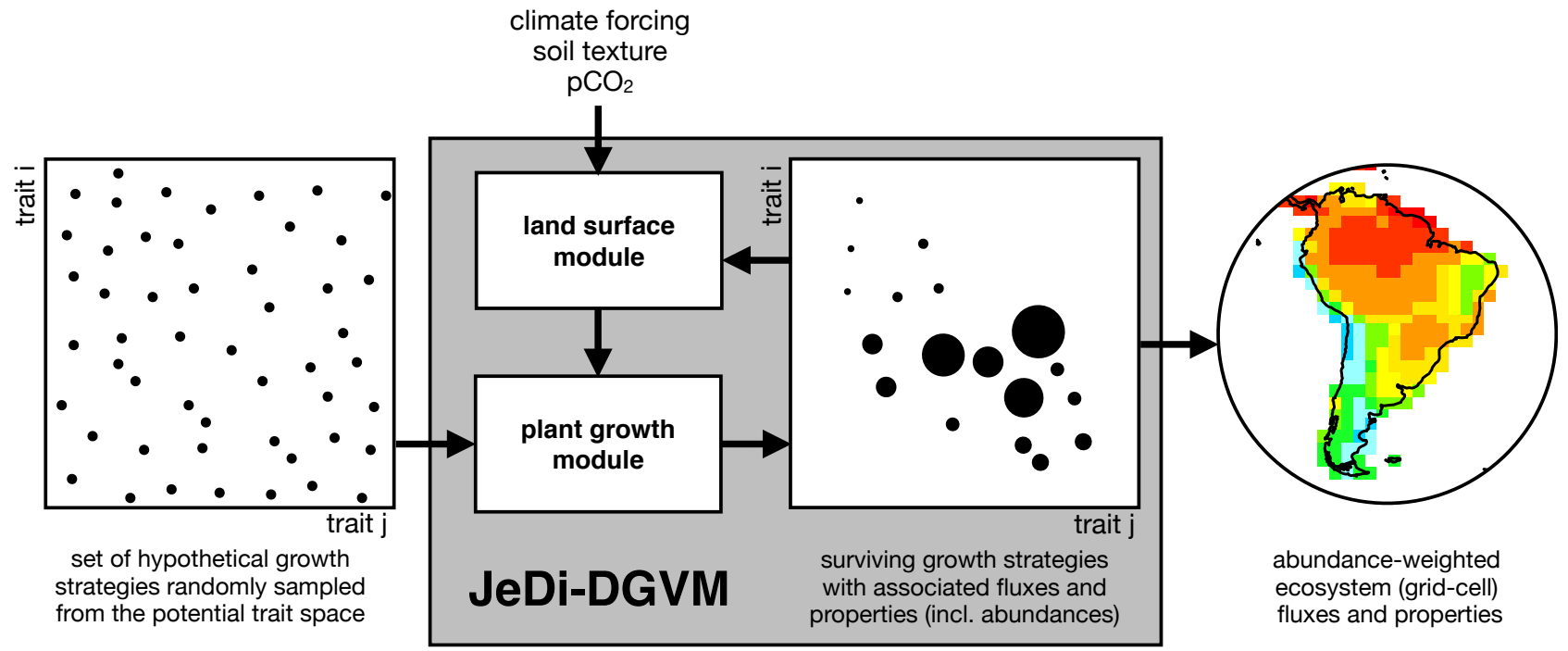

Fig. 1. Schematic diagram of the JeDi-DGVM modelling approach. The model generates a large number of hypothetical plant growth strategies, each defined by 15 functional trait parameters that characterize plant behaviour with regards to carbon allocation, phenology, and ecophysiology. The trait parameter values are randomly sampled from their full observed or theoretical ranges. The plant growth module simulates the development of the plant growth strategies (independently and in parallel) based on fundamental ecophysiological processes (e.g. photosynthesis, respiration, allocation, phenology, and turnover). The environmental conditions of each strategy are provided by the land surface module, which simulates canopy interception, infiltration, evaporation, root water uptake, and runoff using daily meteorological forcings of downwelling shortwave and longwave radiation, air temperature and precipitation. Land surface parameters (e.g. leaf area index, surface albedo, and rooting depth) derived from the carbon pools and trait parameters of each plant growth strategy affect its simulated land surface hydrology and, consequently, its net primary productivity (NPP), i.e. its supply of assimilates. Functional trade-offs and the climatic conditions in each grid cell constrain the range and relative fitness of the surviving growth strategies (i.e. those that are able to maintain a positive balance of stored assimilates). The fluxes and properties of the surviving plant growth strategies are averaged, weighted by their relative biomasses, at each time step and grid cell to produce aggregated ecosystem-scale output variables. The aggregated litter fluxes form the input for an additional module (not shown) for simulating soil carbon dynamics and heterotrophic respiration.

are more conservative, thereby potentially avoiding damage by a turn to less favourable conditions.

To represent this flexibility of how to grow and reproduce in the model, many different plant growth strategies are simulated simultaneously using the same ecophysiological parameterizations under the same atmospheric forcing. The only part in which the plant growth strategies differ is in their values for fifteen functional trait parameters $\left(t_{1}, \ldots, t_{15}\right.$; Table C2). These parameters control the amount of carbon allocated from photosynthesis and storage to six plant carbon pools, the response times to changes in environmental conditions and turnover times of the various carbon pools (i.e. phenology), and other aspects of ecophysiological functioning (e.g. leaf nitrogen concentration, which determines the balance between photosynthesis and respiration).

Each growth strategy is represented by six carbon pools representing leaves, fine roots, aboveground and belowground wood (stems and coarse roots), storage, and reproduction ("seeds"). These compartments are linked to the physical functioning of the land surface which is simulated by the land surface module. For instance, leaf biomass is linked to the amount of absorbed solar radiation, and fine root biomass to the capability of a growth strategy to extract soil moisture from the rooting zone. Both of these examples have functional consequences: more absorbed radiation enhances the supply of energy for photosynthesis and evapotranspiration, and the amount of extracted soil water determines the water status of the plant and the supply of moisture for evapotranspiration. This coupled plant-land surface model is therefore capable of simulating the interaction between development of a plant growth strategy and land surface functioning in a process-based manner.

Each trait parameter is associated with costs and benefits, leading to functional trade-offs because no trait value (or set of trait values) can be optimal for plant fitness in all environments. For example, a particular growth strategy may allocate a relatively high fraction of carbon to fine roots, enhancing the rate at which it can extract moisture from the soil matrix. This may be beneficial in terms of higher productivity. However, it also comes with both real and opportunity costs. That growth strategy would incur the real metabolic costs of growth and maintenance respiration for the additional fine root biomass. A higher fractional allocation to fine roots also necessarily results in a lower fractional allocation to the other carbon pools (e.g. a lower allocation to the aboveground pools and thus a decreased opportunity to 
capture light). In a given environment, there will be some optimum allocation strategy that maximizes productivity. However, in environments with plentiful sunlight and soil moisture, a wide range of allocation strategies will perform close to the optimum. As the climate becomes harsher, the range of well-performing strategies will decrease.

\subsection{Environmental selection}

In order to implement the notion that "Everything is everywhere, but the environment selects", we test essentially the complete range of potential values for each of the 15 trait parameters. For some trait parameters, we sample values from the full mathematically possible range. For example, the trait parameters controlling the fractional allocation of carbon to the different plant carbon pools are only constrained such that together they sum to one. For other trait parameters (e.g. leaf nitrogen concentration), we sample values from observed ranges taken from literature. To effectively implement environmental selection, the model generates a large number of plant growth strategies using a quasirandom Latin hypercube sampling algorithm (McKay et al., 1979). A 15-dimensional hypervolume representing the potential trait space is first divided into many equal subvolumes. A random point defining a plant growth strategy is then selected from each subvolume.

Each grid cell is seeded with a small amount of initial seed biomass for each plant growth strategy. The model mechanistically simulates the development of the plant growth strategies and their interactions with the coupled land surface module. Growth strategies which are able to maintain a positive balance of stored assimilates survive, passing through what Webb et al. (2010) refers to as a "mechanistic performance filter". As environmental conditions change, different strategies will respond in different ways; some may become more productive, others may no longer be able to cope with new conditions and die out. Strategies which were previously filtered out will again be given small amounts of seed carbon and may persist under the new conditions. This process allows the composition of the plant communities in each grid cell to adapt through time, without relying on a priori bioclimatic limits relating the presence or absence of a growth strategy to environmental variables. This mechanistic trial-and-error approach seems potentially better suited to simulate the response of the biosphere to climates without present-day analogues because even under new conditions fundamental functional trade-offs that all plants face are unlikely to change.

\subsection{Aggregation to ecosystem scale}

Some mechanism is needed to aggregate the biogeochemical fluxes and vegetation properties of the potentially many surviving growth strategies within each grid cell. Most current DGVMs calculate grid-cell fluxes and properties as weighted averages across fractional coverages of PFTs. Of those models, the competition between PFTs for fractional area in a grid cell is typically computed implicitly based on moving averages of bioclimatic limits (Arora and Boer, 2006). This approach is not suitable for JeDi-DGVM because its tradeoff-based framework does not rely on a priori bioclimatic limits. A few DGVMs (e.g. Cox, 2001; Arora and Boer, 2006) calculate PFT fractional coverages using a form of the Lotka-Volterra equations, in which the colonization rate of each of $N$ PFTs is linked through a $N$-by- $N$ matrix of competition coefficients. For JeDi-DGVM, this Lotka-Volterra approach quickly becomes computationally burdensome as the size of the necessary competition matrix increases with the square of the potentially large number of tested growth strategies. The necessary competition coefficients are also difficult to determine theoretically (McGill et al., 2006).

Instead, JeDi-DGVM aggregates vegetation fluxes and properties to the grid-cell scale following the "biomass-ratio" hypothesis (Grime, 1998), which postulates that the immediate effects of the functional traits of a species are closely proportional to the relative contribution of that species to the total biomass of the community. Recent work (e.g. Garnier et al., 2004; Vile et al., 2006; Kazakou et al., 2006; Díaz et al., 2007; Quetier et al., 2007) supporting the "biomassratio" hypothesis has shown strong statistical links between community-aggregated functional traits (i.e. the mean trait values of all species in a community, weighted by their massbased relative abundances) and observed ecosystem functions (e.g. aboveground net primary productivity and litter decomposition). Others have combined the concept of community-aggregated functional traits with the maximum entropy (MaxEnt) formalism from statistical mechanics to successfully make predictions, in the other direction, about the relative abundances of individual species within communities (e.g. Shipley et al., 2006b; Sonnier et al., 2010; Laughlin et al., 2011).

Here, rather than weighting the plant functional traits, JeDi-DGVM calculates ecosystem-scale variables by directly averaging the fluxes and ecosystem properties across all surviving growth strategies, weighting the contribution of each strategy by its current biomass relative to the total biomass of all strategies within that grid cell. We refer to these grid-cell-scale variables as community-aggregated fluxes (or properties). As an example, the net primary productivity (NPP) of each growth strategy $i$ at a grid cell $j$, $\mathrm{NPP}_{i j}$, is a function of its trait parameter values $\boldsymbol{T}_{i}$ and the environmental forcing variables $\boldsymbol{X}_{j}$ at that grid cell. The community-aggregated $\mathrm{NPP}^{1},\left\langle\mathrm{NPP}_{j}\right\rangle$, for that grid cell is the sum of the NPP fluxes of all growth strategies $S$ at that grid cell, weighting the contribution of each growth strategy

\footnotetext{
${ }^{1}$ We adopt chevron notation (e.g. $\left.\left\langle\mathrm{NPP}_{j}\right\rangle\right)$ to denote communityaggregated fluxes and properties.
} 
by its mass-based relative abundance $p_{i j}$ :

$$
\left\langle\mathrm{NPP}_{j}\right\rangle=\sum_{i=1}^{S} p_{i, j} \mathrm{NPP}_{i j}=\sum_{i=1}^{S} p_{i j} f\left(\boldsymbol{T}_{i}, \boldsymbol{X}_{j}\right) .
$$

The relative abundance $p_{i j}$ of each surviving growth strategy $i$ in a given grid cell $j$ is proportional to its living biomass $\mathrm{BM}_{i j}$ at that grid cell relative to the sum of the living biomass of all surviving growth strategies $S$ in that grid cell:

$p_{i j}=\frac{\mathrm{BM}_{i j}}{\sum_{k=1}^{S} \mathrm{BM}_{k j}}$.

The living biomass of a growth strategy being the sum of its leaf, fine root, aboveground and belowground wood, and storage carbon pools. Thus, the relative abundances within a plant community range between zero and one and the sum of the abundances is one. More details on the aggregation scheme are provided in Appendix A9.

The resulting community-aggregated fluxes are for the most part diagnostic and do not influence the development of the individual growth strategies or their environmental conditions. However, the community-aggregated litter fluxes do form the input for a relatively simple soil carbon module, which then provides simulated estimates of heterotrophic respiration (see Appendix A10). This implementation of the "biomass-ratio" hypothesis assumes that interactions between plants, both competitive and facilitative, are weak and do not significantly alter plant survival or relative fitness. The potential implications of this assumption are discussed in Sect. 5.3.

\section{Methods}

The Jena Diversity-DGVM described in this paper presents a new approach to terrestrial biogeochemical modelling, in which the functional properties of the vegetation emerge as a result of mechanistic trait filtering via environmental selection. This contrasts with the standard approach to global vegetation modelling which utilizes a small set of PFTs whose predetermined properties are specified by parameter values often determined from databases of observed plant trait values. In an effort to understand if this more diverse representation of the terrestrial biosphere can reasonably capture observed biogeochemical patterns, we contrast the performance of the less constrained JeDi-DGVM approach with the performance of two previously evaluated land surface models based on the PFT paradigm. To do this, we followed an existing systematic protocol established by the Carbon-Land Model Intercomparison Project (C-LAMP; Randerson et al., 2009). The implementation of this protocol here is described below in the following subsection. In Sect. 2.2, we describe the evaluation of the simulated biodiversity patterns. This biodiversity evaluation serves to highlight the parsimonious nature of JeDi-DGVM, i.e. the model produces more testable outputs with fewer a priori inputs than PFT-based models. Finally, in Sect. 3.3, we describe a series of simulation ensembles performed to test the sensitivity of the biogeochemical and biodiversity evaluation results to the number of sampled plant growth strategies.

\subsection{Evaluation of biogeochemical patterns}

JeDi-DGVM was run with 2000 randomly sampled plant growth strategies on a global grid at a spatial resolution of approximately $2.8^{\circ} \times 2.8^{\circ}$, covering all land areas except Antarctica. The model was forced at a daily time step with downward shortwave and longwave radiation, precipitation, and near-surface air temperature from an improved NCEP/NCAR atmospheric reanalysis dataset (Qian et al., 2006). We looped the first $25 \mathrm{yr}$ of the reanalysis dataset (1948-1972) with a fixed, preindustrial atmospheric $\mathrm{CO}_{2}$ concentration until the vegetation and soil carbon pools reached a quasi-steady state $(\sim 3500 \mathrm{yr})$. After this spin-up simulation, a transient simulation was run for years 1798 2004 using prescribed global atmospheric $\mathrm{CO}_{2}$ concentrations from the C4MIP reconstruction of Friedlingstein et al. (2006). This transient simulation was forced by the same climate forcing as the spin-up run for years 1798-1947 and by the full reanalysis dataset for years 1948-2004. We ran an additional experiment to compare the response of JeDi-DGVM to a sudden increase in atmospheric $\mathrm{CO}_{2}$ with results from the Free-Air $\mathrm{CO}_{2}$ Enrichment (FACE) experiments (Norby et al., 2005). This FACE experiment simulation was similar to the transient simulation described above but with the atmospheric $\mathrm{CO}_{2}$ concentration set to $550 \mathrm{ppm}$ for years $1997-$ 2004. We deviated from the C-LAMP experimental protocol by allowing the vegetation to evolve dynamically through the simulations, rather than prescribing the preindustrial land cover dataset. The aspects of the C-LAMP protocol related to $\mathrm{N}$ deposition were not considered, as a nitrogen cycle has not yet been implemented in JeDi-DGVM.

We evaluate the modelled biogeochemical patterns from the transient simulation against multiple observational datasets using a set of systematic metrics. As computed, each C-LAMP metric falls somewhere between zero and one and is then scaled by a numerical weight to produce a score. The weights are based on subjective estimates of a metric's uncertainty, considering both the measurement precision of the observations and the scaling mismatch between the model and observations. Further details about each metric and the justifications behind their particular numerical weighting are described in Randerson et al. (2009). More information about the datasets and scoring methods used in the C-LAMP evaluation is also provided in Appendix D. The metrics, their weights, along with the resulting scores for JeDi-DGVM are summarized in Table 1.

The scores for two terrestrial biosphere models based on the PFT concept, CLM-CN (Thornton et al., 2007) and CLMCASA' (Fung et al., 2005; Doney et al., 2006), are also 
Table 1. Summary of the evaluation metrics and scores. Each metric (column 1) is associated with a possible score (column 3) based on a subjective assessment of its level of uncertainty and model-data scale mismatch. Each metric is broken into metric components (column 2) with associated subscores (column 4). Scores are presented for JeDi-DGVM (this paper) and, for comparison, CLM-CN and CLM-CASA' (previouly evaluated in Randerson et al., 2009). The total score for each model (out of a possible score of 100) is presented at the bottom. MODIS, MODerate Resolution Imaging Spectroradiometer; EMDI, Ecosystem Model-Data Intercomparison.

\begin{tabular}{|c|c|c|c|c|c|c|}
\hline Metric & Metric components & Score & Subscore & JeDi-DGVM & CLM-CASA $^{\prime}$ & CLM-CN \\
\hline \multirow[t]{4}{*}{ Leaf area index } & & 15 & & 13.4 & 13.5 & 12.0 \\
\hline & MODIS phase & & 6 & 5.0 & 5.1 & 4.2 \\
\hline & MODIS maximum & & 5 & 4.7 & 4.6 & 4.3 \\
\hline & MODIS mean & & 4 & 3.7 & 3.8 & 3.5 \\
\hline \multirow[t]{5}{*}{ Net primary productivity } & & 10 & & 8.4 & 8.0 & 8.2 \\
\hline & EMDI observations & & 2 & 1.5 & 1.5 & 1.6 \\
\hline & EMDI histogram & & 4 & 3.4 & 3.0 & 3.4 \\
\hline & MODIS spatial pattern & & 2 & 1.6 & 1.6 & 1.4 \\
\hline & MODIS zonal means & & 2 & 1.9 & 1.9 & 1.8 \\
\hline $\mathrm{CO}_{2}$ seasonal cycle & & 15 & & 11.8 & 10.4 & 7.7 \\
\hline comparison with GLOBALVIEW & $60-90^{\circ} \mathrm{N}$ & & 6 & 4.9 & 4.1 & 2.8 \\
\hline \multirow[t]{2}{*}{ phase and amplitude } & $30-60^{\circ} \mathrm{N}$ & & 6 & 4.5 & 4.2 & 3.2 \\
\hline & $0-30^{\circ} \mathrm{N}$ & & 3 & 2.5 & 2.1 & 1.7 \\
\hline Carbon and energy & & 30 & & 18.3 & 17.2 & 16.6 \\
\hline \multirow{4}{*}{ fluxes from Ameriflux } & Net ecosystem exchange & & 6 & 2.6 & 2.5 & 2.1 \\
\hline & Gross primary productivity & & 6 & 3.5 & 3.4 & 3.5 \\
\hline & Latent heat & & 9 & 6.6 & 6.4 & 6.4 \\
\hline & Sensible heat & & 9 & 5.6 & 4.9 & 4.7 \\
\hline \multirow{5}{*}{$\begin{array}{l}\text { Carbon stocks } \\
\text { and transient dynamics }\end{array}$} & & 30 & & 16.3 & 16.7 & 13.8 \\
\hline & $\begin{array}{l}\text { Aboveground biomass } \\
\text { in the Amazon Basin }\end{array}$ & & 10 & 6.7 & 5.3 & 5.0 \\
\hline & $\begin{array}{l}\mathrm{NPP} \text { stimulation } \\
\text { from elevated } \mathrm{CO}_{2}\end{array}$ & & 10 & 6.9 & 7.9 & 4.1 \\
\hline & $\begin{array}{l}\text { Interannual variability } \\
\text { of terrestrial carbon fluxes }\end{array}$ & & 5 & 2.7 & 3.6 & 3.0 \\
\hline & Fire variability & & 5 & 0.0 & 0.0 & 1.7 \\
\hline Total & & & 100 & 68.2 & 65.7 & 58.4 \\
\hline
\end{tabular}

shown for comparison (both were previously evaluated in Randerson et al., 2009). Unlike JeDi-DGVM, these two models were not run with dynamic vegetation, i.e. they were run with static predefined PFT maps throughout the C-LAMP simulations. However, as the simulations for all three models were run with the same climatic forcing dataset and only evaluated for present-day conditions, comparing their C-LAMP metric scores is still valid.

\subsection{Evaluation of biodiversity patterns}

In contrast to standard DGVMs, its broad sampling across a multidimensional trait space allows JeDi-DGVM to provide insight into potential plant biodiversity through an examination of the simulated functional richness and evenness.

Here, we define functional richness (FR) as simply the number of surviving growth strategies at each grid cell nor- malized by the maximum number of surviving growth strategies in any of the grid cells. Survival for a growth strategy is defined as maintaining a positive balance of stored assimilates. Thus, FR varies between zero for grid cells with no surviving strategies and one at the grid cell (or grid cells) with the maximum number of growth strategies. Following Kleidon et al. (2009), we evaluated the simulated FR against a map of plant species richness derived from observations (Kreft and Jetz, 2007) using a simple linear regression.

Functional evenness (FE) at each grid cell is calculated following the Pielou index (Pielou, 1966), which is the Shannon entropy of the relative abundances $p_{i}$ of the $S$ surviving growth strategies within that grid cell, normalized by the maximum possible Shannon entropy for that community:

$\mathrm{FE}=\frac{\sum_{i=1}^{S} p_{i} \ln p_{i}}{\ln S}$ 
FE approaches one when all growth strategies are nearly equal in abundance. FE approaches zero as more and more plant biomass is found in only one or a few growth strategies. FE is set to zero when there is one or no surviving growth strategies. The Shannon entropy of a given community is basically a measure of uncertainty in predicting the relative abundances of the growth strategies that compose the relative abundance vector $\boldsymbol{p}=\left(p_{1}, p_{2}, \ldots, p_{S}\right)$. While no global dataset of plant functional evenness is available, we are able to contrast the simulated patterns of FE with qualitative trends from literature. To do this, relative abundance distributions are averaged over all grid points falling into four classes of functional richness: grid points with low FR (Q1; $0<\mathrm{FR} \leq 0.25)$, medium (Q2; $0.25<\mathrm{FR} \leq 0.50)$, high $(\mathrm{Q} 3 ; 0.50<\mathrm{FR} \leq 0.75)$, and very high $\mathrm{FR}(\mathrm{Q} 4 ; 0.75<\mathrm{FR} \leq$ 1.00).

\subsection{Evaluating the sensitivity to the number of sampled growth strategies}

The primary underlying hypothesis behind the JeDi-DGVM is that given a sufficiently large number of randomly assembled growth strategies, its mechanistic trait filtering approach will produce reasonable biogeochemical and biodiversity patterns. The questions remains what is a sufficiently large number of growth strategies. To test this, we performed a set of ensemble simulations to explore the sensitivity of the biogeochemical and biodiversity results to the number of randomly sampled growth strategies. We ran 8 diversity ensembles with differing numbers of sampled strategies $(S=10,20$, 50, 100, 200, 500, 1000, and 2000). Each ensemble contains 20 members. Each ensemble member was initialized with different random numbers when sampling the growth strategy trait parameters from their full ranges. The only difference between the various ensemble simulations is the number and identity of their growth strategies. The underlying model equations and all other parameter values are constant across simulations.

Ideally, we would have run these ensemble simulations following the C-LAMP simulation protocol. We could have then compared the mean C-LAMP metric scores across ensembles. Due to the number of simulations involved and length of the spin-up period, this was not computationally feasible. Instead, we ran the ensemble simulations for only $400 \mathrm{yr}$, using the temporal mean values from the last $100 \mathrm{yr}$ for analysis. We focus our analysis on the convergence of the patterns of NPP and functional richness as examples of biogeochemical and biodiversity output variables. We hypothesize that diversity ensembles with higher numbers of sampled growth strategies will show less variation in these variables between their ensemble members.

To provide insight into the mechanisms driving this convergence, we also analysed the global patterns of several community-weighted mean (CWM) trait parameters. These CWM trait parameters are calculated in a similar fashion as the community-aggregated fluxes described earlier:

$\left\langle t_{k j}\right\rangle=\sum_{i=1}^{S} p_{i j} t_{i j k}$,

where $t_{i j k}$ is the value of trait $k$ for growth strategy $i$ at grid cell $j$, and $p_{i j}$ is the relative abundance of that particular growth in that grid cell.

\section{Results}

The results of the biogeochemical evaluation, the biodiversity evaluation, and the sensitivity ensembles are described in Sects. 4.1, 4.2, and 4.3, respectively.

\subsection{Results of the biogeochemical evaluation}

Overall, JeDi-DGVM received a score of 68.2 out of 100 possible points in the evaluation of the simulated biogeochemical patterns following the C-LAMP protocol. This exceeds the scores of the two PFT-based models (CLM-CASA', 65.7, and CLM-CN, 58.4) evaluated in Randerson et al. (2009). Despite having fewer a priori inputs (e.g. no predefined PFT map), JeDi-DGVM matched or exceeded the performance of at least one of the other models on almost every metric. The scores for the individual metrics are summarized in Table 1. We describe the evaluation results for the individual metrics in more detail below in Sect. 4.1.1 through Sect. 4.1.10.

\subsubsection{Phenology}

Figure 2 shows a comparison between the simulated month of maximum leaf area index (LAI) and remote sensing observations (Myneni et al., 2002; Zhao et al., 2005) of the same. The simulated timing of peak LAI matched observations quite well in the moisture-limited grassland and savannah regions of South America, Africa, and Australia. Elsewhere, there were two clear patterns of bias. First, JeDi-DGVM simulated maximum LAI occurring about one month later than the observations across much of the Northern Hemisphere. Second, in the observation dataset, leaf area follows the seasonality of incident solar radiation across large parts of the Amazon Basin, peaking during the early to mid part of the dry season when radiation levels are high and deep-rooted vegetation still has access to sufficient moisture (Myneni et al., 2007). JeDi-DGVM did not capture this opportunistic behaviour; simulated peak LAI in the tropical moist forests of Amazonia, central Africa, and Southeast Asia occurs during the rainy season. However, the issue of whether or not tropical forests green-up during dry periods is still not settled (Samanta et al., 2010; Asner and Alencar, 2010).

Comparisons of simulated and observed maximum and mean LAI are shown in Figs. S1 and S2. Overall, JeDiDGVM matched the observed values reasonably well. The simulated mean LAI values were generally low relative to 
(a) MODIS MOD15A2 (2000-2004)

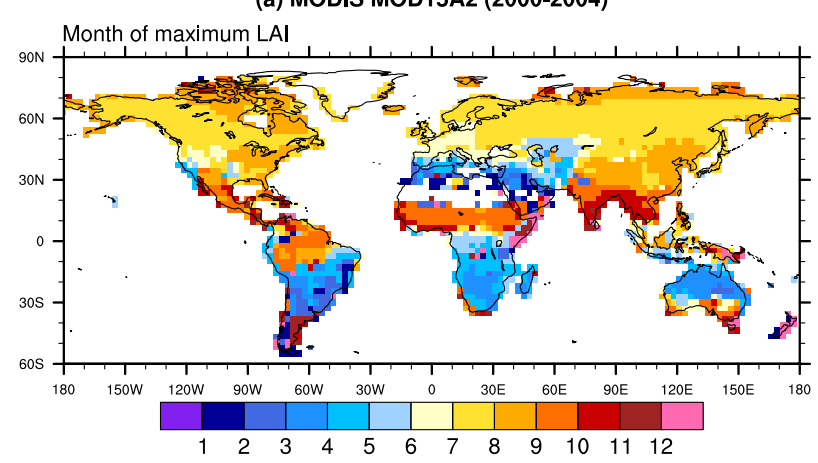

(b) JeDi

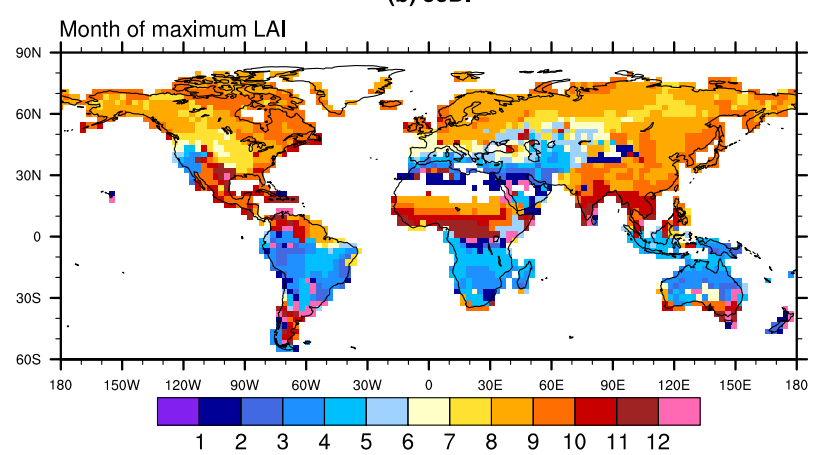

(c) JeDi - MODIS MOD15A2

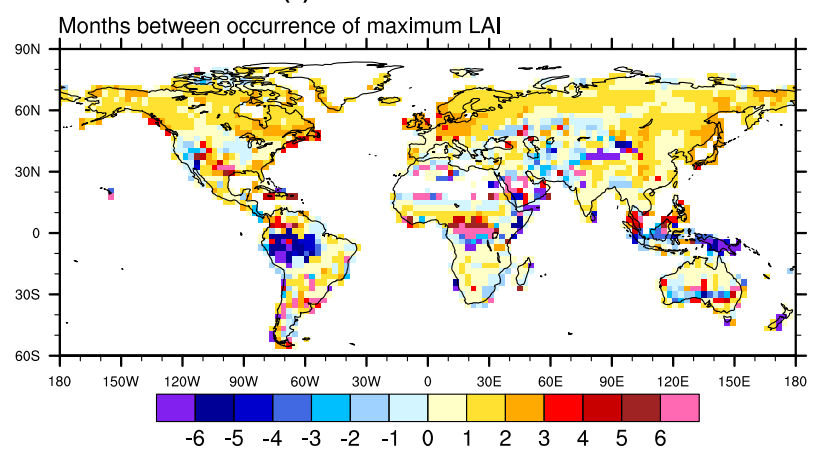

Fig. 2. Mean month of maximum leaf area index for years 20002004 from (a) MODIS MOD15A2 Collection 4 LAI product (Myneni et al., 2002; Zhao et al., 2005), (b) as simulated by JeDiDGVM, and (c) the lag in months between the occurrence of maximum LAI in the MODIS observations and the JeDi-DGVM model output.

the observations across the boreal forest region. Also, both the simulated mean and maximum LAI were higher than observed values in several regions, particularly southeast Brazil, northeast India, the central United States, much of Europe, and eastern China. This may simply be due to the fact that human land use was not accounted for in the simulation set-up and these regions are used extensively for agricultural purposes. These disparities may also indicate a need to re-evaluate the trade-off costs associated with root water uptake, i.e. the construction and maintenance costs of coarse and fine roots.

Overall, the performance of JeDi-DGVM in capturing observed global phenological patterns shows great promise for less constrained modelling approaches that allow the dynamics of the land surface to emerge from climatic constraints.

\subsubsection{Global carbon stocks}

JeDi-DGVM simulated global stocks of vegetation, soil, and litter carbon of $637 \mathrm{Pg} \mathrm{C}, 1904 \mathrm{Pg} \mathrm{C}$, and $208 \mathrm{Pg} \mathrm{C}$, respectively. These values are averages over the simulation period 1980-2004. The vegetation carbon stock simulated by JeDi-DGVM falls within the range of reported values from several PFT-based DGVM studies (500-950 Pg C; Cramer et al., 2001; Sitch et al., 2003; Krinner et al., 2005; Zaehle et al., 2010) and estimates from global carbon inventories (385-650 Pg C; Houghton et al., 2009). Likewise, the modelled estimate for litter carbon is close to the estimate based on carbon inventories $(300 \mathrm{PgC})$ reported in Houghton et al. (2009). The simulated soil carbon stock also falls within the range of previous inventory-based estimates (1200-3000 Pg C; Houghton et al., 2009).

\subsubsection{Gross primary productivity}

JeDi-DGVM simulated a mean global terrestrial gross primary productivity (GPP) of $138 \mathrm{Pg} \mathrm{C} \mathrm{yr}^{-1}$, which is higher than the empirical model estimate of $123 \pm 8 \mathrm{Pg} \mathrm{C} \mathrm{yr}^{-1}$ from Beer et al. (2010), but within the range of uncertainty $\left(118 \pm 26 \mathrm{Pg} \mathrm{C} \mathrm{yr}^{-1}\right)$ of a recent estimate from a processbased model forced with remote sensing observations (Ryu et al., 2011). The zonally averaged simulated GPP shows close agreement $\left(r^{2}=0.89\right)$ with the median estimate from Beer et al. (2010), falling within or near the range of uncertainty across most latitudes (Fig. 3a). JeDi-DGVM performed comparably with five PFT-based terrestrial biosphere models evaluated in that study in reproducing the latitudinal pattern of GPP. Averaging zonally hides some offsetting regional biases, however. For instance, simulated productivity in Amazonia is about $25 \%$ lower than data-driven estimates, but productivity is overestimated throughout most of the Asian tropics (Fig. S3). Overall though, the broad spatial pattern of GPP is reasonably well captured by JeDi-DGVM $\left(r^{2}=0.85\right)$ when compared to the map of data-driven estimates from Beer et al. (2010).

\subsubsection{Net primary productivity}

JeDi-DGVM simulated a mean global terrestrial NPP of $79 \mathrm{PgC} \mathrm{yr}^{-1}$, which is more than one standard deviation greater than the mean estimate from a recent meta-analysis of global NPP studies $\left(56 \pm 14 \mathrm{Pg} \mathrm{Cyr}^{-1}\right.$; Ito, 2011). We hypothesize that this overestimation stems, in part, from the lack of nitrogen limitation within the model. Global analyses of nutrient limitation studies (Elser et al., 2007; LeBauer and 
(a)

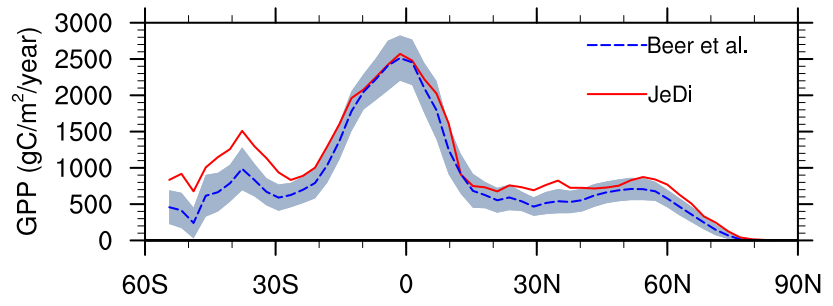

(b)

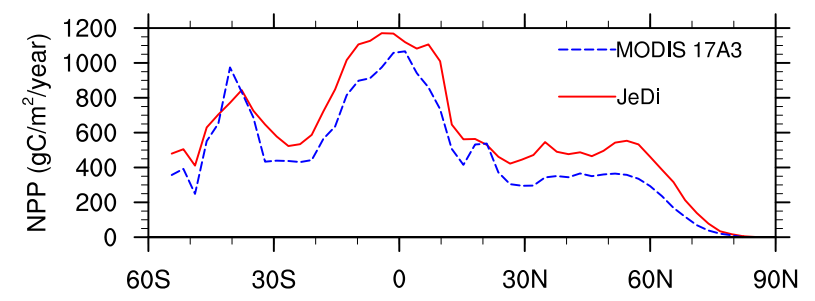

(c)

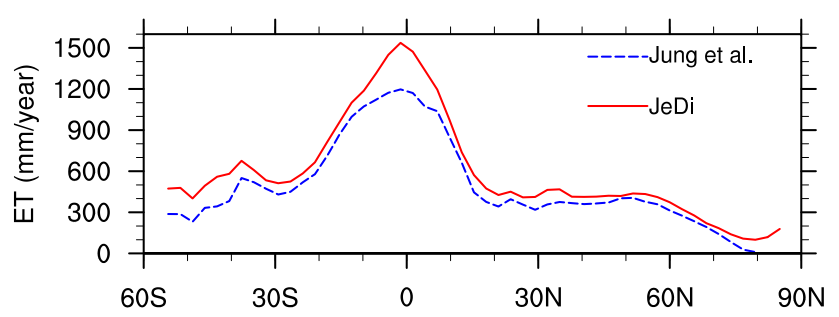

Fig. 3. Comparison of mean annual zonally averaged fluxes as simulated by JeDi-DGVM with (a) data-driven model estimates of gross primary productivity (Beer et al., 2010), (b) net primary productivity from the MODIS MOD17A3 Collection 4.5 product (Heinsch et al., 2006; Zhao et al., 2005, 2006), and (c) data-driven model estimates of evapotranspiration (Jung et al., 2010). The blue-shaded region in (a) represents the median absolute deviation of the five diagnostic models used in producing the data-driven model estimate.

Treseder, 2008) suggest that soil nitrogen availability and the energetic cost of nitrogen fixation and active ion uptake limit terrestrial productivity by about $20 \%$. Adding a mechanistic representation of plant nitrogen acquisition based on plant energetic trade-offs (e.g. J. Fisher et al., 2010) to future versions of JeDi-DGVM is critical, as it is thought that nitrogen availability will likely constrain the capacity of terrestrial ecosystems to continue taking up a large part of anthropogenic carbon emissions (Reich et al., 2006).

In a site-by-site comparison (Fig. 4a), JeDi-DGVM performed relatively well in capturing the variability in NPP across the field-based EMDI observation network (Olson et al., 2001). Although, the model tends to overestimate NPP, particularly at intermediately productive sites. JeDi-DGVM also performed reasonably well and comparably with PFTbased models when the simulated NPP was binned by precipitation class (Fig. 4b). JeDi-DGVM underestimated NPP (a)

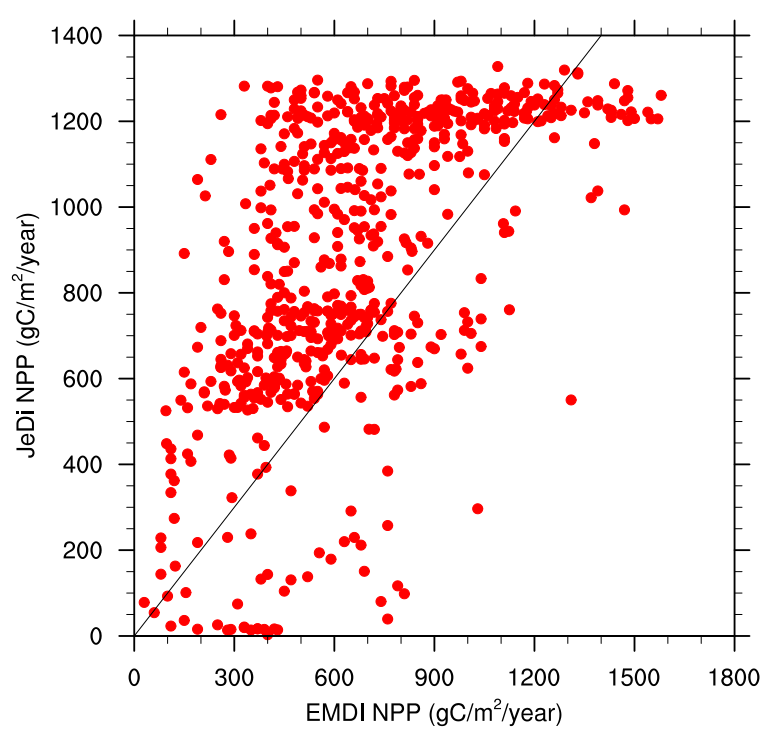

(b)

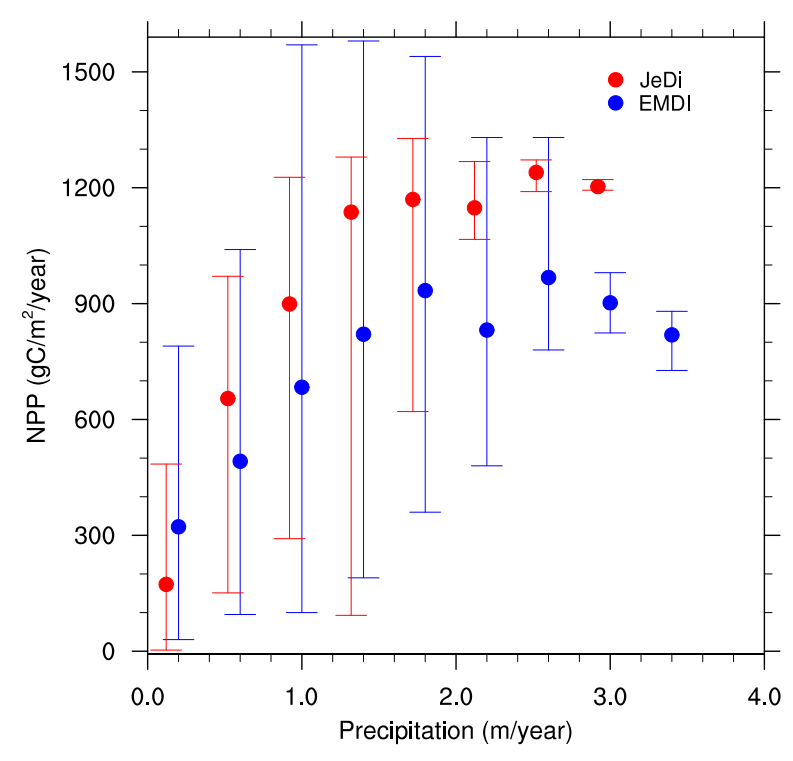

Fig. 4. Comparison of net primary productivity between JeDiDGVM model output (mean over years 1975-2000) and 933 site observations from the Ecosystem Model-Data Intercomparison (EMDI) initiative class B dataset (Olson et al., 2001). Shown as (a) scatter plot where the red dots represent matched pairs of model grid cells and observation sites and the black line is a $1: 1$ line, and (b) the same but normalized by precipitation (binned into 400 $\mathrm{mm} \mathrm{yr}^{-1}$ increments).

at the driest sites $\left(<400 \mathrm{~mm} \mathrm{yr}^{-1}\right)$ and overestimated NPP at wetter sites.

A comparison with remote sensing NPP estimates (MODIS MOD17A3; Myneni et al., 2002; Zhao et al., 2005) reveals that JeDi-DGVM is able to capture the broad spatial patterns of NPP (Fig. S4). JeDi-DGVM prominently 
overestimates productivity, though, in the grassland regions of South America and the Sahel as well as the forested regions of the eastern United States, eastern China, and northern Eurasia. This high bias also emerges in the comparison with the zonally averaged MODIS NPP (Fig. 3b).

\subsubsection{Evapotranspiration}

JeDi-DGVM simulated a mean global terrestrial evapotranspiration (ET) flux of $82 \times 10^{3} \mathrm{~km}^{3} \mathrm{yr}^{-1}$, which is higher than the data-driven model estimate of $65 \pm 3 \times 10^{3} \mathrm{~km}^{3} \mathrm{yr}^{-1}$ of Jung et al. (2010) but within the range of processbased model estimates $\left(60-85 \times 10^{3} \mathrm{~km}^{3} \mathrm{yr}^{-1}\right)$ from the Water Model Intercomparison Project (WaterMIP; Haddeland et al., 2011). Figure S5 shows a spatial comparison of simulated mean annual ET and the data-driven estimates of Jung et al. (2010). Overall, the model performed reasonably well $\left(r^{2}=0.78\right)$ in reproducing the global pattern of ET. The zonal averages, however, show a strong positive bias in the equatorial tropics (Fig. 3c; $r^{2}=0.80$ ). Further analysis revealed that some of this model bias is attributable to an overestimation of canopy interception, especially in tropical forests. Adjusting the parameterizations related to canopy interception and canopy storage capacity has improved model performance for other terrestrial biosphere models (Bonan and Levis, 2006; Liang and Xie, 2008).

\subsubsection{Seasonal cycle of atmospheric $\mathrm{CO}_{2}$}

JeDi-DGVM captured the general temporal pattern $(r=$ $0.84 \pm 0.04,0.83 \pm 0.08,0.80 \pm 0.15$ ) of a spring drawdown of atmospheric $\mathrm{CO}_{2}$ in the Northern Hemisphere followed by an autumnal rise. However, there is a phase offset at many locations with the simulated spring drawdown occurring about one to two months later than observations. This offset may be due to the late leaf expansion mentioned above (Fig. 2) or to limitations stemming from the simple nature of the heterotrophic respiration scheme. JeDi-DGVM overestimated the seasonal amplitude of atmospheric $\mathrm{CO}_{2}$ in the Northern Hemisphere, particularly in the middle and high latitude bands. The ratios of simulated to observed amplitudes were $1.23 \pm 0.08,1.33 \pm 0.26$, and $1.10 \pm 0.16$ for the high, middle, and equatorial latitude bands, respectively. This overestimation in seasonal amplitude is directly attributable to the overestimation of NPP in those regions. Figure 5 illustrates the reasonably good agreement between the simulated seasonal $\mathrm{CO}_{2}$ cycle and GLOBALVIEW measurements (Masarie and Tans, 1995) at a high-latitude (Point Barrow, Alaska, United States), a mid-latitude (Niwot Ridge, Colorado, United States), and a low-latitude station (Mauna Loa, Hawaii, United States). The results for all GLOBALVIEW stations considered here are summarized in a Taylor diagram (Taylor, 2001) in Fig. S6.

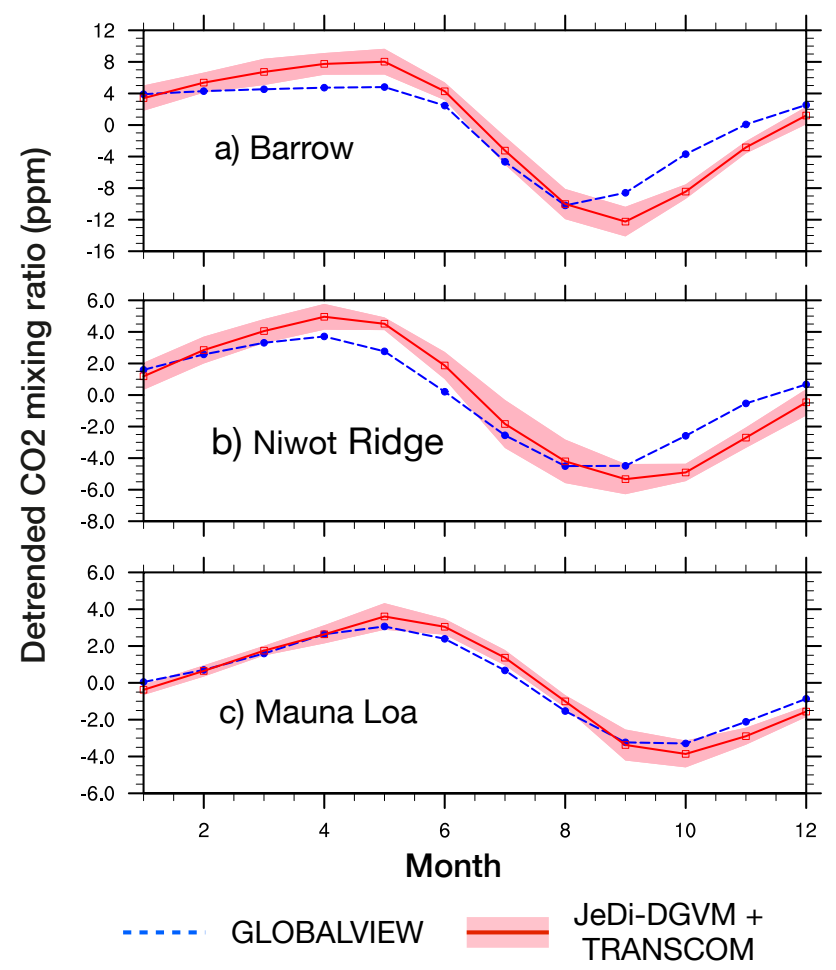

Fig. 5. Mean seasonal cycle of atmospheric $\mathrm{CO}_{2}$ at (a) Barrow, Alaska $\left(71^{\circ} \mathrm{N}\right)$, (b) Niwot Ridge, Colorado $\left(40^{\circ} \mathrm{N}\right)$, and $(\mathbf{c})$ Mauna Loa, Hawaii $\left(20^{\circ} \mathrm{N}\right)$, for years 1991-2000. The dashed blue lines represent the observations from the GLOBALVIEW dataset (Masarie and Tans, 1995). The JeDi-DGVM estimates were obtained by combining the simulated net ecosystem exchange (NEE) fluxes with the monthly impulse response functions (Gurney et al., 2004) of the 13 TRANSCOM atmospheric tracer transport models. The red line represents the mean of the model estimates. The light red shaded region represents one standard deviation around the multimodel mean.

\subsubsection{Net terrestrial carbon exchange}

The net terrestrial carbon sink simulated by JeDi-DGVM is compatible with decadal budgets of the global carbon cycle given the uncertainties regarding the oceanic and anthropogenic fluxes. For the 1980s, JeDi-DGVM simulated a global terrestrial carbon flux of $-2.89 \mathrm{Pg} \mathrm{C} \mathrm{yr}^{-1}$ (negative values indicate a net uptake of carbon by the terrestrial biosphere), which lies within the range of uncertainty from the IPCC ( -3.8 to $0.3 \mathrm{Pg} \mathrm{C} \mathrm{yr}^{-1}$; Denman et al., 2007). In agreement with the IPCC carbon budgets, JeDi-DGVM simulated a larger carbon sink in the $1990 \mathrm{~s}\left(-3.35 \mathrm{Pg} \mathrm{Cyr}^{-1}\right)$, which also lies within the IPCC range of -4.3 to $-1.0 \mathrm{Pg} \mathrm{C} \mathrm{yr}^{-1}$ (Denman et al., 2007). The model estimates presented here suggest a stronger land carbon sink than previous DGVM studies (1.2-2.75 Pg C; Sitch et al., 2008; Randerson et al., 2009).

JeDi-DGVM captured the magnitude of interannual variability of terrestrial net ecosystem exchange (NEE) quite 
well ( $\sigma=0.94 \mathrm{PgC} \mathrm{yr}^{-1}$; Fig. 6) when compared to the TRANSCOM-derived estimates $\left(\sigma=1.04 \mathrm{Pg} \mathrm{Cyr}^{-1}\right.$; Baker et al., 2006) for the period 1988-2004. The model results are also moderately correlated $(r=0.42 ; p<0.05)$ with the year-to-year TRANSCOM anomalies. The simulated anomalies fell within one standard deviation of the multimodel TRANSCOM mean in 12 of the $17 \mathrm{yr}$.

JeDi-DGVM captured the strong positive anomaly associated with the 1998 El Niño event, but not the similarly strong anomaly in 1997. The rapid growth rate of atmospheric $\mathrm{CO}_{2}$ in 1997 has been linked with large peat and forest fires in the Asian tropics (Page et al., 2002; van der Werf et al., 2008). Incorporating mechanistic representations of fire (e.g. Thonicke et al., 2008) and peat dynamics (e.g. Kleinen et al., 2011) in JeDi-DGVM may improve performance on this metric.

JeDi-DGVM was also not able to capture the negative anomaly in 1992-1993. This drawdown has been associated with climate impacts of elevated stratospheric aerosols following the Mount Pinatubo eruption. Some authors (e.g. Gu et al., 2003; Mercado et al., 2009) have linked this anomaly with an increase in NPP due to enhanced diffuse radiation. In this case, a more detailed canopy radiation transfer model (e.g. Drewry et al., 2010) may be required to to appropriately capture the effects of diffuse light on vegetation productivity. Angert et al. (2004), however, argues that the 1992-1993 $\mathrm{CO}_{2}$ drawdown can be better explained by unusually strong oceanic uptake, reduced heterotrophic respiration due to a cooling and drying of the upper soil layers, and a reduction in biomass burning, in which case a mechanistic representation of fire and more sophisticated soil carbon scheme (e.g. Braakhekke et al., 2011) may be necessary. When the two years strongly affected by the Pinatubo eruption (1992-1993) are excluded, the model time series is highly correlated $(r=0.63 ; p<0.01)$ with the interannual TRANSCOM anomalies.

\subsubsection{Comparison with eddy covariance measurements}

JeDi-DGVM performed reasonably well overall in a comparison with eddy covariance observations of terrestrial carbon and energy fluxes (Falge et al., 2002; Heinsch et al., 2006; Stoeckli et al., 2008). Seasonal variation in NEE was often lower in the JeDi-DGVM results than in the flux tower observations. And, although not always present, many sites showed a phase offset of one to two months delay. This is consistent with the model biases described above for the seasonal $\mathrm{CO}_{2}$ cycle and phenology. At many of the temperate forest sites, JeDi-DGVM overestimated the length of the growing season (i.e. GPP was higher than observed in the spring and autumn) and underestimated GPP during the summer peak. JeDi-DGVM captured the seasonal pattern of latent heat fluxes more accurately than that of sensible heat. In fact, the model significantly overestimated the sensible heat fluxes at many sites, indicating the need for a more sophis-

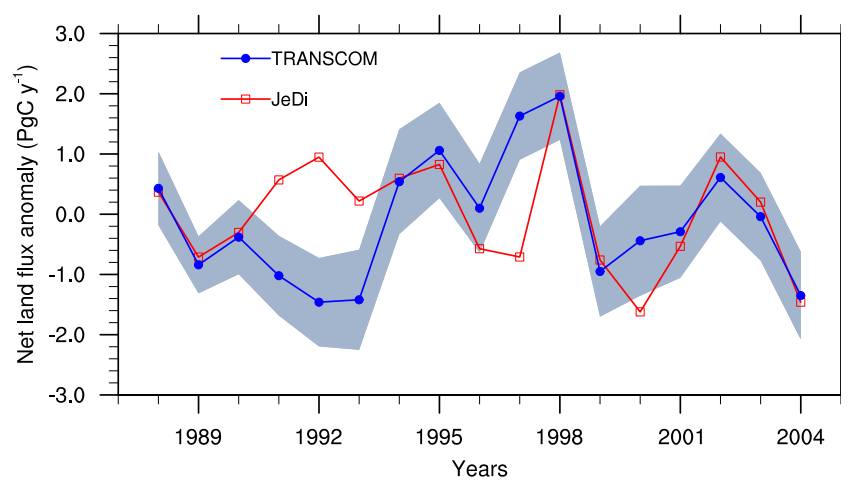

Fig. 6. Comparison of the interannual variability in the global land net ecosystem exchange fluxes from the JeDi-DGVM to the TRANSCOM atmospheric model inversion estimates (Baker et al., 2006) for years 1988-2004. The red line represents the JeDiDGVM flux anomalies from the long-term mean. The blue line represents the mean of the 13 models from the TRANSCOM experiment after removing the seasonal cycle and the long-term mean for each model. The light blue shaded region represents 1 standard deviation around the TRANSCOM multimodel mean.

ticated treatment of the canopy energy balance (e.g. Drewry et al., 2010).

\subsubsection{Carbon stocks and flows in Amazonia}

JeDi-DGVM performed reasonably well in matching the spatial pattern of aboveground living biomass density in South America (Fig. S7, $r=0.83$ ). Within the Amazon Basin, JeDi-DGVM simulated a total aboveground biomass of $59 \mathrm{Pg} \mathrm{C}$, slightly lower than the total of $69 \pm 7 \mathrm{Pg} \mathrm{C}$ estimated from observations by Saatchi et al. (2007). We attribute some of the overestimation of biomass around the perimeter of the Amazon Basin and further south in the Paraná Basin to a lack of human land use and fire as model processes/drivers. The underestimation of aboveground biomass in the central Amazon Basin may be related to the lack of competitive interactions between plant growth strategies. More specifically, the direct competition for light, if incorporated in the model, might favour plant growth strategies that invest proportionally more carbon towards growing woody stems. The implications of the current "biomass-ratio" aggregation scheme and the current lack of resource competition within JeDiDGVM are discussed further in Sect. 5.3.

The simulated Amazonian biomass pattern exhibits better agreement with a newer dataset (Saatchi et al., 2011), which has lower biomass values in the central Amazon Basin and higher biomass values in the western parts of the basin along the Andes. Here, however, we show only the comparison results with Saatchi et al. (2007) to maintain consistency with the C-LAMP evaluation protocol. Future studies will evaluate JeDi-DGVM against newer datasets, e.g. as part of the the International Land Model Benchmarking project (I-LAMB; Luo et al., 2012). 
The carbon allocation and storage scheme in JeDiDGVM provides a basis for contrasting model estimates of carbon pools against carbon budget observations from three mature forest ecosystems in Amazonia synthesized by Malhi et al. (2009). This comparison is summarized in Fig. 7. Despite differences between GPP simulated by JeDi-DGVM $\left(2474 \mathrm{~g} \mathrm{C} \mathrm{m}^{-2} \mathrm{yr}^{-1}\right)$ and observed values (3330 $\pm 420 \mathrm{~g} \mathrm{C} \mathrm{m}^{-2} \mathrm{yr}^{-1}$; Figueira et al., 2008; Malhi et al., 2009), we find that JeDi-DGVM performs well when contrasting Amazon carbon pool and allocation flux estimates. The simulated ratio of autotrophic respiration to GPP $(52 \%)$ was slightly less than the range of the observations $(65 \pm$ $10 \%)$. The fractions of NPP allocated to each plant carbon pool correspond quite well with the observed allocation patterns. The simulated turnover times for the woody pools ( $37 \mathrm{yr}$ ) closely match the mean of the observations ( $40 \pm 4 \mathrm{yr}$ ) from Malhi et al. (2009). Other studies, however, have suggested much longer wood turnover times $(\sim 90 \mathrm{yr})$ (Vieira et al., 2004; Figueira et al., 2008). The simulated stock of coarse woody debris $\left(2373 \mathrm{~g} \mathrm{C} \mathrm{m}^{-2}\right)$ closely matches the range of observed values $\left(2421 \pm 560 \mathrm{~g} \mathrm{C} \mathrm{m}^{-2}\right)$. The mean simulated soil carbon stock $\left(23460 \mathrm{~g} \mathrm{C} \mathrm{m}^{-2}\right)$ for this region is significantly greater than the mean of the observations to $2 \mathrm{~m}$ depth (14 260 $\pm 2728 \mathrm{~g} \mathrm{C} \mathrm{m}^{-2}$; Malhi et al., 2009). However, Quesada et al. (2011) presents evidence for substantial carbon storage below that depth, including a soil carbon stock of $22000 \mathrm{~g} \mathrm{C} \mathrm{m}^{-2}$ to $3 \mathrm{~m}$ depth at the Tapajós site.

\subsubsection{Sensitivity to elevated atmospheric $\mathrm{CO}_{2}$}

Globally, simulated NPP increased by $18 \%$ during the first five years of simulated $\mathrm{CO}_{2}$ enrichment at $550 \mathrm{ppm}$, exhibiting a large step change in the first year. Not surprisingly, simulated net terrestrial carbon uptake also quickly rose to $15.03 \mathrm{Pg} \mathrm{C} \mathrm{yr}^{-1}$ during that time. These values are similar to those exhibited by the PFT-based model CLM-CASA' $(17 \%$ and $12.5 \mathrm{PgC} \mathrm{yr}^{-1}$ ). During the same time period (19972001), mean NPP increased by $15 \pm 1 \%$ at the model grid cells corresponding to the four temperate forest FACE experiments reported in Norby et al. (2005). The observed increase at those sites was higher, $27 \pm 2 \%$. The geographic variation of NPP enhancement (Fig. S8) is broadly similar to the pattern simulated by the global vegetation model LPJ-GUESS (Hickler et al., 2008), with the strongest enhancement occurring in tropical forest regions.

\subsection{Biodiversity patterns}

The geographic pattern of simulated functional richness (Fig. 8a) is highly and significantly $\left(r^{2}=0.71\right)$ correlated with a map of vascular plant species richness derived from observations (Kreft and Jetz, 2007). Out of the 2000 randomly assembled plant growth strategies, 1411 growth strategies survived in at least one grid cell, and the maximum value for a single grid cell was 1322 in western Amazo- nia. These fractions of surviving growth strategies are much higher than those reported by KM2000. This is likely attributable to the difference in the survival criterion. In the earlier model of KM2000, the criterion for survival was whether or not a growth strategy was able to produce more "seed" carbon over its lifetime than its initial amount of seed carbon. Here, the criterion for survival was simply whether or not a growth strategy was able to maintain a positive carbon balance. Nonetheless, JeDi-DGVM is still able to reproduce the observed broad global pattern of plant diversity through mechanistic environmental filtering due to functional tradeoffs, and without invoking historical, competitive, or other factors.

The mean relative abundance distributions for four richness classes (Fig. 9a) are similar in shape to left-skewed log-normal distributions commonly observed throughout nature (McGill et al., 2007). The left-skewness means that rare strategies (species) are greater in number than abundant ones, another commonly observed attribute, especially in tropical rainforests (Hubbell, 1997). With increasing levels of functional richness, the mean as well as the variance of the relative abundance distribution shifts successively to lower values. We also see that there is not necessarily one optimal combination of trait parameters for obtaining high biomass in an environment, but often many differing growth strategies can reach similarly high levels of fitness (cf. Marks and Lechowicz, 2006; Marks, 2007). As the climate becomes less constraining, in terms of increasing availability of light and precipitation, the range of feasible plant growth strategies increases. The ranked abundances of growth strategies (Fig. 9b) clearly show that the simulated relative abundances become increasingly even with higher richness. This pattern is also evident when visually comparing the maps of simulated function richness (Fig. 8a) and community evenness (Fig. 8b). This simulated trend towards greater evenness in more productive regions qualitatively reproduces the observed trend in rank-abundance plots of forests, which show a much steeper decline in abundance in boreal forests than in tropical rainforests (Hubbell, 1979, 1997).

\subsection{Sensitivity to the number of sampled strategies}

In Fig. 10, we show that the simulated pattern of functional richness is robust when a sufficiently large number of growth strategies is sampled. Each set of box and whiskers in Fig. 10a represents the geographic variation in the mean percent of surviving strategies for a diversity ensemble. The percentages of surviving strategies are fairly stable across all of the diversity ensembles. In Fig. 10b, however, we see a dramatic convergence in the fraction of surviving strategies at the local grid-cell scale. Here, each set of box and whiskers represents the geographic variation in the standard deviation of the surviving percentage of growth strategies within a diversity ensemble. Across the 20 simulations in the highest diversity ensemble $(S=2000)$, the standard deviation of 

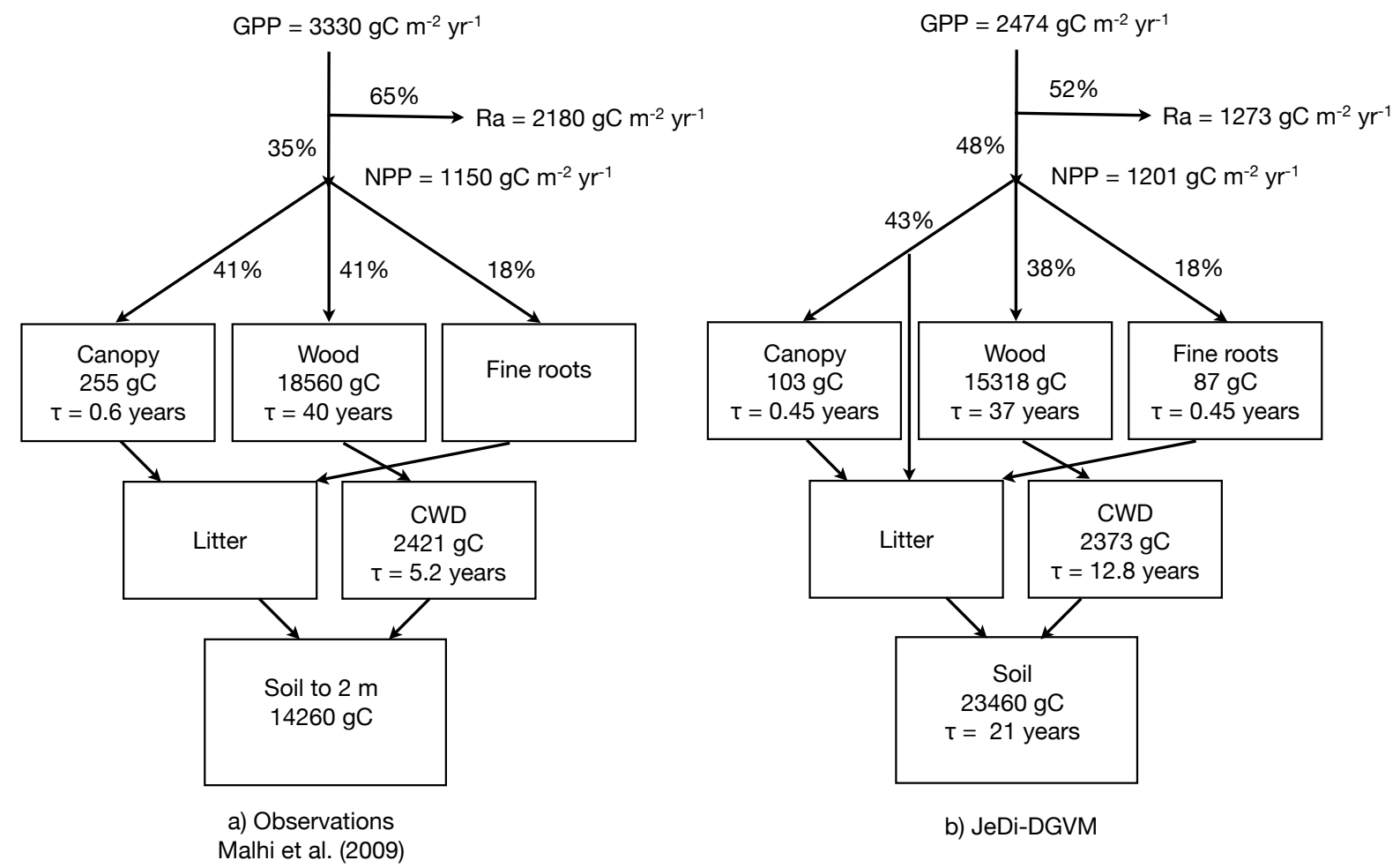

Malhi et al. (2009)

b) JeDi-DGVM

Fig. 7. Carbon pools and fluxes in Amazonia from (a) synthesis of observations (Malhi et al., 2009) and (b) as simulated by JeDi-DGVM for years 1980-2004. GPP, gross primary productivity; $\mathrm{R}_{\mathrm{a}}$, autotrophic respiration; NPP, net primary productivity; CWD, coarse woody debris.

the percent of surviving strategies is less than $1 \%$ for more than $90 \%$ of the vegetated grid cells. This means that their maps of functional richness look nearly identical. Figure 10c shows that not only does the percentage of surviving strategies converge as the number of sampled strategies increases, but that the surviving strategies also have similar trait values. All fifteen traits show significant convergence in their CWM values, as shown by a decrease in the global means of the CWM ensemble standard deviations with increasing sample diversity.

The convergence in the number and identity of the surviving strategies leads to a similar convergence in the simulated biogeochemical patterns. As an example, Fig. 11a shows a scatter plot of the global mean terrestrial NPP values from each ensemble simulation. The diversity ensembles with few sampled strategies, on the left side of the plot, exhibit tremendous variation in global mean NPP. In the diversity ensemble containing 20 simulations with 10 randomly sampled strategies $(S=10)$, global mean NPP varies between 29 to $57 \mathrm{Pg} \mathrm{C}$. As one goes from left to right across the plot, diversity ensembles with increasing numbers of sampled strategies show progressively smaller variation in global mean NPP. At the right side of the plot, the diversity ensemble containing simulations with 2000 randomly sampled strategies $(S=2000)$ has a range of only $1.3 \mathrm{Pg} \mathrm{C}$. Another striking feature of Fig. 11a is that the ensemble mean NPP also increases as you move towards higher diversity ensembles. This is suggestive of positive biodiversity-ecosystem functioning effects (Cardinale et al., 2012), which, while highly intriguing, are beyond the scope of this paper. We discuss the possibility of using JeDi-DGVM to follow up on this topic in Sect. 5.5.

Figure $11 \mathrm{~b}$ illustrates that the convergence of simulated NPP in higher diversity ensembles also holds true at the local grid-cell scale. Each set of box and whiskers in Fig. 12b represents the geographic variation in the coefficient of variation $(\mathrm{CV})$ of mean annual NPP within a diversity ensemble. The median ensemble $\mathrm{CV}$ for the lowest diversity ensemble $(S=10)$ is 0.72 . This implies that the standard deviation in NPP across the 20 simulations in that ensemble is nearly equal to or above the mean NPP values for at least half of all vegetated grid cells. In other words, with only 10 randomly sampled strategies, it is not possible to constrain modelled NPP using the JeDi-DGVM mechanistic trait filtering approach. Moving left across the plot, as the number of sampled strategies increases, the median ensemble $\mathrm{CV}$ decreases. The highest diversity ensemble $(S=2000)$ has a median ensemble CV of 0.03 and the ensemble CV 90th percentile is 0.05 , i.e. the ensemble standard deviation of NPP is less than $5 \%$ of the ensemble mean NPP for $90 \%$ of all vegetated grid cells. 
(a)

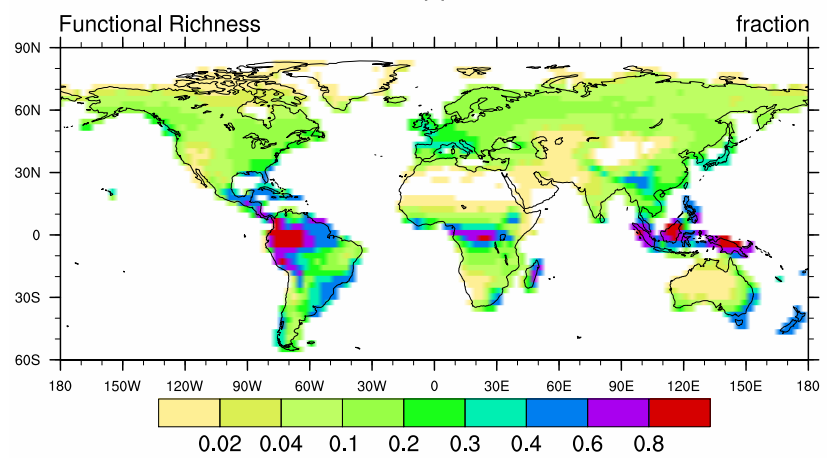

(b)

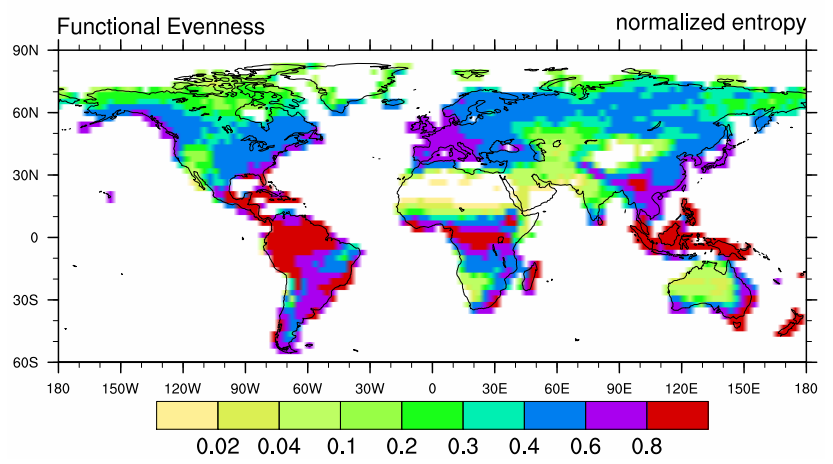

Fig. 8. Geographic patterns of (a) functional richness (FR) and (b) functional evenness (FE) as simulated by JeDi-DGVM.

The geographic pattern of the ensemble NPP CV for the highest diversity ensemble $(S=2000)$ is shown as a map in Fig. 12. Overall, the pattern of the ensemble NPP CV is very similar to the geographic pattern of trait parameter convergence (not shown). The ensemble NPP CV is very low $(<0.02)$ throughout most of the vegetated areas in the tropics and subtropics, meaning that the results are highly robust and not dependent on any particular random set of growth strategies. The ensemble $\mathrm{CV}$ values are higher $(\sim 0.02$ to 0.06$)$ but still reasonably low throughout most of the temperate and boreal forest regions in the midlatitudes. Higher values of ensemble CV (>0.06) are present in desert regions, particularly in central Asia, western Australia, the southwest USA, the edges of the Sahara, and the polar tundra. Future JeDiDGVM studies may be able to further constrain the uncertainty in these regions by sampling more growth strategies. Several test runs with 50000 sampled strategies showed high levels of convergence in all but the most extreme environments. Running JeDi-DGVM with so many strategies, however, is computationally burdensome. Alternative solutions might involve using more sophisticated search algorithms or more carefully choosing the ranges and prior distributions of the sampled trait parameter values. The white regions covering large parts of the Sahara, the Tibetan plateau, Greenland, the Arabian Peninsula, and the high Arctic had too few (a)

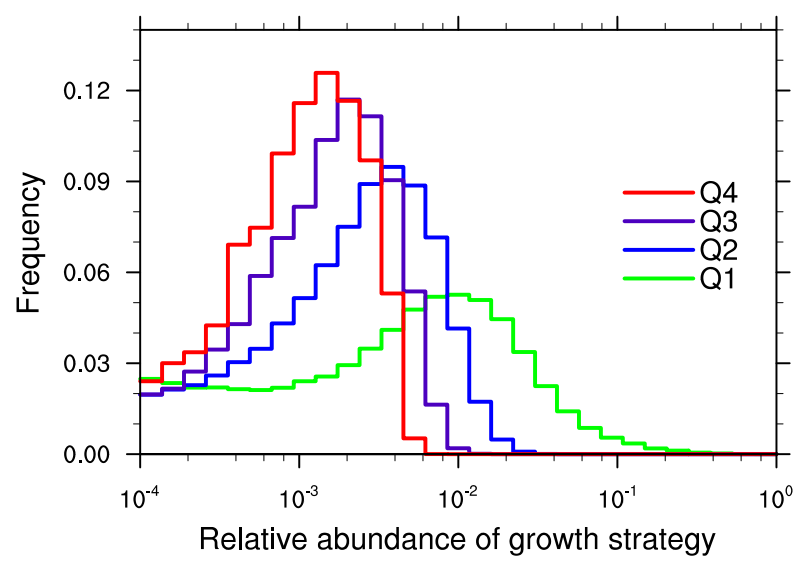

(b)

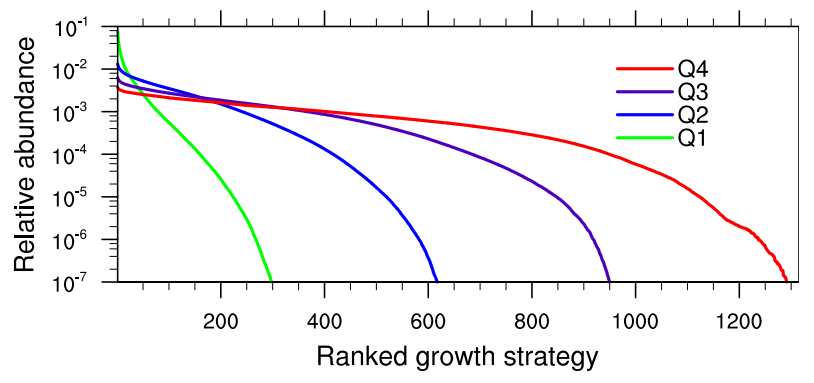

Fig. 9. (a) Simulated relative abundance distributions of plant growth strategies for four richness quartiles. (b) Simulated relative abundance versus growth strategy rank for four richness quartiles (Q1-Q4). On the X-axis, growth strategies are ranked according to their abundances, which in turn are plotted on the y-axis.

surviving growth strategies for analysis. In reality, these regions are sparsely vegetated, if not completely barren, and contribute little to the global exchange fluxes of water and carbon.

To provide further insight into the mechanism driving the convergence of both the biogeochemical and biodiversity patterns, we show three scatter plots containing CWMs of a functional trait parameter with respect to some environmental condition (Fig. 13). In each scatter plot, the red line represents the mean of the uniform prior distribution used in the random sampling of that particular trait parameter. When the values of a particular trait parameter have little influence on the distribution of growth strategy abundances in a grid cell, the grey circle representing that grid cell will fall on or near the red line. Each trait parameterization, however, has been designed such that, at least in some environments, functional trade-offs will cause some range of trait values to be more beneficial than other parts of the trait spectrum. If the mechanism driving the convergence is environmental selection via functional trade-offs, we would expect to see some CWM 

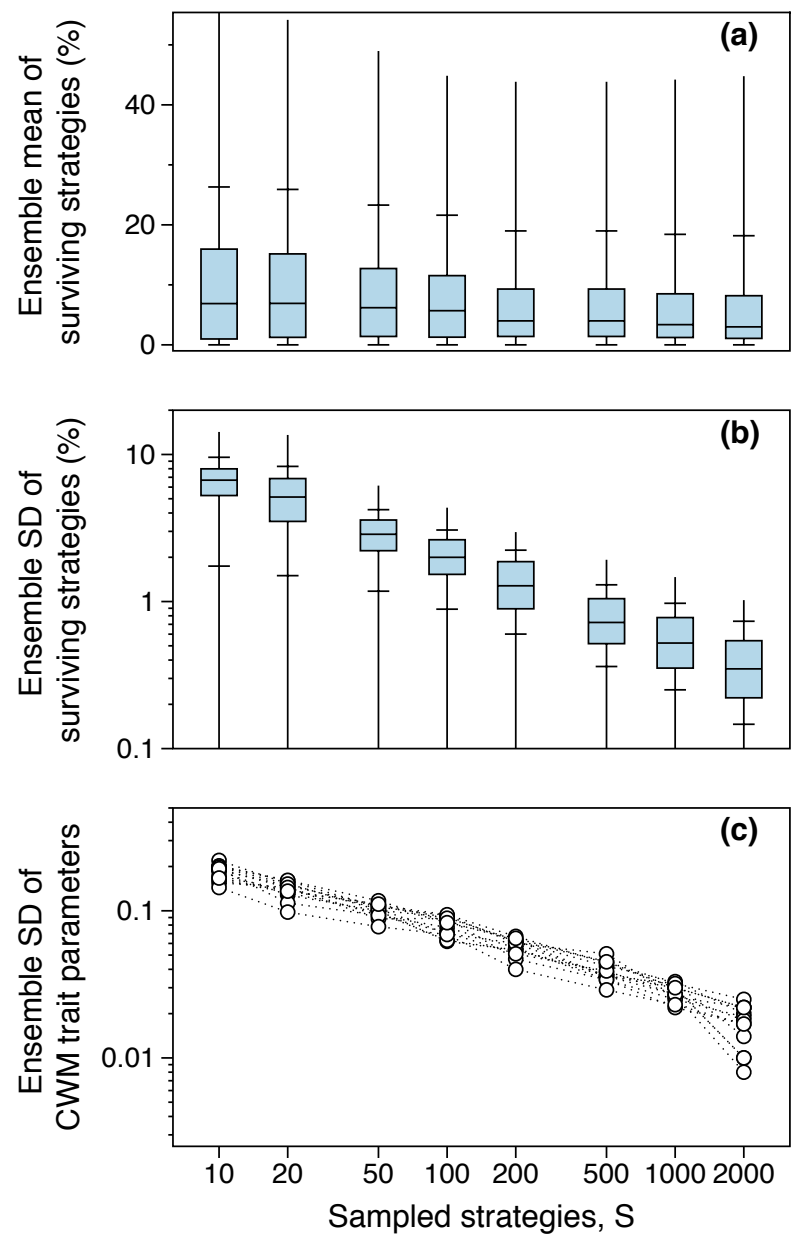

Fig. 10. (a) Box plots showing the geographic variation of the ensemble mean of the percent of surviving strategies. (b) Box plots showing decreasing ensemble standard deviation of the percent of surviving strategies with increasing number of sampled strategies, $S$. Each ensemble contains $20 \mathrm{JeDi}-\mathrm{DGVM}$ simulations with the same number of randomly sampled growth strategies $(S=10,20$, $50,100,200,500,1000$ or 2000). Central boxes show the interquartile range and median across all (a) non-glaciated and (b) vegetated land grid cells; vertical lines indicate the range; horizontal whiskers indicate the 10th and 90th percentiles. (c) Line plots showing decreasing ensemble variation of the abundance-weighted trait values with increasing number of sampled strategies $(S)$. Each circle represents the area-weighted spatial mean of the ensemble standard deviation of the community-weighted mean trait values for one of the 15 functional trait parameters.

trait parameters skewed away from the mean of the uniform prior distribution, i.e. grey circles shifted off of the red line.

In the first scatter plot (Fig. 13a), we show the CWMs of trait parameter $t_{3}$ (denoted as $\left\langle t_{3}\right\rangle$ ) with respect to mean annual temperature. Nearly all of the CWMs from grid cells with mean annual temperatures greater than $10^{\circ} \mathrm{C}$ lie on or near the red line. This indicates that in warm regions, trait
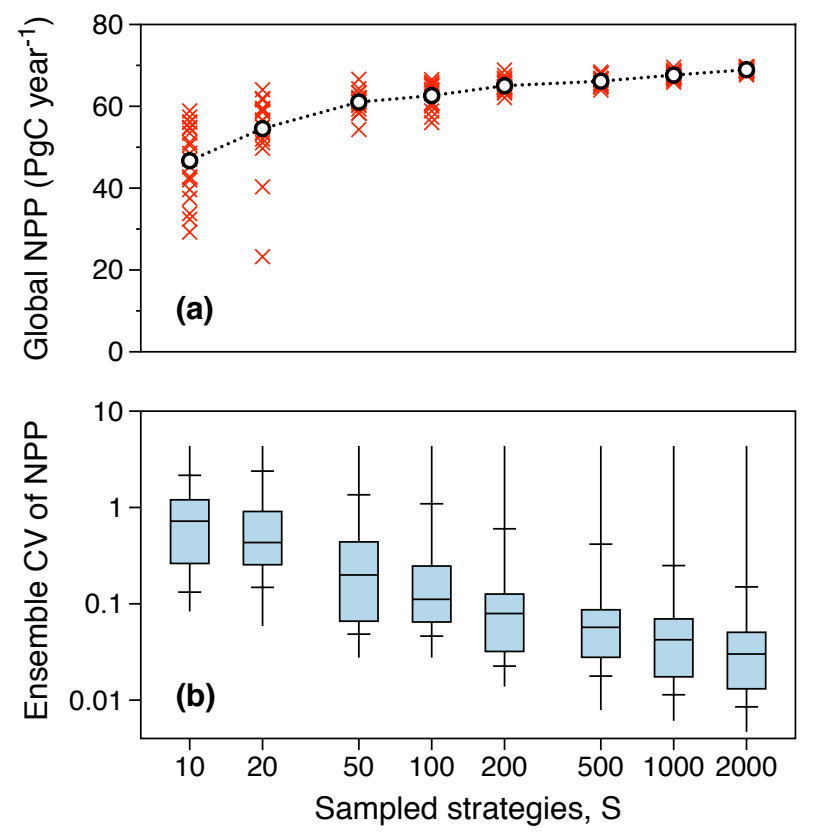

Fig. 11. (a) Scatter plot showing higher values of global terrestrial net primary productivity (NPP) and lower within-ensemble variation with increasing number of sampled strategies. Each red cross represents the terrestrial NPP from a JeDi-DGVM simulation with $S$ randomly sampled strategies. Each diversity ensemble contains 20 simulations with the same number of sampled strategies $(S=10$, $20,50,100,200,500,1000$ or 2000). The white circles represent the ensemble means. (b) Box plots showing decreasing ensemble coefficient of variation of NPP with increasing number of sampled strategies. Central boxes show the interquartile range and median across all vegetated land grid cells; vertical whiskers indicate the range; horizontal whiskers indicate the 10th and 90th percentiles.

parameter $t_{3}$ has little to no influence on the survival or abundance of growth strategies, because there are few, if any, periods of the year in which low temperatures constrain productivity. As you move right across the plot, however, towards colder temperatures, the values of $\left\langle t_{3}\right\rangle$ generally increase. This is because trait parameter $t_{3}$ determines the critical temperature for the onset of plant growth in a linear function between $-5^{\circ} \mathrm{C}$ and $10^{\circ} \mathrm{C}$ (see Appendix A3 for more details). In cooler regions, the timing of the onset of the growing season strongly influences plant survival and abundance, resulting in $\left\langle t_{3}\right\rangle$ values skewed significantly away from the expected prior value of 0.5 .

Figure 13b shows a similar scatter plot of $\left\langle t_{7}\right\rangle$ with respect to the intra-annual precipitation variability. The intra-annual precipitation variability (IPV) of each grid cell is calculated as the coefficient of variation of the climatic monthly means of the precipitation forcing dataset. Trait parameter $t_{7}$ determines the fractional allocation of carbon to belowground growth (see Appendix A5 for more details). In regions with low values of IPV, i.e. where precipitation falls relatively 


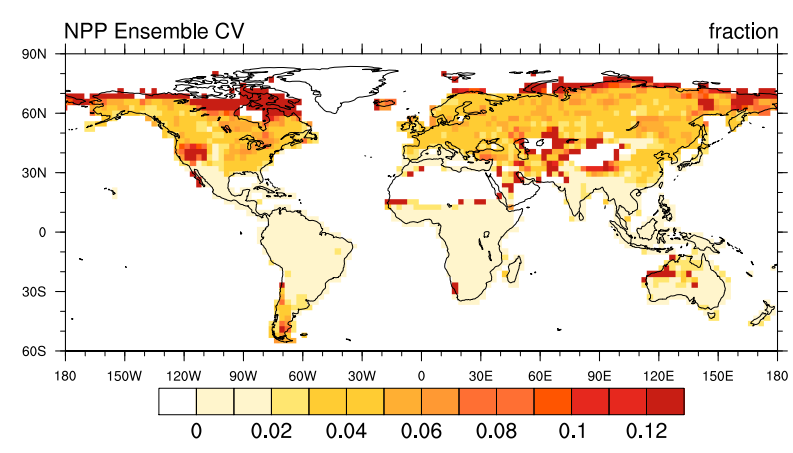

Fig. 12. Geographic pattern of the coefficient of variation of net primary productivity (NPP) across an ensemble of $20 \mathrm{JeDi}-\mathrm{DGVM}$ simulations, each with 2000 randomly sampled species $(S=2000)$.

evenly throughout the year, the values of $\left\langle t_{7}\right\rangle$ generally fall below the expected prior value of 0.25 . In aseasonal regions, allocation of carbon to aboveground growth, and thus increased access to light, seems to outweigh the benefits of belowground growth. As you move left across the plot, however, towards higher IPV values, the values of $\left\langle t_{7}\right\rangle$ generally increase. This illustrates the selective pressure of seasonally dry environments towards growth strategies which prioritize root growth. Additional root biomass allows these growth strategies to sustain productivity throughout dry seasons by taking up water from deeper parts of the soil column.

The last scatter plot shows CWM leaf $\mathrm{N}$ concentrations, $\left\langle\left[\mathrm{N}_{\mathrm{L}}\right]\right\rangle$, with respect to mean annual temperature (Fig. 13c). In the model, the leaf $\mathrm{N}$ concentration, $\left[\mathrm{N}_{\mathrm{L}}\right]$, of each growth strategy is calculated as a linear function of its trait parameter $t_{15}$ (see Appendix A8 for more details). [ $\mathrm{N}_{\mathrm{L}}$ ], in turn, directly affects both the productivity of a growth strategy via photosynthetic capacity and its maintenance respiration rate. Photosynthetic capacity has a unimodal distribution, the shape of which is influenced by air temperature and the ambient $\mathrm{CO}_{2}$ concentration. Leaf maintenance respiration increases monotonically with higher air temperature. Due to this trade-off, for every climatic environment there will be some range of $\left[\mathrm{N}_{\mathrm{L}}\right]$ values that maximize NPP. Because the relative abundance of a growth strategy is strongly linked to NPP, $\left\langle\left[\mathrm{N}_{\mathrm{L}}\right]\right\rangle$ should be skewed towards these more productive trait values. Looking again at the scatter plot, we see the $\left\langle\left[\mathrm{N}_{\mathrm{L}}\right]\right\rangle$ values are indeed skewed away from the expected prior of $0.055 \mathrm{gC} \mathrm{gN}^{-1}$, and they generally decrease with increasing mean annual temperature. This pattern is consistent with the broad global pattern of observed leaf $\mathrm{C}: \mathrm{N}$ ratios (Reich and Oleksyn, 2004).

Whether or not the simulated relationship of leaf $\mathrm{C}: \mathrm{N}$ and mean annual temperatures match the observed global pattern for the correct reasons is still an open question and beyond the scope of this paper. Rather, we have simply shown the three scatter plots in Fig. 13 to provide insight into the mechanistic trait-filtering process driving the convergence of the
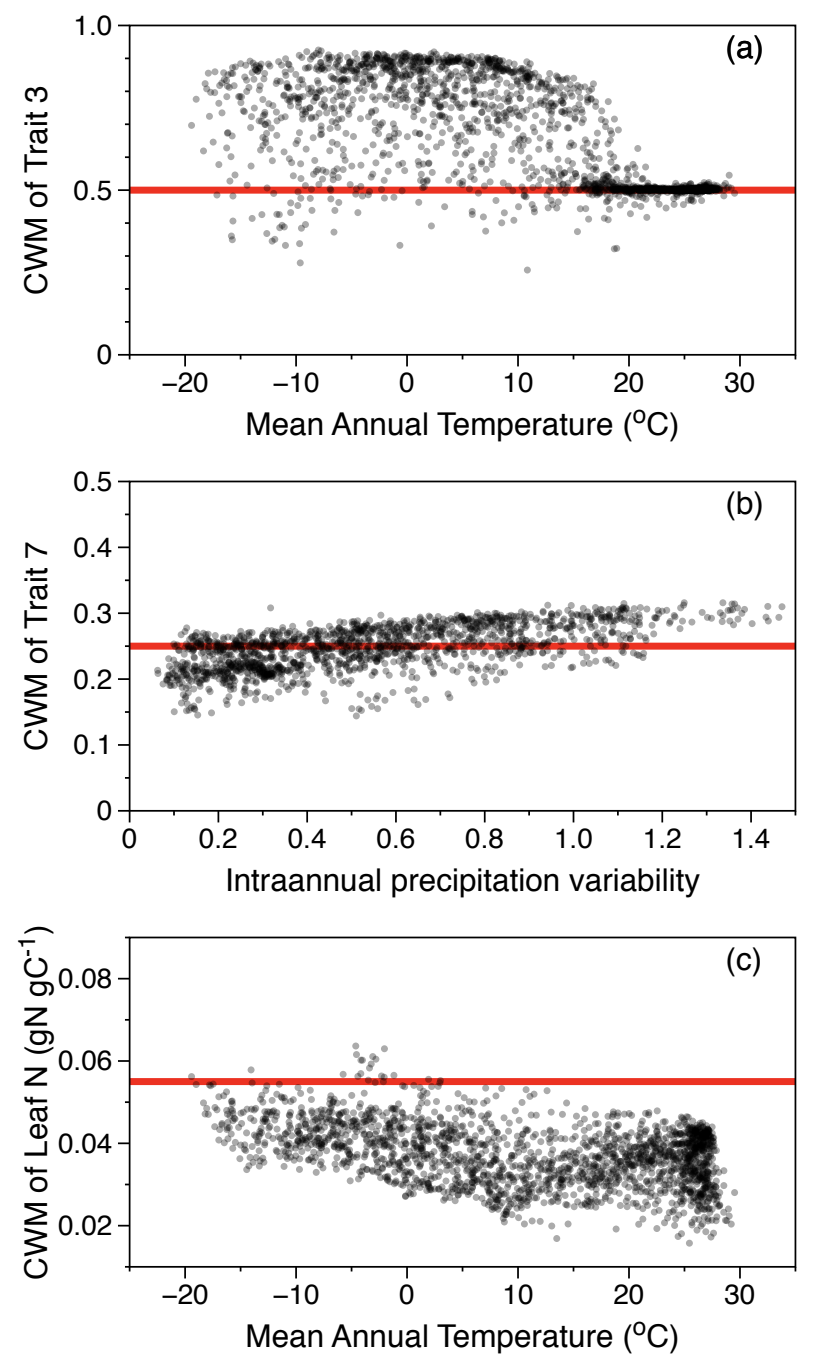

Fig. 13. (a) Scatter plot of the community-weighted means (CWMs) of trait parameter $t_{3}$ with respect to mean annual temperature. Trait parameter $t_{3}$ determines the critical temperature for the onset of plant growth in a linear function between $-5^{\circ} \mathrm{C}$ and $10^{\circ} \mathrm{C}$. (b) Scatter plot of the CWMs of trait parameter $t_{7}$ with respect to intraannual precipitation variability. Trait parameter $t_{7}$ determines the fractional allocation of carbon to belowground growth. Intra-annual precipitation variability is calculated as the coefficient of variation of the climatic monthly means of the precipitation forcing dataset. (c) Scatter plot of the CWMs of leaf $\mathrm{N}$ concentration with respect to mean annual temperature. Leaf $\mathrm{N}$ concentrations are calculated directly as a linear function of trait parameter $t_{15}$. Each grey point represents the CWM across 2000 randomly sampled strategies within a grid cell. The red lines represent the means of the uniform prior distribution used in the random sampling of that particular trait parameter. $(\mathrm{a}=0.50, \mathrm{~b}=0.25, \mathrm{c}=0.055)$.

biogeochemical and biodiversity patterns among the highest diversity ensemble simulations. They are also great examples of the many newly testable mechanistic predictions made possible by JeDi-DGVM's unique and parsimonious 
functional trade-off approach. Future studies should evaluate the simulated geographic distributions of CWM trait parameters against observed trait patterns. This possibility is discussed further in Sect. 5.4.

\section{Discussion}

JeDi-DGVM introduces several novel elements to dynamic vegetation modelling, allowing for an explicit representation of functional diversity that can evolve temporally. As the current implementation represents an initial prototype from which refinements and added functionality will be made, we discuss below several key concepts that underlie the formulation of JeDi-DGVM, and which will likely result in the greatest impact on model improvement in future efforts.

\subsection{Representation of trade-offs}

JeDi-DGVM is a prototype meant to explore the potential utility of a trait-based functional trade-off approach for transitioning the state of the art of global vegetation modelling beyond the limitations of a set of fixed PFTs. One of the greatest potential advantages of this approach is that it does not constrain the vegetated land surface to be represented by a small set of functional types, but instead allows for a more continuous representation of vegetation types that can evolve as a function of climatic suitability. We demonstrate in this work that from this trade-off-based approach a realistic representation of land surface biophysical form and function can emerge.

For this approach to be successful, several key requirements must be met, particularly (1) identification of the key trade-offs that determine the ability of a plant to survive in a given environment, and (2) proper parameterization of the costs and benefits of the traits associated with those tradeoffs. In this current implementation, JeDi-DGVM utilizes 15 functional parameters that characterize the behaviour of a growth strategy in terms of its carbon allocation strategy, phenological dynamics, tissue turnover and the balance between respiration and photosynthesis. The positive performance of JeDi-DGVM in the C-LAMP evaluation lends credibility to this approach, and will motivate further evaluation of the critical plant traits and trade-offs that determine the performance of the vegetated land surface. New information sources linking costs and benefits with observed traits, such as the TRY database (Kattge et al., 2011), will provide important constraints on future refinements of this approach.

\subsection{Is everything everywhere?}

JeDi-DGVM assumes that the distribution of plant growth strategies is able to adjust quickly to climatic changes, allowing all of the sampled plant growth strategies to emerge when a given climate anywhere on the globe becomes suitable. This can be stated through the ecological hypothesis of "Everything is everywhere, but the environment selects" While this ecological hypothesis was originally formulated with respect to the biogeography of marine microbes, terrestrial plant species face considerable barriers to migration (e.g. mountain ranges, deserts, oceans). The timescales of terrestrial plant growth and dispersal also differ greatly from those of fast-lived marine microbes transported along ocean currents. Model-based studies (Malcolm et al., 2002; Loarie et al., 2009) show that the preferred ranges of many plant species could shift tens to hundreds of kilometres over the next century due to anthropogenic greenhouse warming, making the issue of estimating migration rates and the extent to which everything is truly everywhere key to predicting future vegetation composition.

Despite the importance of this issue to the vegetation modelling community (Neilson et al., 2005), only one modelling group (Lee, 2011) has introduced mechanistic migration processes in a DGVM. Lee (2011) attributes this partially to the difficulties associated with the considerable variation in seed dispersal rates within the PFTs used by the current generation of DGVMs. Incorporating aspects of seed dispersal in a functional trade-off framework, through additional traits such as seed size, could help to constrain plant migration rates in climate change simulation experiments. Seed dispersal range, and consequently the rate of plant migration, is closely linked to seed size. Smaller seeds are more easily transported by the wind and animals than larger seeds (Ezoe, 1998). On the other hand, larger seeds allow establishing plants to persist through longer periods of stress. Parameterizing the trade-off between seed size and dispersal rates will be challenging, but possibly less so than modelling migration with a PFT-based scheme.

\subsection{Aggregation scheme and competition}

The aggregation of vegetation states and fluxes across the diversity represented in each computational grid cell is based on the "biomass-ratio" hypothesis. This scheme determines the grid cell flux or state as an average across all surviving plant growth strategies in the grid cell, weighted by their respective biomass, imposing the implicit assumption that interaction between plant growth strategies is weak. For example, JeDi-DGVM does not currently account for the shading of plant growth strategies that resemble understory plants by those that resemble dominant canopy trees. Likewise, the hydrologic conditions that a plant growth strategy experiences are not influenced by the other surviving plant growth strategies in its grid cell. Thus, understory plant growth strategies do not stand to benefit during periods of drought from the observed phenomena of hydraulic redistribution, wherein deep-rooted plants redistribute soil water from lower soil layers (Lee et al., 2005; Prieto et al., 2012). These types of competitive and facilitative interactions are known to influence community-assembly processes at the local scale (Cavender-Bares et al., 2009), leading to 
trait divergence. However, at larger scales, including the spatial resolution of the simulation results presented here, trait selection and trait convergence due to environmental filtering have been shown to be the dominant community-assembly processes (Kraft et al., 2008; Swenson and Weiser, 2010; Freschet et al., 2011; Kraft et al., 2011).

The "biomass-ratio" aggregation scheme was chosen for its simplicity and its demonstrated effectiveness for making statistical predictions about community fluxes from trait abundance information at the field scale (Garnier et al., 2004; Vile et al., 2006; Kazakou et al., 2006; Díaz et al., 2007; Quetier et al., 2007). However, the mechanistic tradeoff-based trait filtering framework of JeDi-DGVM does not preclude the integration of more sophisticated aggregation schemes. For example, Bohn et al. (2011) recently used JeDiDGVM model output together with the simple population dynamics model DIVE (Dynamics and Interactions of VEgetation) to explore how seed competition, resource competition and environmental disturbances might influence community structure. In the future, the trade-off-based modelling approach of JeDi-DGVM could be directly integrated with the representation of population dynamics from the DIVE model or from other recent models (e.g. the Ecosystem Demography model; Moorcroft et al., 2001; Medvigy et al., 2009; R. Fisher et al., 2010) which explicitly account for canopy height structure and age classes.

With these more explicit competition schemes, growth strategies would directly compete for resources such as light. Currently with the "biomass-ratio" approach, the development of each growth strategy is simulated completely independently of the others, much like if they were potted plants grown in greenhouses. The contribution of each growth strategy to the grid-cell fluxes is weighted by its relative biomass only. This implicitly assumes that larger strategies will win out of over smaller strategies. There is no explicit consideration of plant height or disturbance processes that act differently upon different strategies. With a more explicit competition scheme, the strategies would constantly interact; as one strategy grew higher than its competitors, it would have preferential access to light, thus reducing the amount of light available for the other strategies. This would likely reduce the number of surviving strategies and may even alter the identity of the most abundant strategy (cf. Franklin et al., 2012).

Also, the current version of JeDi-DGVM may have difficulties representing savannah-like ecosystems. If you imagine a grid cell with just two successful growth strategies, a grass-like strategy and a tree-like strategy, in the current version of JeDi-DGVM the much higher biomass density of the tree-like strategy will dominate in the mass-weighting scheme. This will cause the grid-cell to have forest-like fluxes and physical characteristics. In reality, environmental heterogeneity and disturbance processes, such as fire and herbivory, might prevent the tree-like strategy from dominating the grid cell. JeDi-DGVM could be improved by explicitly modelling these processes. This could also alter the timescale of simulated shifts in vegetated composition.

\subsection{Further evaluation}

Here, we evaluated the feasibility of using the JeDi-DGVM modelling approach to simulate broad-scale patterns of terrestrial biogeochemistry and ecosystem properties. However, another key and unique test for this approach would be to directly compare the emergent patterns of simulated functional trait parameters with our growing knowledge about the geographic distribution of plant traits and their environmental co-variates. This information could come from trait databases (e.g. TRY; Kattge et al., 2011) or remote sensing products (e.g. canopy nitrogen observations; Ollinger et al., 2008). A further test would be to compare simulated shifts in functional trait parameters and allocation patterns with observed shifts in trait abundances from ecosystem manipulation experiments, e.g. irrigation (Axelsson and Axelsson, 1986), $\mathrm{CO}_{2}$ enhancement (Ainsworth and Long, 2004), or throughfall exclusion (Fisher et al., 2007). These fine-scale comparisons would help further refine various aspects of the biogeochemical formulations and trade-offs incorporated into JeDi-DGVM, and give greater confidence in projections regarding the future fate of the terrestrial biosphere.

In Sect. 4.1.9, we briefly compared the simulated allocation of NPP to different plant carbon pools with carbon budget observations (Malhi et al., 2009) from three Amazonian forest ecosystems. This analysis should be expanded globally by comparing the the simulated patterns of carbon flows and stocks with observations from other existing datasets based on carbon inventories (Cannell, 1982; Litton et al., 2007; Luyssaert et al., 2007; Malhi et al., 2011). More specifically, one could look at how the simulated allocation patterns vary along environmental gradients (cf. Litton and Giardina, 2008; Cornwell and Ackerly, 2009). In this study, we only examined the community-aggregated allocation fluxes. It would be equally interesting to explore how the simulated partitioning of NPP varies among surviving plant growth strategies within grid cells (cf. Ackerly and Cornwell, 2007).

For instance, Wolf et al. (2011) and Malhi et al. (2011) found evidence that the strongest allocation trade-off was not between root and shoots, as has been commonly thought, but rather more specifically between allocation to fine roots and aboveground wood. This relationship is likely mediated between sites by hydrological conditions and within sites by the competitive dynamics between faster and slower growing trees. In principle, the functional trade-off modelling approach of JeDi-DGVM should be able to capture both of these phenomena. However, this might require the introduction of further trade-off constraints, e.g. related to disturbances, wood economics, and plant hydraulics (cf. Hickler et al., 2006; Chave et al., 2009; Falster et al., 2010).

The evaluation of JeDi-DGVM presented here has almost entirely ignored the effects of human land use. These land 
use processes are known to be dramatically altering large portions of the terrestrial biosphere (cf. Foley et al., 2005). Future model evaluations could account for these processes by excluding grid cells known to be heavily modified by humans. Ideally, however, future versions of JeDi-DGVM would model human land use processes directly.

\subsection{Potential applications}

The "bottom-up" functional trade-off-based modelling framework presented here represents a step forward in the development of a comprehensive and predictive representation of the terrestrial biosphere for use in earth system models. By mechanistically simulating the full range and continuous nature of plant functional diversity, it will be possible to explore new areas of research.

1. JeDi-DGVM could be used to investigate the relationships between plant biodiversity and ecosystem functioning. Experimental and theoretical ecologists have debated the magnitude and direction of these relationships for decades (McCann, 2000; Loreau, 2001; Reiss et al., 2009). Results from biodiversity manipulation experiments at the field scale, however, generally agree that diversity promotes ecosystem stability (France and Duffy, 2006; Tilman et al., 2006; Ives and Carpenter, 2007; Proulx et al., 2010). This implies that PFTbased vegetation models, by under-representing functional diversity, might overestimate the response of terrestrial ecosystems to climatic variability and change. With JeDi-DGVM, it is now possible to make numerical estimates of these biodiversity-ecosystem functioning relationships at the global scale and their significance for modelling the fate of the terrestrial biosphere in the twenty-first century. This could be accomplished by running a diverse JeDi-DGVM simulation with many plant growth strategies and another simulation wherein the functional diversity is artificially reduced (e.g. recreating something like PFTs by simulating only a single plant growth strategy at each grid cell characterized by the community-aggregated functional trait parameters from the first simulation). It would be interesting to compare the temporal variability in the simulated ecosystem fluxes of both approaches, as well as the ability of the two simulated ecosystems to adapt to changing environmental forcings.

2. By coupling the JeDi-DGVM trade-off-based approach with an optimization algorithm, it is possible to seek out those functional trait combinations that maximize a particular ecosystem service. JeDi-DGVM could be used, for example, to investigate the optimal set of functional trait parameters which maximize the allocation to seed biomass under the present-day climate of each model grid cell, allowing for estimates of the upper bound of realizable yields as a function of climatic constraint.
3. Climate model projections point towards the possibility of novel climates without modern or palaeo-analogues (Jackson and Williams, 2004; Williams and Jackson, 2007). This causes difficulties for PFT-based DGVM modelling approaches because they often rely so heavily on bioclimatic relationships based on present-day empirical observations. Because JeDi-DGVM samples functional trait parameters from their full theoretical ranges, it may produce surviving growth strategies or compositions of growth strategies without presentday analogues (Reu et al., 2013). Coupling JeDiDGVM directly within an earth system model would allow for the exciting possibility of exploring how these no-analogue vegetation compositions influence atmosphere-biosphere interactions.

\section{Conclusions}

In this paper, we introduced the JeDi-DGVM, which represents a new class of dynamic global vegetation models that simulates many randomly assembled hypothetical plant growth strategies, rather than the traditional approach of using a small number of PFTs defined a priori. In a systematic evaluation, we have shown that its bottom-up plant functional trade-off approach, together with a simple mass-based aggregation mechanism, is able to capture the broad patterns of terrestrial biogeochemical fluxes and associated land surface properties reasonably well. The evaluation results compare favourably with two other state-of-the-art TBMs based on the older PFT paradigm. Additionally, we have shown that unlike PFT-based models, JeDi-DGVM is able to mechanistically reproduce the global-scale biogeographical patterns of plant species richness and community evenness. Finally, these biogeochemical and biodiversity patterns were shown to be robust when the number of randomly sampled growth strategies simulated was sufficiently large. This robustness is the result of a mechanistic trait filtering process made possible by the careful formulations of functional trade-offs within the model structure, and not simply due to averaging of many unbiased random variables.

Because it is more closely based on first principles, JeDiDGVM requires less input data and is able to produce a wider range of testable outputs than earlier DGVMs based on the PFT concept. This new approach sets the foundation for future applications in which the simulated vegetation response to global change has a greater ability to adapt through changes in ecosystem composition, having potentially wideranging implications for biosphere-atmosphere interactions under global change. 


\section{Appendix A}

\section{Jena Diversity-Dynamic Global Vegetation Model (JeDi-DGVM) description}

JeDi-DGVM builds upon the plant diversity model of KM2000, which itself took many model formulations from earlier land surface (Roeckner et al., 1996) and terrestrial biosphere models (e.g. Potter et al., 1993; Knorr and Heimann, 1995; Kaduk and Heimann, 1996). Here, the ecophysiological parameterizations have been kept relatively simple to keep the computational requirements manageable. This makes it possible to simulate the development of many plant growth strategies in parallel across a global grid over long simulation periods within a reasonable time frame on a single Linux workstation. That said, several of the formulations and parameter values, particularly with respect to the calculation of productivity and respiration, have been changed to improve the realism of the simulated fluxes. Also, whereas the KM2000 model simulated the life cycle of individual generic plants from germination to death, the JeDiDGVM introduces tissue turnover and thus simulates something closer to the mean of a population for each plant growth strategy. Finally, the most important new feature is the introduction of a scaling mechanism to aggregate the exchange fluxes and land surface properties of many plant growth strategies to the community level based on the "biomassratio" hypothesis.

\section{A1 Plant module overview}

The plant module simulates the development of plant growth strategies based on the fundamental ecophysiological processes of photosynthesis, respiration, allocation, phenology, and reproduction. Plant development is coupled in a processbased manner to a land surface hydrology module which simulates canopy interception, throughfall, infiltration, evaporation, root water uptake, and surface runoff, using daily meteorological forcing of downwelling shortwave and net longwave radiation, precipitation, and near-surface air temperature. The variables and parameters involved in the development of the plant growth strategies are summarized in Table B4. The details of the land surface module are described in Appendix B.

Each plant growth strategy is represented by six carbon tissue pools defined per unit area: stored assimilates $C_{\mathrm{A}}$, leaves $C_{\mathrm{L}}$, fine roots $C_{\mathrm{R}}$, aboveground wood (branches and stems) $C_{\mathrm{WL}}$, belowground wood (coarse roots) $C_{\mathrm{WR}}$, and a reproductive (or "seed") pool $C_{\mathrm{S}}$. When growing conditions are favourable, carbon germinates from the "seed" pool to the storage pool. The plant then begins to grow by allocating carbon from the storage pool to the various tissue pools. The tissue pools are also subject to turnover and senescence. The litter fluxes from these two processes serve as input to the soil carbon module. The sizes of the tissue pools influence the pa- rameter values of the land surface module, affecting both the absorption of solar radiation and the land surface hydrology. For example, the absorption of solar radiation, which supplies the energy for photosynthesis and evapotranspiration, is proportional to leaf area index (LAI), which is derived from leaf biomass. Fine root biomass affects the maximum rate of water uptake from the rooting zone, influencing the plant's water status and the supply of moisture for evapotranspiration. Likewise, the coarse root biomass of a plant determines the hydrologic depth of its rooting zone. The land surface conditions in turn affect the net primary productivity (NPP), which forms the input to the storage pool. A plant growth strategy is considered to be alive as long as the carbon in the storage pool is greater than zero $\left(C_{\mathrm{A}}>0\right)$. The details of these processes are described in the following subsections.

The particular functioning of a plant growth strategy is defined by a set of 15 functional trait parameters $\left(t_{1}, \ldots, t_{15}\right)$. These functional trait parameters control the allocation of carbon from the storage pool to the other tissue pools, the tissue turnover rates, the phenological response to environmental conditions, and the ecophysiological balance between photosynthesis and respiration. All of the functional trait parameters range between zero and one. However, these ranges are often extended by using the functional trait parameters as either exponents or coefficients. Each functional trait parameter is associated with one or more functional trade-offs. For instance, a higher allocation to fine roots enhances the rate at which a plant can extract moisture from the soil matrix, but this comes at the expense of allocation to the aboveground pools and thus a decreased ability to capture light for photosynthesis, as well as the metabolic cost of maintaining that biomass. The implementation of these trade-offs are explained in further detail below. The descriptions of the functional trait parameters are summarized in Table $\mathrm{C} 2$.

\section{A2 Vegetation carbon pool dynamics}

The following differential equations describe the dynamics of the vegetation carbon pools.

$$
\begin{aligned}
\frac{\mathrm{d} C_{\mathrm{A}}}{\mathrm{d} t} & =\mathrm{NPP}+\mathrm{GERM}-\sum C_{\mathrm{A}} A_{\mathrm{tissue}}\left(1-c_{\mathrm{RES}, \text { tissue }}\right) \\
\frac{\mathrm{d} C_{\mathrm{S}}}{\mathrm{d} t} & =C_{\mathrm{A}} A_{\mathrm{S}}\left(1-c_{\mathrm{RES}, \mathrm{S}}\right)-\mathrm{GERM}-\frac{C_{\mathrm{S}}}{\tau_{\mathrm{S}}} \\
\frac{\mathrm{d} C_{\mathrm{L}}}{\mathrm{d} t} & =C_{\mathrm{A}} A_{\mathrm{L}}\left(1-c_{\mathrm{RES}, \mathrm{L}}\right)-\frac{C_{\mathrm{L}}}{\tau_{\mathrm{L}}} \\
\frac{\mathrm{d} C_{\mathrm{R}}}{\mathrm{d} t} & =C_{\mathrm{A}} A_{\mathrm{R}}\left(1-c_{\mathrm{RES}, \mathrm{R}}\right)-\frac{C_{\mathrm{R}}}{\tau_{\mathrm{R}}} \\
\frac{\mathrm{d} C_{\mathrm{WL}}}{\mathrm{d} t} & =C_{\mathrm{A}} A_{\mathrm{WL}}\left(1-c_{\mathrm{RES}, \mathrm{WL}}\right)-\frac{C_{\mathrm{WL}}}{\tau_{\mathrm{WL}}} \\
\frac{\mathrm{d} C_{\mathrm{WR}}}{\mathrm{d} t} & =C_{\mathrm{A}} A_{\mathrm{WR}}\left(1-c_{\mathrm{RES}, \mathrm{WR}}\right)-\frac{C_{\mathrm{WR}}}{\tau_{\mathrm{WR}}}
\end{aligned}
$$

The details of the various terms are described below in the following subsections. 


\section{A3 Growing conditions}

The timing of plant growth and germination is controlled by environmental conditions, specifically, soil wetness $f_{\mathrm{W}}$ and near-surface air temperature $T$. Soil wetness $f_{\mathrm{W}}$ is defined as the ratio of moisture $W$ stored in the rooting zone relative to the maximum storage capacity of the rooting zone $W_{\mathrm{MAX}}$. Functional trait parameters $t_{1}$ and $t_{2}$ and time constants $\tau_{\mathrm{W}}$ and $\tau_{\mathrm{T}}$ determine how quickly a plant responds to changes in the environmental conditions.

$$
\begin{aligned}
f_{\mathrm{GROW}, T}(t) & =\frac{T+\tau_{\mathrm{T}} f_{\mathrm{GROW}, T}(t-\Delta t)}{1+\tau_{\mathrm{T}}} \\
\text { with } \tau_{\mathrm{T}} & =10^{4 t_{1}-2} \\
f_{\mathrm{GROW}, W}(t) & =\frac{f_{\mathrm{W}}+\tau_{\mathrm{W}} f_{\mathrm{GROW}, W}(t-\Delta t)}{1+\tau_{\mathrm{W}}} \\
\text { with } f_{\mathrm{W}} & =\frac{W}{W_{\mathrm{MAX}}} \text { and } \tau_{\mathrm{W}}=10^{4 t_{2}-2} \\
f_{\mathrm{GROW}, G}(t) & =\frac{f_{\mathrm{W}, \text { bare }}+\tau_{\mathrm{W}} f_{\mathrm{GROW}, G}(t-\Delta t)}{1+\tau_{\mathrm{W}}} \\
\text { with } f_{\mathrm{W}, \text { bare }} & =\frac{W_{\text {bare }}}{W_{\mathrm{MAX}, 0}}
\end{aligned}
$$

Values of functional trait parameters $t_{1}$ and $t_{2}$ near zero represent a short memory and thus a quick response to change, while larger values represent a longer memory and a slower response. For example, a plant with a low value of $\tau_{\mathrm{T}}$ would react almost immediately to a warm day in early spring, whereas a plant with a larger value would react only after several days or weeks of spring warmth. Likewise, a high value of $\tau_{\mathrm{W}}$ would lead a plant to continue to allocate carbon despite persisting drought conditions.

For germination, only the soil wetness of the top $50 \mathrm{~mm}$ $W_{\text {top }}$ (see Eq. B16) relative to the storage capacity of bare non-vegetated soil is considered. Germination and growth only occur when both the temperature function $f_{\mathrm{GROW}, T}$ is above a critical temperature $T_{\text {crit }}$ and the relevant soil wetness condition, $f_{\mathrm{GROW}, W}$ or $f_{\mathrm{GROW}, G}$, is greater than a critical value of 0.5 . The critical temperature $T_{\text {crit }}$ is a linear function of functional trait parameter $t_{3}$ between $-5{ }^{\circ} \mathrm{C}$ and $10{ }^{\circ} \mathrm{C}$.

$$
\begin{aligned}
& f_{\mathrm{GROW}}= \begin{cases}0 & f_{\mathrm{GROW}, W}<0.5 \text { and } f_{\mathrm{GROW}, T}<T_{\text {crit }} \\
1 & f_{\mathrm{GROW}, W} \geq 0.5 \text { or } f_{\mathrm{GROW}, T} \geq T_{\text {crit }}\end{cases} \\
& f_{\mathrm{GERM}}= \begin{cases}0 & f_{\mathrm{GROW}, G}<0.5 \text { and } f_{\mathrm{GROW}, T}<T_{\text {crit }} \\
1 & f_{\mathrm{GROW}, G} \geq 0.5 \text { or } f_{\mathrm{GROW}, T} \geq T_{\text {crit }}\end{cases}
\end{aligned}
$$

\section{A4 Germination}

Germination of carbon from the "seed" pool $C_{\mathrm{S}}$ to the storage pool $C_{\mathrm{A}}$ occurs when germination conditions are favourable $\left(f_{\text {GERM }}=1\right)$ and the "seed" pool is not empty $\left(C_{\mathrm{S}}>0\right)$ :

$$
\mathrm{GERM}=f_{\mathrm{GERM}} \gamma_{\mathrm{GERM}} \frac{C_{\mathrm{S}}}{\max \left(p, k_{\mathrm{GERM}}\right)}
$$

with $\gamma_{\text {GERM }}=10^{4 t_{4}-4}$.

Functional trait parameter $t_{4}$ modulates the germination fraction $\gamma_{\mathrm{GERM}}$, the fraction of "seed" carbon $C_{\mathrm{S}}$ which can germinate to the storage pool $C_{\mathrm{A}}$ in a single daily time step (Cohen, 1968; Alvarado and Bradford, 2002). Values of $t_{4}$ near zero result in a conservative strategy with only a small fraction of "seed" carbon germinating to the storage pool per day when germination conditions are met $\left(f_{\text {GERM }}=1\right)$. Higher values yield increasingly more opportunistic strategies. When germination conditions are favourable $\left(f_{\text {GERM }}=\right.$ 1) and the "seed" pool is $C_{\mathrm{S}}=0$, a small amount of initial carbon is added to the "seed" pool to allow a growth strategy to begin growth. When this occurs, an equivalent amount of carbon is added to the community-aggregated gross primary productivity (see Appendix A9) to maintain the conservation of mass in the grid-cell variables.

\section{A5 Carbon allocation}

Plants allocate carbon from the storage pool to growth when the growing conditions are favourable $\left(f_{\mathrm{GROW}}=1\right)$. Allocation to the "seed" pool occurs when net primary productivity is greater then zero $\left(f_{\text {SEED }}=1\right.$ when NPP $\left.>0\right)$. The amount of carbon allocated to each tissue pool is proportional to the size of the storage pool $C_{\mathrm{A}}$ and to the set of functional trait parameters, $t_{5}, \ldots, t_{10}$, which together form the plant's carbon allocation strategy:

$$
\begin{aligned}
A_{\mathrm{S}} & =f_{\mathrm{SEED}} \frac{t_{5}}{t_{5}+t_{6}+t_{7}+t_{8}} \\
A_{\mathrm{L}} & =f_{\mathrm{GROW}}\left(1-t_{9}\right) \frac{t_{6}}{t_{5}+t_{6}+t_{7}+t_{8}} \\
A_{\mathrm{R}} & =f_{\mathrm{GROW}}\left(1-t_{10}\right) \frac{t_{7}}{t_{5}+t_{6}+t_{7}+t_{8}} \\
A_{\mathrm{WL}} & =f_{\mathrm{GROW}} f_{\mathrm{VEG}} t_{9} \frac{t_{6}}{t_{5}+t_{6}+t_{7}+t_{8}} \\
A_{\mathrm{WR}} & =f_{\mathrm{GROW}} f_{\mathrm{VEG}} t_{10} \frac{t_{7}}{t_{5}+t_{6}+t_{7}+t_{8}} .
\end{aligned}
$$

The allocation fractions are mathematically constrained such that they sum to less than one $\left(\sum A_{\text {tissue }}<1\right)$. The unallocated fraction $\left(1-\sum A_{\text {tissue }}\right)$ remains in the storage pool $C_{\mathrm{A}}$ for future growth or maintenance respiration. 


\section{A6 Turnover and senescence}

The turnover times $\tau_{\mathrm{WL}}$ and $\tau_{\mathrm{WR}}$ of the woody tissue pools are defined as functions of functional trait parameter $t_{11}$ :

$\tau_{\mathrm{WL}}=\tau_{\mathrm{WR}}=365\left(79 t_{11}+1\right)$.

Eq. (A6) yields a range of turnover times between 1 and $80 \mathrm{yr}$. The base turnover time, $\tau_{\mathrm{L}, 0}$, for the leaf and fine root pools is defined as a function of functional trait parameter $t_{12}$ :

$\tau_{\mathrm{L}, 0}=\frac{365}{12} 10^{2.0 t_{12}}$

Equation (A7) yields a range of turnover times logdistributed between 1 and 100 months, which covers the range of observations in the TRY database (Kattge et al., 2011). The turnover times for the "seed" and storage pools are assumed constant across all plant growth strategies (see Table B4).

Senescence is triggered when both NPP and the timeaveraged net primary productivity $f_{\mathrm{NPP}}$ are negative, where

$f_{\mathrm{NPP}}(t)=\frac{\mathrm{NPP}+\tau_{\mathrm{NPP}} f_{\mathrm{NPP}}(t-\Delta t)}{1+\tau_{\mathrm{NPP}}}$

with $\tau_{\mathrm{NPP}}=10^{5 t_{13}-2}$.

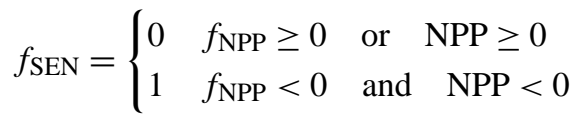

Functional trait parameter $t_{13}$ in time constant $\tau_{\text {NPP }}$ describes the memory of past NPP conditions. Values of $t_{13}$ near zero represent a short persistence during periods of negative NPP, while values closer to one represent longer persistence. During periods of senescence, the turnover rates of the leaf and fine root pools increase proportional to a constant factor, $\tau_{\text {SEN }}$. The relative magnitude of this increase is determined by functional trait parameter $t_{14}$ :

$$
\begin{aligned}
\tau_{\mathrm{L}} & =\left(\frac{1}{\tau_{\mathrm{L}, 0}}+\frac{1}{\tau_{\mathrm{SEN}}} f_{\mathrm{SEN}} t_{14}\right)^{-1} \\
\tau_{\mathrm{R}} & =\left(\frac{1}{\tau_{\mathrm{L}, 0}}+\frac{1}{\tau_{\mathrm{SEN}}} f_{\mathrm{SEN}}\left(1-t_{14}\right)\right)^{-1} .
\end{aligned}
$$

\section{A7 Land surface parameters}

The land surface parameters (maximum plant available water storage in the rooting zone $W_{\mathrm{MAX}}$, leaf area index LAI, potential supply rate for transpiration $S$, fractional vegetative cover $f_{\mathrm{VEG}}$, fractional forest cover $f_{\mathrm{FOR}}$, snow-free surface albedo $a_{\mathrm{ns}}$, and the storage capacity of the canopy $W_{\text {LMAX }}$ ) relate the development of a plant growth strategy to the coupled land surface module, which simulates its environmental conditions. The module itself is based on the land surface component of the ECHAM4 atmospheric general circulation model (Roeckner et al., 1996) along with modifications introduced by KM2000, and is described in detail in Appendix B. These parameters are computed for each plant growth strategy from its carbon tissue pools and functional trait parameters.

$$
\begin{aligned}
\mathrm{LAI} & =c_{\mathrm{L}} \mathrm{SLA} \\
f_{\mathrm{VEG}} & =1-e^{-k \mathrm{LAI}} \\
f_{\mathrm{FOR}} & =1-e^{-c_{\mathrm{FOR}} C_{\mathrm{WL}}} \\
W_{\mathrm{LMAX}} & =c_{\mathrm{WLMAX}} \mathrm{LAI} \\
a_{\mathrm{ns}} & =f_{\mathrm{VEG}} a_{\mathrm{VEG}}+\left(1-f_{\mathrm{VEG}}\right) a_{\mathrm{SOIL}} \\
W_{\max } & =\max \left[W_{\max , 0}, c_{\mathrm{PAW}} \sqrt{c_{\mathrm{SRL}} C_{\mathrm{WR}}}\right] \\
S & =c_{\mathrm{SRU}} C_{\mathrm{R}} f_{\mathrm{W}}
\end{aligned}
$$

The land surface parameters and their conversion constants are summarized in Table C3.

The leaf area index, LAI, of a plant growth strategy is calculated as the product of its leaf biomass $C_{\mathrm{L}}$ and its specific leaf area SLA. The SLA of a plant growth strategy is estimated as a function of leaf lifespan using an empirical relationship derived by Reich et al. (1997), where $\tau_{\mathrm{L}_{0}}$ is the base leaf turnover rate from Eq. (A7).

$\mathrm{SLA}=0.030\left(\frac{365}{\tau_{\mathrm{L}_{0}}}\right)^{-0.46}$

This establishes a trade-off such that a plant growth strategy falls along a spectrum between an evergreen strategy with thicker, long-lived leaves and a deciduous strategy with thinner, short-lived leaves (Reich et al., 1998; Westoby et al., 2002; Shipley et al., 2006a).

The leaf area index LAI is then used to determine both the fractional vegetation cover $f_{\text {VEG }}$ according to the LambertBeer law (Monsi and Saeki, 1953) and the water storage capacity of the canopy $W_{\text {LMAX }}$. The parameterization of the fractional forest cover $f_{\mathrm{FOR}}$ is taken as an analogy of the formulation used for vegetative cover $f_{\mathrm{VEG}}$. The snow-free surface albedo $a_{\mathrm{ns}}$ is calculated as the mean of the canopy albedo $a_{\text {VEG }}$ and the bare soil albedo $a_{\text {SOIL (constant for all }}$ plant growth strategies), weighted by the fractional vegetation cover $f_{\mathrm{VEG}}$. The canopy albedo $a_{\mathrm{VEG}}$ of a plant growth strategy is a linear function of the canopy nitrogen concentration $\left[N_{\mathrm{L}}\right]$ (Hollinger et al., 2010).

$a_{\mathrm{VEG}}=3.216\left[N_{\mathrm{L}}\right]+0.02$

The formulations regarding root properties ( $W_{\text {MAX }}$ and $S$ ) are obtained from first principles. The motivation for using a square-root relationship for the maximum plant available water storage in the rooting zone comes from the Shinozaki et al. (1964) pipe model. From the pipe model perspective, the root system is viewed as an assemblage of pipes which connect the root ends (the organs responsible for water absorption from the soil) with the leaves. If we assume a 
uniform density of root ends within the rooting zone, we obtain a square root relationship between the depth of the rooting zone and the total length of the coarse roots (given by the product of the coarse root biomass $C_{\mathrm{WR}}$ and an assumed constant specific root length parameter $c_{\mathrm{SRL}}$ ). The maximum plant available soil water storage $W_{\mathrm{MAX}}$ is then given by the product of this rooting zone depth and the unit plant available water capacity $c_{\mathrm{PAW}}$ (i.e. the difference between field capacity and permanent wilting point per unit depth) taken from a global dataset (Dunne and Willmott, 1996). Finally, we assume the potential supply rate for transpiration $S$ is related to the fine root biomass $C_{\mathrm{R}}$ and soil wetness $f_{\mathrm{W}}$ via a constant specific root water uptake parameter $c_{\mathrm{SRU}}$.

\section{A8 Net primary productivity}

The net primary productivity NPP of each plant growth strategy is computed as the difference between its gross primary productivity GPP and its autotrophic respiration flux RES $\mathrm{S}_{\mathrm{a}}$.

$\mathrm{NPP}=\mathrm{GPP}-\mathrm{RES}_{\mathrm{a}}$

The parameters and variables involved in the calculation of these fluxes are summarized in Table $\mathrm{C} 4$.

GPP is estimated using a big-leaf non-rectangular hyperbola approach (Johnson and Thornley, 1984; Franklin, 2007):

$$
\begin{aligned}
\mathrm{GPP} & =\frac{h}{2 \theta}\left[\left(\phi I_{\mathrm{a}}+P_{\max }\right)\right. \\
& \left.-\sqrt{\left(\phi I_{\mathrm{a}}+P_{\max }\right)^{2}-4 \theta \phi I_{\mathrm{a}} P_{\max }}\right] \alpha_{\mathrm{H}_{2} \mathrm{O} .}
\end{aligned}
$$

While more sophisticated and likely more accurate photosynthesis schemes are abundant, we chose to use this relatively simple approach for its computational expediency and to keep the number of necessary parameters low. Absorbed photosynthetically active radiation $I_{\mathrm{a}}$ is derived, following the Lambert-Beer law of light extinction, from the photosynthetically active radiation (assumed to be half of downward shortwave radiation) above the canopy $I_{0}$ and the fractional coverage of vegetation (Monsi and Saeki, 1953):

$I_{\mathrm{a}}=I_{0} f_{\mathrm{VEG}}$.

The light-saturated canopy photosynthetic capacity $P_{\max }$ of a plant growth strategy is estimated as a linear function of the canopy nitrogen concentration $\left[N_{\mathrm{L}}\right]$ following an empirical relationship proposed by Ollinger et al. (2008) assuming a foliar carbon content of $0.48 \mathrm{gC} \mathrm{gDM}^{-1}$. Similar relationships between $\mathrm{N}$ content and photosynthetic capacity are well-documented at the leaf scale (Field and Mooney, 1986; Reich et al., 1997; Wright et al., 2004).

$$
\begin{aligned}
& P_{\max }=\left(59.2 \cdot 10^{-4}\left[N_{\mathrm{L}}\right]+1.1 \cdot 10^{-4}\right) \alpha_{T} \\
& {\left[N_{\mathrm{L}}\right]=0.01+0.08 \cdot t_{15}}
\end{aligned}
$$

The canopy nitrogen concentration $\left[N_{\mathrm{L}}\right]$ itself is a linear function of functional trait parameter $t_{15}$, leading to a range of values between 0.01 and $0.09 \mathrm{gN} \mathrm{gC}^{-1}$. The supply of nitrogen is not considered as a limiting factor. The curvature parameter $\theta$ is assumed constant across all plant growth strategies. Day length $h$ is computed from the cosine of the solar zenith angle, which varies with season and latitude (Hartmann, 1994). The quantum efficiency $\phi$ and the factor $\alpha_{T}$ modifying the light-saturated photosynthetic capacity are computed as functions of both air temperature and ambient $\mathrm{CO}_{2}$ concentrations following Cannell and Thornley (1998).

The moisture stress factor $\alpha_{\mathrm{H}_{2} \mathrm{O}}$ is a function of the ratio between the potential supply rate for transpiration $(S)$ and the atmospheric demand for transpiration $(D$; further details in Appendix B).

$\alpha_{\mathrm{H}_{2} \mathrm{O}}=1-\exp (-S / D)$

The autotrophic respiration $\mathrm{RES}_{\mathrm{a}}$ of a plant growth strategy is calculated as the sum of its growth respiration, $\mathrm{RES}_{\mathrm{g}}$, and maintenance respiration, $\mathrm{RES}_{\mathrm{m}}$, fluxes (McCree, 1970; Thornley, 1970). Growth respiration consumes a fixed fraction, $c_{\mathrm{RES}}$, tissue, of the carbon allocated from the storage pool $C_{\mathrm{A}}$ to the tissue pool. These fractions are assumed to be constant across all plant growth strategies.

$$
\mathrm{RES}_{\mathrm{g}}=C_{\mathrm{A}} \sum\left(A_{\text {tissue }} c_{\mathrm{RES}, \text { tissue }}\right)
$$

Following Ryan (1991), maintenance respiration $\mathrm{RES}_{\mathrm{m}}$ is calculated based on the nitrogen content of each tissue, a specific respiration rate, $c_{\mathrm{RES}, \mathrm{N}}$, at $20^{\circ} \mathrm{C}$ and a $Q_{10}$ temperature function.

$$
\begin{aligned}
\operatorname{RES}_{\mathrm{m}}= & c_{\mathrm{RES}, \mathrm{N}} Q_{10, \mathrm{a}}{ }^{\left(\frac{T-20}{10}\right)}\left[N_{\mathrm{L}}\right] \\
& {\left[\left(C_{\mathrm{L}}+C_{\mathrm{R}}\right)+c_{\text {sapwood }}\left(C_{\mathrm{WL}}+C_{\mathrm{WR}}\right)\right] }
\end{aligned}
$$

The fine root nitrogen concentration $\left[N_{\mathrm{R}}\right]$ is assumed to be equal to the leaf nitrogen concentration $\left[N_{\mathrm{L}}\right]$ for all plant growth strategies. The fractions of sapwood carbon to woody carbon (0.05) and sapwood nitrogen to leaf nitrogen (0.10) are similarly assumed constant across all plant growth strategies and are accounted for by parameter $c_{\text {sapwood }}$. The "seed" and storage carbon pools are not subject to maintenance respiration within the model; however, they do decay at a constant rate as described in Sect. A6.

\section{A9 Scaling from plant growth strategies to community-aggregated fluxes}

JeDi-DGVM calculates community-aggregated fluxes and properties assuming the "biomass-ratio" hypothesis (Grime, 1998), i.e. as the mean over the individual plant growth strategies weighted by their mass-based relative abundances. The instantaneous relative abundance $p_{(i, j)}^{*}$ of a plant growth strategy $i$ in a grid cell $j$ is assumed to be proportional to its living biomass at that grid cell relative to the sum of the living biomass of all surviving growth strategies $S$ in that grid 
cell. The living biomass, $C_{\mathrm{tot}(i, j)}$, of a growth strategy is the sum of its leaf, fine root, woody and storage carbon pools $\left(C_{\mathrm{tot}(i, j)}=C_{\mathrm{A}(i, j)}+C_{\mathrm{L}(i, j)}+C_{\mathrm{R}(i, j)}+C_{\mathrm{WL}(i, j)}+C_{\mathrm{WR}(i, j)}\right)$.

$$
\begin{aligned}
p_{(i, j)}^{*} & =\frac{C_{\operatorname{tot}(i, j)}}{\sum_{k=1}^{S} C_{\mathrm{tot}(k, j)}} \\
\frac{\mathrm{d} p_{(i, j)}}{\mathrm{d} t} & =\frac{p_{(i, j)}^{*}-p_{(i, j)}}{\tau_{p}}
\end{aligned}
$$

The relative abundance $p_{(i, j)}$ used for the calculation of community-aggregated fluxes and properties relaxes towards the instantaneous relative abundance $p_{(i, j)}^{*}$ at timescale $\tau_{\mathrm{p}}$ (= 365 days). This relaxation mechanism was introduced to alleviate numerical issues. This mass-weighted aggregation scheme conserves water and carbon quantities at the gridcell scale. Equations A24 and A25 reconcile the fact that the prognostic variables are defined per unit area but weighted by mass. Energy is not fully conserved due to the empirical nature of the snowmelt parameterization and the lack of ground heat storage. The mass-weighted scheme itself, however, does not preclude the conservation of energy.

In the previous subsections describing the development of individual plant growth strategies, we omitted subscript notation to improve readability. Throughout the remainder of this appendix, we adopt chevron (angled bracket) notation to denote community-aggregated fluxes and properties. As an example, the community-aggregated net primary productivity $\left\langle\mathrm{NPP}_{j}\right\rangle$ for a given grid cell $j$ is equal to the sum of the NPP fluxes of all the plant growth strategies $S$ in that grid cell weighted by their respective mass-based relative abundances.

$$
\left\langle\mathrm{NPP}_{j}\right\rangle=\sum_{i=1}^{S} p_{(i, j)} \mathrm{NPP}_{(i, j)}
$$

\section{A10 Soil carbon}

The soil carbon module in JeDi-DGVM is loosely based on the soil carbon component of the JSBACH land surface model (Raddatz et al., 2007; Thum et al., 2011). The parameters and variables of the soil carbon module are summarized in Table C5. The following differential equations describe the dynamics of the three detritus carbon pools, fine litter carbon $C_{\mathrm{LIT}}$, woody litter carbon $C_{\mathrm{CWD}}$, and soil carbon $C_{\mathrm{SOIL}}$.

$$
\begin{aligned}
\frac{\mathrm{d} C_{\mathrm{LIT}}}{\mathrm{d} t} & =\left\langle\mathrm{LIT}_{\mathrm{L}}\right\rangle+\left\langle\mathrm{LIT}_{\mathrm{R}}\right\rangle+\left\langle\mathrm{LIT}_{\mathrm{A}}\right\rangle+\left\langle\mathrm{LIT}_{\mathrm{S}}\right\rangle-\mathrm{DEC}_{\mathrm{LIT}} \\
\frac{\mathrm{d} C_{\mathrm{CWD}}}{\mathrm{d} t} & =\left\langle\mathrm{LIT}_{\mathrm{WL}}\right\rangle+\left\langle\mathrm{LIT}_{\mathrm{WR}}\right\rangle-\mathrm{DEC}_{\mathrm{CWD}} \\
\frac{\mathrm{d} C_{\mathrm{SOIL}}}{\mathrm{d} t} & =\left(1-c_{\text {lit } \triangleright \mathrm{atm}}\right) \mathrm{DEC}_{\mathrm{LIT}}+\left(1-c_{\mathrm{cwd} \triangleright \mathrm{atm}}\right) \mathrm{DEC}_{\mathrm{CWD}} \\
& -\mathrm{DEC}_{\mathrm{SOIL}}
\end{aligned}
$$

The soil carbon dynamics are not computed separately for each plant growth strategy. Instead, carbon enters the two common litter pools through the community-aggregated litter fluxes $\left\langle\mathrm{LIT}_{\text {tissue }}\right\rangle$ from the turnover of the various vegetation tissue pools.

$$
\begin{aligned}
\left\langle\mathrm{LIT}_{\text {tissue }}\right\rangle & =\sum_{k=1}^{n}\left(p_{(k)} \frac{C_{\mathrm{tissue}(k)}}{\tau_{\mathrm{tissue}(k)}}\right) \\
& +\sum_{k=1}^{n}\left(C_{\mathrm{tissue}(k)} \max \left(0,-\Delta p_{(k)}\right)\right) \\
\left\langle\mathrm{LIT}_{\mathrm{S}}\right\rangle & =\sum_{k=1}^{n} \frac{C_{\mathrm{S}(k)}}{\tau_{\mathrm{A}(k)}}
\end{aligned}
$$

The second term in the calculation of $\left\langle\mathrm{LIT}_{\text {tissue }}\right\rangle$ is necessary to maintain the conservation of carbon when the relative abundance of a plant growth strategy decreases during the current time step. Likewise, the vegetation carbon pools (except the "seed" pool $C_{\mathrm{S}}$ ) are scaled down when the relative abundance of a growth strategy increases during the current time step.

$$
C_{\text {tissue }(t)}=C_{\text {tissue }(t-\Delta t)} \frac{p_{(t-\Delta t)}}{p_{(t-\Delta t)}+\max (0, \Delta p)}
$$

The decomposition fluxes $\mathrm{DEC}_{x}$ out of the detritus carbon pools are computed from the amount of carbon in that pool, a $Q_{10}$ temperature response function, and a fixed turnover time for that pool at reference temperature $20^{\circ} \mathrm{C}$. The value of 1.4 for the sensitivity of heterotrophic respiration to air temperature $Q_{10, \mathrm{~h}}$ is taken from a recent global study of FLUXNET sites (Mahecha et al., 2010). Fixed fractions of the decomposition fluxes from the litter pools enter the common soil carbon pool.

$\operatorname{DEC}_{x}=Q_{10, h}{ }^{\left(\frac{T-20}{10}\right)} \frac{C_{x}}{\tau_{x}}$

The heterotrophic respiration flux $\mathrm{RES}_{\mathrm{h}}$ to the atmosphere is estimated as the sum of the fractions of the decomposition fluxes from the litter pools not entering the soil carbon pool and the decomposition flux out of the soil carbon pool.

$$
\mathrm{RES}_{\mathrm{h}}=c_{\text {lit atm }} \mathrm{DEC}_{\mathrm{LIT}}+c_{\mathrm{cwd} \triangleright \mathrm{atm}} \mathrm{DEC}_{\mathrm{CWD}}+\mathrm{DEC}_{\text {SOIL }}
$$

Finally, the community-aggregated net ecosystem exchange NEE is calculated as the difference between the heterotrophic respiration and the community-aggregated net primary productivity fluxes.

$\mathrm{NEE}=\mathrm{RES}_{\mathrm{h}}-\langle\mathrm{NPP}\rangle$ 


\section{Appendix B}

\section{Land surface module}

The land surface hydrology module of JeDi-DGVM is largely based on the land surface component of the ECHAM4 atmospheric general circulation model (Roeckner et al., 1996) along with modifications introduced by KM2000. It consists of four budget equations for water stored in the vegetation canopy $W_{\mathrm{L}}$, in the snow cover $W_{\mathrm{S}}$, in the rooting zone $W$, and below the rooting zone $W_{\mathrm{SUB}}$.

$$
\begin{aligned}
\frac{\mathrm{d} W_{\mathrm{L}}}{\mathrm{d} t} & =P_{\text {rain }}-E_{\text {can }}-F_{\text {thfall }} \\
\frac{\mathrm{d} W_{\mathrm{S}}}{\mathrm{d} t} & =P_{\text {snow }}-F_{\text {melt }}-E_{\text {snow }} \\
\frac{\mathrm{d} W}{\mathrm{~d} t} & =F_{\text {thfall }}+F_{\text {melt }}-F_{\text {runoff }}-E_{\text {bare }}-E_{\text {trans }} \\
& -F_{\text {drain }}-F_{\Delta \mathrm{Wmax}} \\
\frac{\mathrm{d} W_{\mathrm{SUB}}}{\mathrm{d} t} & =F_{\text {drain }}-F_{\text {subdrain }}+F_{\Delta \mathrm{Wmax}}
\end{aligned}
$$

The variables and parameters of the land surface module are summarized in Tables C6 and C7. The module runs on a daily time step using forcing variables: precipitation flux $(P)$, near-surface air temperature $(T)$, and downward shortwave and longwave radiation fluxes $\left(R_{\mathrm{sw} \downarrow}\right.$ and $\left.R_{\mathrm{lw} \downarrow}\right)$. The various flux terms of the budget equations are described below. A schematic diagram of the land surface module is shown in Fig. B1.

\section{B1 Water storage and runoff generation}

The partitioning of precipitation between snow $P_{\text {snow }}$ and rain $P_{\text {rain }}$ depends on near-surface air temperature $T$ following Wigmosta et al. (1994).

$$
\begin{aligned}
P_{\text {snow }} & = \begin{cases}P & T \leq-1.1 \\
P \frac{3.3-T}{4.4} & -1.1<T<3.3 \\
0 & T \geq 3.3\end{cases} \\
P_{\text {rain }} & =P-P_{\text {snow }}
\end{aligned}
$$

Rainfall is first intercepted in the canopy reservoir $W_{\mathrm{L}}$ up to a maximum storage capacity $W_{\mathrm{Lmax}}$, which depends on LAI (see Eq. A11). If a precipitation event causes the water in the canopy reservoir to exceed its storage capacity, the excess water flows from the canopy reservoir to the rooting zone as throughfall $F_{\text {thfall }}$.

$F_{\text {thfall }}=\max \left(0, W_{\mathrm{L}}+P_{\text {rain }}-W_{\mathrm{Lmax}}\right)$

Snowmelt $F_{\text {melt }}$ is computed according to a day-degree formula using a melt rate of $3.22 \mathrm{~mm} \mathrm{~d}^{-1}{ }^{\circ} \mathrm{C}^{-1}$ (Hagemann and Dümenil, 1997).

$$
F_{\text {melt }}= \begin{cases}0 & T<0 \\ \min \left(3.22 T, P_{\text {snow }}+W_{\mathrm{S}}\right) & T \geq 0\end{cases}
$$

Surface runoff $F_{\text {runoff }}$ occurs when the throughfall or snowmelt fluxes cause the rooting zone reservoir to exceed its maximum capacity $W_{\mathrm{MAX}}$ (see Eq. A11).

$$
F_{\text {runoff }}= \begin{cases}F_{\text {thfall }} & T \leq 0 \\ \max \left(0, W+F_{\text {thfall }}+F_{\text {melt }}-W_{\max }\right) & T>0\end{cases}
$$

When the air temperature drops below $0{ }^{\circ} \mathrm{C}$, the soil is assumed to be frozen, inhibiting infiltration, and the entire throughfall flux becomes surface runoff.

Drainage from the rooting zone $F_{\text {drain }}$ supplies water to the subrooting zone and depends on the soil wetness ( $f_{\mathrm{W}}=$ $W / W_{\text {MAX }}$ ).

$F_{\text {drain }}= \begin{cases}0 & f_{\mathrm{W}} \leq 0.05 \\ d_{\min } f_{\mathrm{W}} & 0.05<f_{\mathrm{W}}<0.9 \\ d_{\min } f_{\mathrm{W}}+\left(d_{\max }-d_{\min }\right)\left(\frac{f_{\mathrm{W}}-0.9}{1-0.9}\right)^{d} & f_{\mathrm{W} \geq 0.9}\end{cases}$

When the rooting zone is between $5 \%$ and $90 \%$ of field capacity, it drains slowly $\left(d_{\min }=0.24 \mathrm{~mm} \mathrm{~d}^{-1}\right)$ with a linear dependence on soil wetness. When the rooting zone nears saturation $\left(f_{\mathrm{W}} \geq 0.9\right)$, the drainage rate quickly increases with increasing wetness towards its maximum drainage rate $\left(d_{\max }=2.40 \mathrm{~mm} \mathrm{~d}^{-1}\right)$. Drainage from the rooting zone ceases when the soil wetness falls below $5 \%$.

When the incoming drainage from the overlying rooting zone $F_{\text {drain }}$ causes the subrooting zone to exceed its maximum capacity ( $W_{\text {SUB, max }}$ ), the excess flows out as subrooting zone drainage $F_{\text {subdrain }}$ :

$F_{\text {Subdrain }}=\max \left(0, W_{\text {SUB }}+F_{\text {drain }}-\left(W_{\text {SUB, } \max }-W_{\text {max }}\right)\right)$,

where $W_{\text {SUB, } \max }$ is maximum storage capacity of the entire soil column.

The flux term $F_{\Delta W \max }$ accounts for changes in the depth of the rooting zone $W_{\mathrm{MAX}}$ (see Eq. A11) due to the balance between carbon allocation to coarse root growth and the loss of coarse root biomass via turnover.

$F_{\Delta W \max }= \begin{cases}\Delta W_{\max } \cdot \frac{W_{\text {SUB }}}{W_{\text {SUUB }}-W_{\max }} & \Delta W_{\max }<0 \\ \Delta W_{\max } \cdot \frac{W}{W_{\max }} & \Delta W_{\max }>0\end{cases}$

Coarse root growth (i.e. an increase in the depth of the rooting zone $W_{\mathrm{MAX}}$ ) leads to a virtual flow of water from the subrooting zone to the rooting zone. Likewise, a decrease in the depth of the rooting zone due to coarse root turnover leads to a virtual flow of water from the rooting zone to the subrooting zone. 


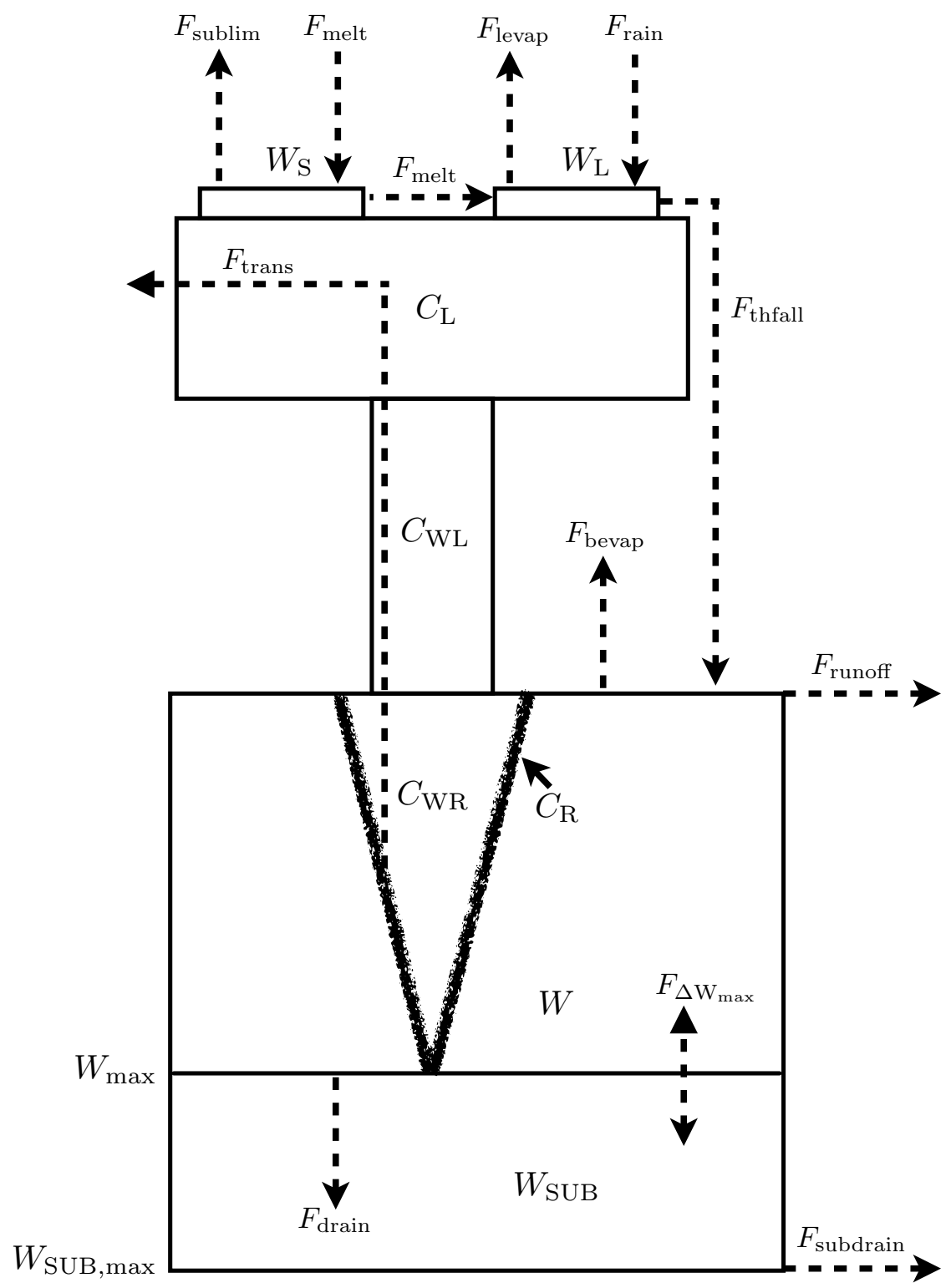

Fig. B1. Schematic diagram of the land surface module. For symbols, see Tables C4, C3, C6, and C7.

\section{B2 Potential evapotranspiration}

The fractional snow area $f_{\text {SNOw }}$ depends on the amount of water in the snow cover $W_{\mathrm{S}}$ :

$f_{\mathrm{SNOW}}=\min \left(1, \frac{W_{\mathrm{S}}}{W_{\text {Scrit }}}\right)$,

where $W_{\mathrm{S} \text {, crit }}$ is the critical snow depth (water equivalent). Following Robock (1980), the albedo of snow $a_{\mathrm{s}}$ depends on air temperature $T$ and the fractional forest cover $f_{\mathrm{FOR}}$ (see Eq. A11).

$$
\begin{aligned}
a_{\mathrm{s}, \min } & =0.3 f_{\mathrm{FOR}}+0.4\left(1-f_{\mathrm{FOR}}\right) \\
a_{\mathrm{s}, \max } & =0.4 f_{\mathrm{FOR}}+0.8\left(1-f_{\mathrm{FOR}}\right) \\
a_{\mathrm{S}} & = \begin{cases}0 & T \geq 0 \\
a_{\mathrm{S}, \max }-\left(a_{\mathrm{s}, \max }-a_{\mathrm{s}, \min }\right) \frac{T+10}{10} & -10<T<0 \\
1 & T \leq-10\end{cases}
\end{aligned}
$$

The potential evapotranspiration fluxes for the snowcovered and snow-free fractions are estimated using the Priestley-Taylor equation (Priestley and Taylor, 1972) from the net radiation fluxes described below, the slope of the sat- 
uration vapour pressure curve $\epsilon$ at air temperature $T$, the psychrometric constant $\Gamma$, the latent heat of vaporization $\lambda$, and the Priestley-Taylor coefficient $\alpha_{\mathrm{p}}$.

$$
\begin{aligned}
D_{\mathrm{s}} & =\alpha_{\mathrm{p}} \frac{\epsilon(T)}{\epsilon(T)+\Gamma} \frac{R_{\mathrm{net}, \mathrm{s}}}{\lambda} \\
D_{\mathrm{ns}} & =\alpha_{\mathrm{p}} \frac{\epsilon(T)}{\epsilon(T)+\Gamma} \frac{R_{\mathrm{net}, \mathrm{ns}}}{\lambda}
\end{aligned}
$$

The net radiative energy available for evaporative processes $R_{\text {net }}$ is calculated separately for the snow-covered and snowfree fractions from the downward shortwave, $R_{\mathrm{sw} \downarrow}$, and net longwave, $R_{\mathrm{lw}}$, radiation fluxes, day length $h$, and the albedo of the respective fraction $\left(a_{\mathrm{s}}\right.$ and $\left.a_{\mathrm{ns}}\right)$.

$$
\begin{aligned}
& R_{\mathrm{net}, \mathrm{s}}=f_{\mathrm{SNOW}} 86400\left(R_{\mathrm{Sw} \downarrow}\left(1-a_{\mathrm{s}}\right)+\frac{h}{86400} R_{\mathrm{lw}}\right) \\
& R_{\mathrm{net}, \mathrm{ns}}=\left(1-f_{\mathrm{SNOW}}\right) \\
& 86400\left(R_{\mathrm{Sw} \downarrow}\left(1-a_{\mathrm{ns}}\right)+\frac{h}{86400} R_{\mathrm{lw}}\right)
\end{aligned}
$$

Net longwave radiation $R_{\mathrm{lw}}$ is the sum of the downward longwave radiation forcing $R_{\mathrm{lw} \downarrow}$ and upward longwave radiation, $R_{\mathrm{lw} \uparrow}$, estimated from the near-surface air temperature in Kelvin $\left(T_{\mathrm{K}}=T+273.16\right)$ using the Stefan-Boltzmann equation:

$R_{\mathrm{lw} \uparrow}=\epsilon \sigma T_{\mathrm{K}}^{4}$,

where $\epsilon$ is the average emissivity of land surfaces (Brutsaert, 1982) and $\sigma$ is the Stefan-Boltzmann constant.

\section{B3 Actual evapotranspiration}

\section{B3.1 Sublimation from snow cover}

Sublimation from snow $E_{\text {snow }}$ is taken as the minimum of the potential evaporation rate for the snow-covered fraction $D_{\mathrm{s}}$ and the supply of water in the snow cover $W_{\mathrm{S}}$.

$F_{\text {sublim }}=\min \left(D_{\mathrm{s}}, W_{\mathrm{S}}\right)$

\section{B3.2 Evaporation from canopy interception reservoir}

Similarly, evaporation from the canopy reservoir $E_{\text {can }}$ is taken as the minimum of the potential evapotranspiration rate for the snow-free fraction and the supply of water in the canopy $W_{\mathrm{L}}$.

$E_{\text {can }}=\min \left(D_{\mathrm{ns}}, W_{\mathrm{L}}\right)$

\section{B3.3 Bare soil evaporation}

Bare soil evaporation $E_{\text {bare }}$ occurs in the fraction of the snowfree area not covered by vegetation $\left(1-f_{\mathrm{VEG}}\right)$ and declines linearly with decreasing soil moisture.

$E_{\mathrm{bare}}=\min \left\{\begin{array}{l}b\left(1-f_{\mathrm{VEG}}\right)\left(D_{\mathrm{ns}}-E_{\mathrm{can}}\right) \\ W\end{array}\right.$

$b= \begin{cases}0.5\left[1-\cos \left(\pi \frac{W-\left(W_{\max }-W_{\text {top }}\right)}{W_{\text {top }}}\right)\right] & W \geq W_{\max }-W_{\text {top }} \\ 0 & W<W_{\max }-W_{\text {top }}\end{cases}$

The factor $b$ limits soil evaporation to the water in the top $50 \mathrm{~mm}$ of the rooting zone ( $\left.W_{\text {top }}\right)$.

\section{B3.4 Transpiration}

Transpiration $E_{\text {trans }}$ is reduced by the factor $\alpha_{\mathrm{H}_{2} \mathrm{O}}$ from Eq. (A18), which is a saturating function of the available supply for transpiration $S$ and the atmospheric demand for transpiration $\left(D_{\mathrm{ns}}-E_{\mathrm{can}}\right)$.

$E_{\text {trans }}=\min \left\{\begin{array}{l}\alpha_{\mathrm{H}_{2} \mathrm{O}} f_{\mathrm{VEG}}\left(D_{\mathrm{ns}}-E_{\mathrm{can}}\right) \\ W-E_{\mathrm{bare}}\end{array}\right.$

\section{B4 Approximation of latent and sensible heat fluxes}

The total evapotranspiration flux ET is calculated as the sum of evaporation from the canopy reservoir and bare soil, sublimation from snow, and transpiration by the vegetation.

$$
\begin{aligned}
\mathrm{ET} & =E_{\text {can }}+E_{\text {bare }}+E_{\text {snow }}+E_{\text {trans }} \\
L & =\lambda \mathrm{ET} \\
R_{\text {net }} & =f_{\text {SNOW }} R_{\text {net, } \mathrm{s}}+\left(1-f_{\text {SNOW }}\right) R_{\text {net,ns }} \\
H & =R_{\text {net }}-L
\end{aligned}
$$

The latent heat flux $L$ is estimated by multiplying the evapotranspiration flux by the latent heat of vaporization for water $\lambda$. Total net radiation $R_{\text {net }}$ is computed as the weighted combination of the net radiation over snow-covered and snowfree areas. Sensible heat $H$ is assumed to make up the difference between the net radiation and latent heat fluxes. 


\section{Appendix C}

Model parameters and variables

Table C1. State variables and parameters of the plant growth module.

\begin{tabular}{|c|c|c|}
\hline Symbol & Description & Value/units \\
\hline \multicolumn{3}{|c|}{ Vegetation carbon pools } \\
\hline$C_{\mathrm{A}}$ & Assimilates/storage carbon pool & $\mathrm{gC} \mathrm{m}^{-2}$ \\
\hline$C_{\mathrm{L}}$ & Leaves carbon pool & $\mathrm{gC} \mathrm{m}^{-2}$ \\
\hline$C_{\mathrm{R}}$ & Fine roots carbon pool & $\mathrm{gC} \mathrm{m}^{-2}$ \\
\hline$C_{\mathrm{WL}}$ & Woody stem carbon pool & $\mathrm{gC} \mathrm{m}^{-2}$ \\
\hline$C_{\mathrm{WR}}$ & Coarse roots carbon pool & $\mathrm{gC} \mathrm{m}^{-2}$ \\
\hline$C_{\mathrm{S}}$ & Reproduction carbon pool & $\mathrm{gC} \mathrm{m}^{-2}$ \\
\hline \multicolumn{3}{|c|}{ Growing conditions } \\
\hline$f_{\mathrm{GROW}, T}$ & Time-weighted temperature conditions & ${ }^{\circ} \mathrm{C}$ \\
\hline$f_{\mathrm{GROW}, W}$ & Time-weighted soil moisture conditions & 0 to 1 \\
\hline$f_{\mathrm{GERM}, W}$ & Time-weighted soil moisture conditions for germination & 0 to 1 \\
\hline$f_{\mathrm{GERM}}$ & $0:$ no germination, 1 : germination & \\
\hline$f_{\mathrm{GROW}}$ & $0:$ no growth, $1:$ growth & \\
\hline$\tau_{\mathrm{T}}$ & Response time to temperature conditions & days \\
\hline$\tau_{\mathrm{W}}$ & Response time to moisture conditions & days \\
\hline \multicolumn{3}{|c|}{ Allocation and germination } \\
\hline$A_{\mathrm{L}}$ & Allocation from storage to leaves & 0 to 1 \\
\hline$A_{\mathrm{R}}$ & Allocation from storage to fine roots & 0 to 1 \\
\hline$A_{\mathrm{WL}}$ & Allocation from storage to stem & 0 to 1 \\
\hline$A_{\mathrm{WR}}$ & Allocation from storage to coarse roots & 0 to 1 \\
\hline$A_{\mathrm{S}}$ & Allocation from storage to reproduction & 0 to 1 \\
\hline$\gamma_{\text {GERM }}$ & Germination fraction & days $^{-1}$ \\
\hline \multicolumn{3}{|c|}{ Turnover and senescence } \\
\hline$\tau_{\text {tissue }}$ & Turnover times of vegetation carbon pools & days \\
\hline$f_{\mathrm{NPP}}$ & Time-weighted productivity conditions & $\mathrm{gC} \mathrm{m}^{-2} \mathrm{~d}^{-1}$ \\
\hline$\tau_{\mathrm{NPP}}$ & Response time to productivity conditions & days \\
\hline$f_{\text {SEN }}$ & $0:$ no senescence, $1:$ senescence & \\
\hline \multicolumn{3}{|c|}{ Carbon fluxes } \\
\hline GERM & Germination & $\mathrm{gC} \mathrm{m}^{-2} \mathrm{~d}^{-1}$ \\
\hline GPP & Gross primary productivity & $\mathrm{gC} \mathrm{m}^{-2} \mathrm{~d}^{-1}$ \\
\hline $\mathrm{RES}_{\mathrm{a}}$ & Autotrophic respiration & $\mathrm{gC} \mathrm{m}^{-2} \mathrm{~d}^{-1}$ \\
\hline NPP & Net primary productivity & $\mathrm{gC} \mathrm{m}^{-2} \mathrm{~d}^{-1}$ \\
\hline
\end{tabular}


Table C2. Summary of the functional trait parameters. This table summarizes the parameters in the model description which define a plant growth strategy. Column 2 gives a brief description of the effect of this parameter on the plant behaviour and column 3 gives the equation in which the parameter occurs. All of these parameters range between zero and one.

\begin{tabular}{lll}
\hline Parameter & Description & Equation \\
\hline$t_{1}$ & Growth response time to moisture conditions & (A2) \\
$t_{2}$ & Growth response time to temperature conditions & (A2) \\
$t_{3}$ & Critical temperature for growth & (A3) \\
$t_{4}$ & Germination fraction & (A4) \\
$t_{5}$ & Allocation to reproduction & (A5) \\
$t_{6}$ & Allocation to aboveground growth & (A5) \\
$t_{7}$ & Allocation to belowground growth & (A5) \\
$t_{8}$ & Allocation to storage & (A5) \\
$t_{9}$ & Relative allocation to aboveground structure & (A5) \\
$t_{10}$ & Relative allocation to belowground structure & (A5) \\
$t_{11}$ & Turnover time of structural pools & (A6) \\
$t_{12}$ & Turnover time of leaf and fine root pools & (A7) \\
$t_{13}$ & Senescence response time to productivity conditions & (A8) \\
$t_{14}$ & Relative senescence aboveground & (A9) \\
$t_{15}$ & Plant nitrogen status & (A17) \\
\hline
\end{tabular}

Table C3. Parameters and state variables of the interface between the land surface module and the plant growth module.

\begin{tabular}{lll}
\hline Symbol & Description & Value/units \\
\hline Land surface parameters needed by land surface module & \\
\hline LAI & Leaf area index, depends on $C_{\mathrm{L}}$ & $\mathrm{m}^{2} \mathrm{~m}^{-2}$ \\
$f_{\text {VEG }}$ & Fractional vegetation cover & 0 to 1 \\
$f_{\mathrm{FOR}}$ & Fractional forest cover & 0 to 1 \\
$a_{\mathrm{ns}}$ & Snow-free surface albedo & 0 to 1 \\
$W_{\mathrm{MAX}}$ & Maximum plant available soil water storage, depending on $C_{\mathrm{WR}}$ & $\mathrm{mm}$ \\
$S$ & Potential supply rate for transpiration, depending on $C_{\mathrm{R}}$ & $\mathrm{mm} \mathrm{d}^{-1}$ \\
\hline Conversion & parameters & \\
\hline SLA & Specific leaf area, depends on $\tau_{\mathrm{L}}$, converts $C_{\mathrm{L}}$ to LAI & $\mathrm{m}^{2} \mathrm{gC}^{-1}$ \\
$c_{\mathrm{WLMAX}}$ & Conversion factor for $C_{\mathrm{L}}$ to $W_{\mathrm{LMAX}}$ & $0.2 \mathrm{~mm} \mathrm{~m}^{-2}$ \\
$c_{\mathrm{FOR}}$ & Conversion factor for $C_{\mathrm{WL}}$ to $f_{\mathrm{FOR}}$ & $0.002 \mathrm{~m}^{2} \mathrm{gC}^{-1}$ \\
$a_{\text {VEG }}$ & Canopy albedo & 0 to 1 \\
$a_{\mathrm{SOIL}}$ & Bare soil albedo & 0.2 \\
$W_{\mathrm{MAX}, 0}$ & Minimum value of $W_{\mathrm{MAX}}$ & $50 \mathrm{~mm}$ \\
$c_{\mathrm{PAW}}$ & Unit plant available water capacity & $\mathrm{mm} \mathrm{H}_{2} \mathrm{O} \mathrm{mm}$ \\
$k$ & Light extinction coefficient & 0.5 \\
$c_{\mathrm{SRL}}$ & Specific coarse root length, relates $C_{\mathrm{R}}$ to $W_{\mathrm{MAX}}$ & $2250 \mathrm{~mm} \mathrm{gC}^{-1}$ \\
$c_{\mathrm{SRU}}$ & Specific root water uptake, relates $C_{\mathrm{R}}$ to $S$ & $0.5 \mathrm{~mm} \mathrm{gC}^{-1} \mathrm{~d}^{-1}$ \\
\hline
\end{tabular}


Table C4. Variables and parameters used in net primary productivity calculations.

\begin{tabular}{lll}
\hline Symbol & Description & Value/units \\
\hline$h$ & Day length & $\mathrm{s}$ \\
$\theta$ & Convexity of photosynthesis-radiation curve & 0.9 \\
$\phi$ & Photosynthetic quantum efficiency & $2.73 \mu \mathrm{gC} \mathrm{J}-1$ \\
$I_{\mathrm{a}}$ & Absorbed photosynthetically active radiation & $\mathrm{W} \mathrm{m}^{-2}$ \\
$P_{\mathrm{max}}$ & Light-saturated photosynthetic rate & $\mathrm{gC} \mathrm{m}^{-2} \mathrm{~s}^{-1}$ \\
{$\left[N_{\mathrm{L}}\right]$} & Canopy nitrogen concentration & $\mathrm{gN} \mathrm{gC}^{-1}$ \\
$\alpha_{\mathrm{T}}$ & Temperature limitation on productivity & 0 to 1 \\
$\alpha_{\mathrm{H}} \mathrm{O}$ & Water limitation on productivity & 0 to 1 \\
$c_{\mathrm{RES}, \text { tissue }}$ & Growth respiration coefficient & $\mathrm{gC} \mathrm{gC}^{-1}$ \\
$c_{\mathrm{RES}, \mathrm{N}}$ & Maintenance respiration coefficient & $\mathrm{gC} \mathrm{gN}^{-1}$ \\
$Q_{10, \mathrm{AR}}$ & Temperature sensitivity of autotrophic respiration & 1.6 \\
\hline
\end{tabular}

Table C5. State variables, fluxes, and parameters of the soil carbon module.

\begin{tabular}{|c|c|c|}
\hline Symbol & Description & Value/units \\
\hline \multicolumn{3}{|c|}{ Detritus carbon pools } \\
\hline$C_{\mathrm{LIT}}$ & Fine litter carbon pool & $\mathrm{gC} \mathrm{m}^{-2}$ \\
\hline$C_{\mathrm{CWD}}$ & Woody litter carbon pool & $\mathrm{gC} \mathrm{m}^{-2}$ \\
\hline$C_{\mathrm{SOIL}}$ & Soil carbon pool & $\mathrm{gC} \mathrm{m}^{-2}$ \\
\hline \multicolumn{3}{|c|}{ Carbon fluxes } \\
\hline$\left\langle\mathrm{LIT}_{\text {tissue }}\right\rangle$ & Community-aggregated litter fluxes & $\mathrm{gC} \mathrm{m}^{-2} \mathrm{~d}^{-1}$ \\
\hline $\mathrm{DEC}_{\mathrm{X}}$ & Decomposition fluxes from the detritus carbon pools & $\mathrm{gC} \mathrm{m}^{-2} \mathrm{~d}^{-1}$ \\
\hline$\langle\mathrm{GPP}\rangle$ & Community-aggregated gross primary productivity & $\mathrm{gC} \mathrm{m}^{-2} \mathrm{~d}^{-1}$ \\
\hline$\left\langle\operatorname{RES}_{a}\right\rangle$ & Community-aggregated autotrophic respiration & $\mathrm{gC} \mathrm{m}^{-2} \mathrm{~d}^{-1}$ \\
\hline $\mathrm{RES}_{\mathrm{h}}$ & Heterotrophic respiration & $\mathrm{gC} \mathrm{m}^{-2} \mathrm{~d}^{-1}$ \\
\hline NEE & Net ecosystem exchange & $\mathrm{gC} \mathrm{m}^{-2} \mathrm{~d}^{-1}$ \\
\hline \multicolumn{3}{|l|}{ Parameters } \\
\hline$c_{\text {lit } \triangleright \text { atm }}$ & Fraction of fine litter decomposition to atmosphere & 0.77 \\
\hline$c_{\mathrm{cwd} \triangleright \mathrm{atm}}$ & Fraction of woody litter decomposition to atmosphere & 0.2 \\
\hline$\tau_{\text {LIT }}$ & Turnover time of fine litter at $20^{\circ} \mathrm{C}$ & $2.05 \mathrm{yr}$ \\
\hline$\tau_{\mathrm{CWD}}$ & Turnover time of woody litter at $20^{\circ} \mathrm{C}$ & $60 \mathrm{yr}$ \\
\hline$\tau_{\mathrm{SOIL}}$ & Turnover time of soil carbon at $20^{\circ} \mathrm{C}$ & $100 \mathrm{yr}$ \\
\hline$Q_{10, \mathrm{HR}}$ & Heterotrophic respiration coefficient & 1.4 \\
\hline
\end{tabular}


Table C6. Forcing, state, and flux variables of the land surface module.

\begin{tabular}{lll}
\hline Symbol & Description & Value/units \\
\hline Forcing variables & \\
\hline$P$ & Precipitation & $\mathrm{mm} \mathrm{d}^{-1}$ \\
$R_{\text {Sw } \downarrow}$ & Downwelling shortwave radiation & $\mathrm{W} \mathrm{m}^{-2}$ \\
$R_{\mathrm{lW} \downarrow}$ & Downward longwave radiation & $\mathrm{W} \mathrm{m}^{-2}$ \\
$T$ & 2 m air temperature & ${ }^{\circ} \mathrm{C}$ \\
\hline Water pools & \\
\hline$W_{\mathrm{S}}$ & Water stored in snow cover & \\
$W_{\mathrm{L}}$ & Water intercepted in canopy & $\mathrm{mm}$ \\
$W$ & Water stored in rooting zone & $\mathrm{mm}$ \\
$W_{\text {SUB }}$ & Water stored below rooting zone & $\mathrm{mm}$ \\
\hline Water fluxes & $\mathrm{mm}$ \\
\hline$P_{\text {snow }}$ & Snowfall & \\
$P_{\text {rain }}$ & Rainfall & $\mathrm{mm} \mathrm{d}^{-1}$ \\
$F_{\text {melt }}$ & Snowmelt & $\mathrm{mm} \mathrm{d}^{-1}$ \\
$F_{\text {thfall }}$ & Throughfall & $\mathrm{mm} \mathrm{d}^{-1}$ \\
$F_{\text {runoff }}$ & Runoff & $\mathrm{mm} \mathrm{d}^{-1}$ \\
$F_{\text {drain }}$ & Drainage from rooting zone & $\mathrm{mm} \mathrm{d}^{-1}$ \\
$F_{\Delta \text { Wmax }}$ & Flux due to change in rooting zone depth & $\mathrm{mm} \mathrm{d}^{-1}$ \\
$F_{\text {subdrain }}$ & Drainage from subrooting zone & $\mathrm{mm} \mathrm{d}^{-1}$ \\
$E_{\text {bare }}$ & Bare soil evaporation & $\mathrm{mm} \mathrm{d}^{-1}$ \\
$E_{\text {can }}$ & Evaporation from the canopy reservoir & $\mathrm{mm} \mathrm{d}^{-1}$ \\
$E_{\text {snow }}$ & Sublimation from snow cover & $\mathrm{mm} \mathrm{d}^{-1}$ \\
$E_{\text {trans }}$ & Transpiration & $\mathrm{mm} \mathrm{d}^{-1}$ \\
\hline & &
\end{tabular}

Table C7. Other parameters and variables of the land surface module.

\begin{tabular}{|c|c|c|}
\hline Symbol & Description & Value/units \\
\hline \multicolumn{3}{|c|}{ Drainage parameters } \\
\hline$d_{\min }$ & Slow drainage rate & $0.24 \mathrm{~mm} \mathrm{~d}^{-1}$ \\
\hline$d_{\max }$ & Fast drainage rate & $2.4 \mathrm{~mm} \mathrm{~d}^{-1}$ \\
\hline$d$ & Drainage exponent & 1.5 \\
\hline$W_{\text {SUBmax }}$ & Maximum storage capacity of the entire soil column & $1500 \mathrm{~mm}$ \\
\hline \multicolumn{3}{|c|}{ Snow cover parameters } \\
\hline$a_{\mathrm{s}, \min }$ & Minimum snow albedo & 0.4 to 0.8 \\
\hline$a_{\mathrm{s}, \max }$ & Maximum snow albedo & 0.3 to 0.4 \\
\hline$a_{\mathrm{S}}$ & Snow albedo & 0.3 to 0.8 \\
\hline$W_{\mathrm{S}, \text { crit }}$ & Critical snow depth & $10 \mathrm{~mm}$ \\
\hline$f_{\mathrm{SNOW}}$ & Fractional snow area & 0 to 1 \\
\hline \multicolumn{3}{|c|}{ Evapotranspiration parameters and variables } \\
\hline$\epsilon$ & Average emissivity of land surfaces & 0.97 \\
\hline$\sigma$ & Stefan-Boltzmann constant & $5.6703 \times 10^{-8} \mathrm{~W} \mathrm{~m}^{-2} \mathrm{~K}^{-4}$ \\
\hline$\alpha_{\mathrm{p}}$ & Priestley-Taylor coefficient & 1.26 \\
\hline$\epsilon(T)$ & Slope of the saturation vapour pressure curve & $\mathrm{Pa} \mathrm{K}^{-1}$ \\
\hline$\Gamma$ & Psychrometric constant & $65 \mathrm{~Pa} \mathrm{~K}^{-1}$ \\
\hline$\lambda$ & Latent heat of vaporization for water & $2500 \mathrm{~J} \mathrm{~kg}^{-1}$ \\
\hline$R_{\text {net, } \mathrm{s}}$ & Net radiation on snow-covered areas & $\mathrm{Jd}^{-2}$ \\
\hline$R_{\text {net, ns }}$ & Net radiation on snow-free areas & $\mathrm{J} \mathrm{d}^{-2}$ \\
\hline$D_{\mathrm{S}}$ & Potential evapotranspiration from snow-covered areas & $\mathrm{mm} \mathrm{d}^{-1}$ \\
\hline$D_{\mathrm{ns}}$ & Potential evapotranspiration from snow-free areas & $\mathrm{mm} \mathrm{d}^{-1}$ \\
\hline$W_{\text {top }}$ & Bare soil evaporation depth & $50 \mathrm{~mm}$ \\
\hline
\end{tabular}




\section{Appendix D}

\section{C-LAMP evaluation protocol}

\section{D1 Phenology}

Simulated leaf area index (LAI) values were evaluated against remote sensing observations from the MODerate resolution Imaging Spectroradiometer (MODIS) (Myneni et al., 2002; Zhao et al., 2005; MOD15A2 Collection 4). Specifically, three phenology metrics were considered; the timing of maximum LAI, the maximum monthly LAI, and the annual mean LAI. All three metrics used monthly mean LAI observations and modelled estimates from years 2000 to 2004. The LAI phase metric was computed at each grid cell as the offset in months between the observed and simulated maximum LAI values, normalized by the maximum possible offset $(6$ months), and finally, averaged across biomes. The maximum and annual mean LAI metrics $M$ were computed using the equation

$M=1-\frac{\sum_{i=1}^{n} \frac{\left|m_{i}-o_{i}\right|}{m_{i}+o_{i}}}{n}$,

where $m_{i}$ is the simulated LAI at the grid cell corresponding to the satellite observation $\left(o_{i}\right)$ and $n$ is the number of model grid cells in each biome. Global means for these metrics were computed by averaging $M$ across different biome types.

\section{D2 Global patterns of productivity and evapotranspiration}

Modelled estimates of net primary productivity (NPP) were compared with a compilation of field-based observations from the Ecosystem Model-Data Intercomparison (EMDI) (Olson et al., 2001) and remote sensing estimates extracted from the MODIS MOD17A3 Collection 4.5 product (Heinsch et al., 2006; Zhao et al., 2005, 2006). We compared the mean annual NPP as simulated by JeDi-DGVM for years 1975-2000 with the EMDI observations on a point-by-point basis for each observation site to the corresponding model grid cell using Eq. (D1) described above. As a second NPP metric, we used Eq. (D1) again with the modelled and observed values averaged into discrete precipitation bins of $400 \mathrm{~mm} \mathrm{yr}^{-1}$. For the third and fourth NPP metrics, we computed the coefficient of determination $\left(r^{2}\right)$ between the mean annual MODIS and modelled NPP (for years 2000-2004) for all non-glaciated land grid cells and for the zonal means.

In addition to the NPP metrics from the C-LAMP protocol, we also evaluated JeDi-DGVM against spatially explicit, data-driven model estimates of evapotranspiration (ET; Jung et al., 2010) and gross primary productivity (GPP; Beer et al., 2010). The estimate of ET (Jung et al., 2010) was compiled by upscaling FLUXNET site measurements with geospatial information from remote sensing and surface meteorological data using a model tree ensemble algorithm (Jung et al., 2009). It covers years 1982-2008, although here we only used model years 1982-2004 for the comparison due to the limitation of the meteorological forcing dataset. The estimate of GPP (Beer et al., 2010) was derived from five empirical models calibrated against FLUXNET observations. It covers years 1998-2005, although here we only used model years 1998-2004 for the comparison.

\section{D3 Seasonal cycle of atmospheric $\mathrm{CO}_{2}$}

The annual cycle of atmospheric $\mathrm{CO}_{2}$ was simulated by applying atmospheric impulse response functions from the Atmospheric Tracer Transport Model Intercomparison Project (TRANSCOM) Phase 3 Level 2 experiments (Gurney et al., 2004) to the JeDi-DGVM net ecosystem exchange (NEE) fluxes. The monthly JeDi-DGVM NEE fluxes for years 1991-2000 were aggregated into 11 TRANSCOM land basis regions. These aggregated NEE fluxes were then multiplied by monthly response functions from Baker et al. (2006), yielding simulated atmospheric $\mathrm{CO}_{2}$ time series for 57 observation stations around the globe. This process was repeated for all 13 TRANSCOM atmospheric transport models and the multimodel mean annual cycle was compared with observations from the GLOBALVIEW dataset (Masarie and Tans, 1995). We computed the coefficient of determination $\left(r^{2}\right)$ as a measure of phase and the ratio of modelled annual amplitude $A_{\mathrm{M}}$ to observed amplitude $A_{\mathrm{O}}$ as a measure of magnitude (see Eq. D2).

$M=1-\left|\frac{A_{\mathrm{M}}}{A_{\mathrm{O}}}-1\right|$

These two metrics were computed for three latitude bands in the Northern Hemisphere $\left(0-30^{\circ} \mathrm{N}, 30-60^{\circ} \mathrm{N}, 60-90^{\circ} \mathrm{N}\right)$. All stations within each band were weighted equally. The scores from the mid and high latitude bands were given more weight due to their stronger annual signal and the relatively smaller contributions of oceanic and anthropogenic fluxes in those regions.

\section{D4 Interannual variability in $\mathrm{CO}_{2}$ fluxes}

The same TRANSCOM response functions (Baker et al., 2006) and the GLOBALVIEW $\mathrm{CO}_{2}$ measurements (Masarie and Tans, 1995) described above were combined to obtain estimates of the interannual variability in global terrestrial NEE fluxes for years 1988-2004. We compared these inversion estimates with JeDi-DGVM, again incorporating information about the phase and magnitude. The phase agreement was evaluated by the coefficient of determination $\left(r^{2}\right)$ between the simulated global annual mean NEE fluxes and the TRANSCOM-based estimates. The magnitude of interannual variability was calculated using the standard deviation of the simulated and observed values as $A_{\mathrm{M}}$ and $A_{\mathrm{O}}$ in Eq. (D2). The phase and magnitude metrics were then averaged together with equal weighting. 
In their C-LAMP evaluation, Randerson et al. (2009) evaluated the magnitude and pattern of simulated fire emissions against observations in the Global Fire Emissions Database version 2 (GFEDv2; van der Werf et al., 2006). Here, we set the score for this metric to zero because JeDi-DGVM does not simulate fire emissions.

\section{D5 Eddy covariance measurements of energy and carbon}

Simulated monthly mean surface energy and carbon fluxes were evaluated against gap-filled L4 Ameriflux data (Falge et al., 2002; Heinsch et al., 2006; Stoeckli et al., 2008). For each Ameriflux data month, we sampled the corresponding model grid output. Then, we constructed an annual cycle of monthly means, and using Eq. (D1) computed metrics for NEE, GPP, and the fluxes of sensible and latent heat. All 74 tower sites were weighted equally.

\section{D6 Carbon stocks and flows in Amazonia}

Simulated aboveground living biomass in Amazonia was evaluated against the LBA-ECO LC-15 Amazon Basin Aboveground Live Biomass Distribution Map compiled by Saatchi et al. (2007). We used Eq. (D1) to calculate the model-data agreement between the simulated aboveground live biomass and the observed biomass values at each grid cell within the Amazon Basin. The model output used for comparison was the sum of the simulated aboveground wood and leaf carbon pools for the year 2000. Although, not part of the metric calculation, we also compared the JeDi-DGVM results with carbon budget observations from three mature forest ecosystems in Amazonia (Malhi et al., 2009).

\section{D7 Sensitivity of NPP to elevated $\mathrm{CO}_{2}$ concentrations}

To evaluate the sensitivity of simulated NPP to elevated $\mathrm{CO}_{2}$ concentrations, we performed a model experiment (described in Sect. 3.1) to mimic the treatment plots in FACE experiments. We calculated the mean percentage increase in NPP between the control and elevated $\mathrm{CO}_{2}$ simulations for years 1997-2001. Using Eq. (D1), we compared the simulated increases at four temperate forest grid cells with corresponding site-level average increases reported by Norby et al. (2005). We also report a global map of the simulated NPP response to a step change in $\mathrm{CO}_{2}$ concentrations from ambient to $550 \mathrm{ppm}$.

\section{Supplementary material related to this article is available online at: http://www.biogeosciences.net/10/ 4137/2013/bg-10-4137-2013-supplement.pdf.}

Acknowledgements. This research was sponsored by the Max Planck Society through their support of the Max Planck Research Group for Biospheric Theory and Modelling. D. T. Drewry was supported by the National Science Foundation International Research Fellowship Program (IRFP), award OISE-0900556. D. T. Drewry acknowledges support of the Jet Propulsion Laboratory, California Institute of Technology, under a contract with the National Aeronautics and Space Administration. We gratefully acknowledge Kerstin Sickel and Steffen Richter for their technical support with the JeDi-DGVM model code. We thank James T. Randerson, Forrest M. Hoffmann, and Cynthia D. Nevison for sharing the scripts and data for calculating and plotting the C-LAMP metrics.

The service charges for this open access publication have been covered by the Max Planck Society.

Edited by: P. Stoy

\section{References}

Ackerly, D. and Cornwell, W. K.: A trait-based approach to community assembly: partitioning of species trait values into within- and among-community components, Ecol. Lett., 10, 135-145, 2007.

Ainsworth, E. A. and Long, S. P.: What have we learned from 15 years of free-air $\mathrm{CO}_{2}$ enrichment (FACE)? A meta-analytic review of the responses of photosynthesis, canopy properties and plant production to rising $\mathrm{CO}_{2}$, New Phytol., 165, 351-372, 2004.

Alton, P. B.: How useful are plant functional types in global simulations of the carbon, water, and energy cycles?, J. Geophys. Res., 116, 1-13, 2011.

Alvarado, V. and Bradford, K.: A hydrothermal time model explains the cardinal temperatures for seed germination, Plant Cell Environ., 25, 1061-1069, 2002.

Angert, A., Biraud, S., Bonfils, C., Buermann, W. and Fung, I.: $\mathrm{CO} 2$ seasonality indicates origins of post-Pinatubo sink, Geophys. Res. Lett., 31, L11103, doi:10.1029/2004GL019760, 2004.

Arora, V. and Boer, G.: Simulating competition and coexistence between plant functional types in a dynamic vegetation model, Earth Interact., 10, 1-30, 2006.

Asner, G. P. and Alencar, A.: Drought impacts on the Amazon forest: the remote sensing perspective, New Phytol., 187, 569-578, 2010.

Axelsson, E. and Axelsson, B.: Changes in carbon allocation patterns in spruce and pine trees following irrigation and fertilization, Tree Physiol., 2, 189-204, 1986.

Baas-Becking, L.: Geobiologie of Inleiding tot de Milieukunde, van Stockum and Zoon, The Hague, the Netherlands, 1934.

Baker, D., Law, R., Gurney, K., Rayner, P., Peylin, P., Denning, A., Bousquet, P., Bruhwiler, L., Chen, Y., Ciais, P., Fung, I., Heimann, M., John, J., Maki, T., Maksyutov, S., Masarie, K., Prather, M., Pak, B., Taguchi, S., and Zhu, Z.: TransCom 3 inversion intercomparison: impact of transport model errors on the interannual variability of regional $\mathrm{CO}_{2}$ fluxes, 1988-2003, Global Biogeochem. Cy., 20, GB1002, doi:10.1029/2004GB002439, 2006.

Beer, C., Reichstein, M., Tomelleri, E., Ciais, P., Jung, M., Carvalhais, N., Rodenbeck, C., Arain, M. A., Baldocchi, D. D., Bo- 
nan, G., Bondeau, A., Cescatti, A., Lasslop, G., Lindroth, A., Lomas, M., Luyssaert, S., Margolis, H., Oleson, K. W., Roupsard, O., Veenendaal, E., Viovy, N., Williams, C., Woodward, F. I., and Papale, D.: Terrestrial gross carbon dioxide uptake: global distribution and covariation with climate, Science, 329, 834-838, 2010.

Bloom, A. J., Chapin, F. S. I., and Mooney, H.: Resource limitation in plants - an economic analogy, Annu. Rev. Ecol. Syst., 16, 363392, 1985.

Bohn, K., Dyke, J. G., Pavlick, R., Reineking, B., Reu, B., and Kleidon, A.: The relative importance of seed competition, resource competition and perturbations on community structure, Biogeosciences, 8, 1107-1120, doi:10.5194/bg-8-1107-2011, 2011.

Bonan, G. and Levis, S.: Evaluating aspects of the community land and atmosphere models (CLM3 and CAM3) using a dynamic global vegetation model, J. Climate, 19, 2290-2301, 2006.

Bonan, G., Levis, S., Kergoat, L., and Oleson, K. W.: Landscapes as patches of plant functional types: an integrating concept for climate and ecosystem models, Global Biogeochem. Cy., 16, 118, 2002.

Box, E.: Plant functional types and climate at the global scale, J. Veg. Sci., 7, 309-320, 1996.

Braakhekke, M. C., Beer, C., Hoosbeek, M. R., Reichstein, M., Kruijt, B., Schrumpf, M., and Kabat, P.: SOMPROF: A vertically explicit soil organic matter model, Ecol. Model., 222, 17121730, 2011.

Bruggeman, J. and Kooijman, S.: A biodiversity-inspired approach to aquatic ecosystem modeling, Limnol. Oceanogr., 52, 15331544, 2007.

Brutsaert, W.: Evaporation into the Atmosphere, Theory, History, and Applications, Kluwer Academic Publishers, Dordrecht, The Netherlands, 1982.

Cannell, M. G. R.: World Forest Biomass and Primary Production Data, Academic Press, London, UK, 1982.

Cannell, M. G. R. and Thornley, J.: Temperature and $\mathrm{CO}_{2}$ responses of leaf and canopy photosynthesis: a clarification using the non-rectangular hyperbola model of photosynthesis, Ann. Bot.-London, 82, 883-892, 1998.

Cardinale, B. J., Duffy, J. E., Gonzalez, A., Hooper, D. U., Perrings, C., Venail, P., Narwani, A., Mace, G. M., Tilman, D., Wardle, D. A., Kinzig, A. P., Daily, G. C., Loreau, M., Grace, J. B., Larigauderie, A., Srivastava, D. S., and Naeem, S.: Biodiversity loss and its impact on humanity, Nature, 486, 59-67, 2012.

Cavender-Bares, J., Kozak, K. H., Fine, P. V. A., and Kembel, S. W.: The merging of community ecology and phylogenetic biology, Ecol. Lett., 12, 693-715, 2009.

Chapin, F. S. I., BretHarte, M., Hobbie, S., and Zhong, H.: Plant functional types as predictors of transient responses of arctic vegetation to global change, J. Veg. Sci., 7, 347-358, 1996.

Chave, J., Coomes, D., Jansen, S., Lewis, S. L., Swenson, N. G., and Zanne, A. E.: Towards a worldwide wood economics spectrum, Ecol. Lett., 12, 351-366, 2009.

Cohen, D.: A general model of optimal reproduction in a randomly varying environment, J. Ecol., 56, 219-228, 1968.

Cornwell, W. K. and Ackerly, D.: Community assembly and shifts in plant trait distributions across an environmental gradient in coastal California, Ecol. Monogr., 79, 109-126, 2009.

Cox, P.: Description of the TRIFFID Dynamic Global Vegetation Model, Hadley Centre, Bracknell, UK, 2001.
Cox, P., Betts, R. A., Jones, C. D., Spall, S. A., and Totterdell, I. J.: Acceleration of global warming due to carbon-cycle feedbacks in a coupled climate model, Nature, 408, 184-187, 2000.

Cramer, W., Bondeau, A., Woodward, F. I., Prentice, I. C., Betts, R. A., Brovkin, V., Cox, P., Fisher, V., Foley, J. A., Friend, A. D., Kucharik, C., Lomas, M. R., Ramankutty, N., Sitch, S., Smith, B., White, A., and Young-Molling, C.: Global response of terrestrial ecosystem structure and function to $\mathrm{CO}_{2}$ and climate change: results from six dynamic global vegetation models, Glob. Change Biol., 7, 357-373, 2001.

Denman, K., Brasseur, G., Chidthaisong, A., Ciais, P., Cox, P., Dickinson, R., Hauglustaine, D., Heinze, C., Holland, E., Jacob, D., Lohnmann, U., Ramachandran, S., da Silva Dias, P., Wofsy, S. C., and Zhang, X.: Couplings between changes in the climate system and biogeochemistry, Climate Change 2007: The Physical Science Basis, Contribution of Working Group I to the Fourth Assessment Report of the Intergovernmental Panel on Climate Change, Cambridge, United Kingdom, 2007.

Díaz, S. and Cabido, M.: Vive la différence: plant functional diversity matters to ecosystem processes, Trends Ecol. Evol., 16, 646-655, 2001.

Díaz, S., Fargione, J., Chapin, F. S., and Tilman, D.: Biodiversity loss threatens human well-being, PLoS Biol., 4, 1300-1305, 2006.

Díaz, S., Lavorel, S., de Bello, F., Quetier, F., Grigulis, K., and Robson, T. M.: Incorporating plant functional diversity effects in ecosystem service assessments, P. Natl. Acad. Sci., 104, 2068420689, 2007.

Doney, S., Lindsay, K., Fung, I., and John, J.: Natural variability in a stable, 1000-yr global coupled climate-carbon cycle simulation, J. Climate, 19, 3033-3054, 2006.

Drewry, D., Kumar, P., Long, S., Bernacchi, C., Liang, X., and Sivapalan, M.: Ecohydrological responses of dense canopies to environmental variability: 1 . interplay between vertical structure and photosynthetic pathway, J. Geophys. Res., 115, G04022, doi:10.1029/2010JG001340, 2010.

Dunne, K. and Willmott, C.: Global distribution of plant extractable water capacity of soil, Int. J. Climatol., 16, 841-859, 1996.

Dutkiewicz, S., Follows, M. J., and Bragg, J. G.: Modeling the coupling of ocean ecology and biogeochemistry, Global Biogeochem. Cy., 23, GB4017, doi:10.1029/2008GB003405, 2009.

Elser, J. J., Bracken, M. E. S., Cleland, E. E., Gruner, D. S., Harpole, W. S., Hillebrand, H., Ngai, J. T., Seabloom, E. W., Shurin, J. B., and Smith, J. E.: Global analysis of nitrogen and phosphorus limitation of primary producers in freshwater, marine and terrestrial ecosystems, Ecol. Lett., 10, 1135-1142, 2007.

Ezoe, H.: Optimal dispersal range and seed size in a stable environment, J. Theor. Biol., 190, 287-293, 1998.

Falge, E., Baldocchi, D. D., Tenhunen, J., Aubinet, M., Bakwin, P., Berbigier, P., Bernhofer, C., Burba, G., Clement, R., Davis, K. J., Elbers, J. A., Goldstein, A. H., Grelle, A., Granier, A., Guomundsson, J., Hollinger, D., Kowalski, A. S., Katul, G., Law, B. E., Malhi, Y., Meyers, T., Monson, R. K., Munger, J. W., Oechel, W., Paw U, K. T., Pilegaard, K., Rannik, Ü., Rebmann, C., Suyker, A., Valentini, R., Wilson, K., and Wofsy, S.: Seasonality of ecosystem respiration and gross primary production as derived from FLUXNET measurements, Agr. Forest Meteorol., 113, 53-74, 2002. 
Falster, D. S., Brännström, Å., Dieckmann, U., and Westoby, M.: Influence of four major plant traits on average height, leaf-area cover, net primary productivity, and biomass density in singlespecies forests: a theoretical investigation, J. Ecol., 99, 148-164, 2010.

Figueira, A. M. E. S., Miller, S. D., de Sousa, C. A. D., Menton, M. C., Maia, A. R., da Rocha, H. R., and Goulden, M. L.: Effects of selective logging on tropical forest tree growth, J. Geophys. Res.-Biogeo., 113, G00B05, doi:10.1029/2007JG000577, 2008.

Fisher, J., Sitch, S., Malhi, Y., and Fisher, R.: Carbon cost of plant nitrogen acquisition: a mechanistic, globally applicable model of plant nitrogen uptake, retranslocation, and fixation, Global Biogeochem. Cy., 187, 666-681, 2010.

Fisher, R., Williams, M., Lola da Costa, A., Malhi, Y., Lola da Costa, R. F., Almeida, S., and Meir, P.: The response of an Eastern Amazonian rain forest to drought stress: results and modelling analyses from a throughfall exclusion experiment, Glob. Change Biol., 13, 2361-2378, 2007.

Fisher, R., McDowell, N., Purves, D., Moorcroft, P., Sitch, S., Cox, P., Huntingford, C., Meir, P., and Woodward, F. I.: Assessing uncertainties in a second-generation dynamic vegetation model caused by ecological scale limitations, New Phytol., 187, 666-681, 2010.

Foley, J. A., Prentice, I. C., Ramankutty, N., Levis, S., Pollard, D., Sitch, S., and Haxeltine, A.: An integrated biosphere model of land surface processes, terrestrial carbon balance, and vegetation dynamics, Global Biogeochem. Cy., 10, 603-628, 1996.

Foley, J. A., Levis, S., Costa, M., Cramer, W., and Pollard, D.: Incorporating dynamic vegetation cover within global climate models, Ecol. Appl., 10, 1620-1632, 2000.

Foley, J. A., Defries, R., Asner, G. P., Barford, C., Bonan, G., Carpenter, S. R., Chapin, F. S., Coe, M. T., Daily, G. C., Gibbs, H. K., Helkowski, J. H., Holloway, T., Howard, E. A., Kucharik, C. J., Monfreda, C., Patz, J. A., Prentice, I. C., Ramankutty, N., and Snyder, P. K.: Global consequences of land use, Science, 309, 570-574, 2005.

Follows, M. J. and Dutkiewicz, S.: Modeling diverse communities of marine microbes, Ann. Rev. Mar. Sci., 3, 427-451, 2011.

Follows, M. J., Dutkiewicz, S., Grant, S., and Chisholm, S. W.: Emergent biogeography of microbial communities in a model ocean, Science, 315, 1843-1846, 2007.

France, K. E. and Duffy, J. E.: Diversity and dispersal interactively affect predictability of ecosystem function, Nature, 441, 11391143, 2006.

Franklin, O.: Optimal nitrogen allocation controls tree responses to elevated $\mathrm{CO}_{2}$, New Phytol., 174, 811-822, 2007.

Franklin, O., Johansson, J., Dewar, R. C., Dieckmann, U., McMurtrie, R. E., Brännström, A., and Dybzinski, R.: Modeling carbon allocation in trees: a search for principles, Tree Physiol., 32, 648666, 2012.

Freschet, G. T., Dias, A. T. C., Ackerly, D., Aerts, R., Van Bodegom, P. M., Cornwell, W. K., Dong, M., Kurokawa, H., Liu, G., Onipchenko, V. G., Ordoñez, J. C., Peltzer, D. A., Richardson, S. J., Shidakov, I. I., Soudzilovskaia, N. A., Tao, J., and Cornelissen, J. H. C.: Global to community scale differences in the prevalence of convergent over divergent leaf trait distributions in plant assemblages, Global Ecol. Biogeogr., 20, 755-765, 2011.
Friedlingstein, P., Joel, G., Field, C. B., and Fung, I. Y.: Toward an allocation scheme for global terrestrial carbon models, Glob. Change Biol., 5, 755-770, 1999.

Friedlingstein, P., Cox, P., Betts, R. A., Bopp, L., von Bloh, W., Brovkin, V., Cadule, P., Doney, S., Eby, M., Fung, I., Bala, G., John, J., Jones, C., Joos, F., Kato, T., Kawamiya, M., Knorr, W., Lindsay, K., Matthews, H. D., Raddatz, T., Rayner, P., Reick, C., Roeckner, E., Schnitzler, K. G., Schnur, R., Strassmann, K., Weaver, A. J., Yoshikawa, C., and Zeng, N.: Climate-carbon cycle feedback analysis: results from the C 4MIP model intercomparison, J. Climate, 19, 3337-3353, 2006.

Friend, A., Stevens, A., Knox, R., and Cannell, M.: A processbased, terrestrial biosphere model of ecosystem dynamics (Hybrid v3.0), Ecol. Model., 95, 249-287, 1997.

Fung, I. Y., Doney, S., Lindsay, K., and John, J.: Evolution of carbon sinks in a changing climate, P. Natl. Acad. Sci. USA, 102, 11201-11206, 2005.

Garnier, E., Cortez, J., Billes, G., Navas, M., Roumet, C., Debussche, M., Laurent, G., Blanchard, A., Aubry, D., Bellmann, A., Neill, C., and Toussaint, J.: Plant functional markers capture ecosystem properties during secondary succession, Ecology, 85, 2630-2637, 2004.

Grime, J. P.: Benefits of plant diversity to ecosystems: immediate, filter and founder effects, J. Ecol., 86, 902-910, 1998.

Groenendijk, M., Dolman, A. J., van der Molen, M. K., Leuning, R., Arneth, A., Delpierre, N., Gash, J. H. C., Lindroth, A., Richardson, A. D., and Verbeeck, H.: Assessing parameter variability in a photosynthesis model within and between plant functional types using global fluxnet eddy covariance data, Agr. Forest Meteorol., 151, 22-38, 2011.

Gu, L., Baldocchi, D. D., Wofsy, S. C., Munger, J. W., Michalsky, J., Urbanski, S., and Boden, T.: Response of a deciduous forest to the Mount Pinatubo eruption: enhanced photosynthesis, Science, 299, 2035-2038, 2003.

Gurney, K., Law, R., Denning, A., Rayner, P., Pak, B., Baker, D., Bousquet, P., Bruhwiler, L., Chen, Y., Ciais, P., Fung, I., Heimann, M., John, J., Maki, T., Maksyutov, S., Peylin, P., Prather, M., and Taguchi, S.: Transcom 3 inversion intercomparison: model mean results for the estimation of seasonal carbon sources and sinks, Global Biogeochem. Cy., 18, GB1010, doi:10.1029/2003GB002111, 2004.

Haddeland, I., Clark, D. B., Franssen, W., Ludwig, F., Voß, F., Arnell, N. W., Bertrand, N., Best, M., Folwell, S., Gerten, D., Gomes, S., Gosling, S. N., Hagemann, S., Hanasaki, N., Harding, R., Heinke, J., Kabat, P., Koirala, S., Oki, T., Polcher, J., Stacke, T., Viterbo, P., Weedon, G. P., and Yeh, P.: Multimodel estimate of the global terrestrial water balance: setup and first results, J. Hydrometeorol., 12, 869-884, 2011.

Hagemann, S. and Dümenil, L.: A parametrization of the lateral waterflow for the global scale, Clim. Dynam., 14, 17-31, 1997.

Hall, C., Stanford, J., and Hauer, F.: The distribution and abundance of organisms as a consequence of energy balances along multiple environmental gradients, Oikos, 65, 377-390, 1992.

Harrison, S. P., Prentice, I. C., Barboni, D., Kohfeld, K. E., Ni, J., and Sutra, J.-P.: Ecophysiological and bioclimatic foundations for a global plant functional classification, J. Veg. Sci., 21, 300317, 2010.

Hartmann, D. L.: Global Physical Climatology, International Geophysics Series, 1st edn., Academic Press, San Francisco, 1994. 
Heinsch, F., Zhao, M., Running, S. W., Kimball, J. S., Nemani, R. R., Davis, K. J., Bolstad, P. V., Cook, B. D., Desai, A. R., Ricciuto, D. M., Law, B. E., Oechel, W. C., Kwon, H., Luo, H., Wofsy, S. C., Dunn, A. L., Munger, J. W., Baldocchi, D. D., Xu, L., Hollinger, D. Y., Richardson, A. D., Stoy, P. C., Siqueira, M. B. S., Monson, R. K., Burns, S. P., and Flanagan, L. B.: Evaluation of remote sensing based terrestrial productivity from MODIS using regional tower eddy flux network observations, IEEE T. Geosci. Remote, 44, 1908-1925, 2006.

Hickler, T., Prentice, I. C., Smith, B., Sykes, M. T., and Zaehle, S.: Implementing plant hydraulic architecture within the LPJ dynamic global vegetation model, Global Ecol. Biogeogr., 15, 567$577,2006$.

Hickler, T., Smith, B., Prentice, I. C., Mjöfors, K., Miller, P., Arneth, A., and Sykes, M. T.: $\mathrm{CO}_{2}$ fertilization in temperate FACE experiments not representative of boreal and tropical forests, Glob. Change Biol., 14, 1531-1542, 2008.

Hollinger, D. Y., Ollinger, S. V., Richardson, A. D., Meyers, T. P., Dail, D. B., Martin, M. E., Scott, N. A., Arkebauer, T. J., Baldocchi, D. D., Clark, K. L., Curtis, P. S., Davis, K. J., Desai, A. R., Dragoni, D., Goulden, M. L., Gu, L., Katul, G. G., Pallardy, S. G., Paw U, K. T., Schmid, H. P., Stoy, P. C., Sukyer, A. E., and Verma, S. B.: Albedo estimates for land surface models and support for a new paradigm based on foliage nitrogen concentration, Glob. Change Biol., 16, 696-710, 2010.

Houghton, R. A., Hall, F., and Goetz, S. J.: Importance of biomass in the global carbon cycle, J. Geophys. Res., 114, G00E03, doi:10.1029/2009JG000935, 2009.

Hubbell, S. P.: Tree dispersion, abundance, and diversity in a tropical dry forest, Science, 203, 1299-1309, 1979.

Hubbell, S. P.: A unified theory of biogeography and relative species abundance and its application to tropical rain forests and coral reefs, Coral Reefs, 16, 9-21, 1997.

Ito, A.: A historical meta-analysis of global terrestrial net primary productivity: are estimates converging?, Glob. Change Biol., 17, 3161-3175, 2011.

Ives, A. R. and Carpenter, S. R.: Stability and diversity of ecosystems, Science, 317, 58-62, 2007.

Jackson, S. and Williams, J.: Modern analogs in quaternary paleoecology: here today, gone yesterday, gone tomorrow?, Annu. Rev. Earth Pl. Sc., 32, 495-537, 2004.

Johnson, I. R. and Thornley, J. H. M.: A model of instantaneous and daily canopy photosynthesis, J. Theor. Biol., 107, 531-545, 1984.

Jung, M., Reichstein, M., and Bondeau, A.: Towards global empirical upscaling of FLUXNET eddy covariance observations: validation of a model tree ensemble approach using a biosphere model, Biogeosciences, 6, 2001-2013, doi:10.5194/bg-6-20012009, 2009.

Jung, M., Reichstein, M., Ciais, P., Seneviratne, S. I., Sheffield, J., Goulden, M. L., Bonan, G., Cescatti, A., Chen, J., de Jeu, R., Dolman, A. J., Eugster, W., Gerten, D., Gianelle, D., Gobron, N., Heinke, J., Kimball, J., Law, B. E., Montagnani, L., Mu, Q., Mueller, B., Oleson, K. W., Papale, D., Richardson, A. D., Roupsard, O., Running, S., Tomelleri, E., Viovy, N., Weber, U., Williams, C., Wood, E. F., Zaehle, S., and Zhang, K.: Recent decline in the global land evapotranspiration trend due to limited moisture supply, Nature, 467, 951-954, 2010.
Kaduk, J. and Heimann, M.: Assessing the climate sensitivity of the global terrestrial carbon cycle model SILVAN, Phys. Chem. Earth, 21, 529-535, 1996.

Kattge, J., Knorr, W., Raddatz, T. J., and Wirth, C.: Quantifying photosynthetic capacity and its relationship to leaf nitrogen content for global-scale terrestrial biosphere models, Glob. Change Biol., 15, 976-991, 2009.

Kattge, J., Díaz, S., Lavorel, S., Prentice, I. C., Leadley, P., Bönisch, G., Garnier, E., Westoby, M., Reich, P., Wright, I. J., Cornelissen, J. H. C., Violle, C., Harrison, S., van Bodegom, P., Reichstein, M., Enquist, B., Soudzilovskaia, N., Ackerly, D., Anand, M., Atkin, O., Bahn, M., Baker, T., Baldocchi, D. D., Bekker, R., Blanco, C., Blonder, B., Bond, W., Bradstock, R., Bunker, D., Casanoves, F., Cavender-Bares, J., Chambers, J. Q., Chapin, F. S. I., Chave, J., Coomes, D., Cornwell, W., Craine, J., Dobrin, B., Duarte, L., Durka, W., Elser, J., Esser, G., Estiarte, M., Fagan, W., Fang, J., Fernández-Méndez, F., Fidelis, A., Finegan, B., Flores, O., Ford, H., Frank, D., Freschet, G., Fyllas, N., Gallagher, R., Green, W., Gutierrez, A., Hickler, T., Higgins, S. L., Hodgson, J., Jalili, A., Jansen, S., Joly, C., Kerkhoff, A., Kirkup, D., Kitajima, K., Kleyer, M., Klotz, S., Knops, J., Kramer, K., Kühn, I., Kurokawa, H., Laughlin, D., Lee, T., Leishman, M., Lens, F., Lenz, T., Lewis, S., Lloyd, J., Llusià, J., Louault, F., Ma, S., Mahecha, M., Manning, P., Massad, T., Medlyn, B., Messier, J., Moles, A., Müller, S., Nadrowski, K., Naeem, S., Niinemets, Ü., Nöllert, S., Nüske, A., Ogaya, R., Oleksyn, J., Onipchenko, V., Onoda, Y., Ordoñez, J., Overbeck, G., Ozinga, W., Patiño, S., Paula, S., Pausas, J., Peñuelas, J., Phillips, O., Pillar, V., Poorter, H., Poorter, L., Poschlod, P., Prinzing, A., Proulx, R., Rammig, A., Reinsch, S., Reu, B., Sack, L., Salgado-Negret, B., Sardans, J., Shiodera, S., Shipley, B., Siefert, A., Sosinski, E., Soussana, J.-F., Swaine, E., Swenson, N., Thompson, K., Thornton, P., Waldram, M., Weiher, E., White, M., White, S., Wright, J., Yguel, B., Zaehle, S., Zanne, A., and Wirth, C.: TRY - a global database of plant traits, Glob. Change Biol., 17, 2905-2935, 2011.

Kazakou, E., Vile, D., Shipley, B., Gallet, C., and Garnier, E.: Covariations in litter decomposition, leaf traits and plant growth in species from a mediterranean old-field succession, Funct. Ecol., 20, 21-30, 2006.

Kleidon, A. and Mooney, H.: A global distribution of biodiversity inferred from climatic constraints: results from a process-based modelling study, Glob. Change Biol., 6, 507-523, 2000.

Kleidon, A., Fraedrich, K., and Low, C.: Multiple steady-states in the terrestrial atmosphere-biosphere system: a result of a discrete vegetation classification?, Biogeosciences, 4, 707-714, doi:10.5194/bg-4-707-2007, 2007.

Kleidon, A., Adams, J., Pavlick, R., and Reu, B.: Simulated geographic variations of plant species richness, evenness and abundance using climatic constraints on plant functional diversity, Environ. Res. Lett., 4, 1, doi:10.1088/1748-9326/4/1/014007, 2009.

Kleinen, T., Brovkin, V., and Schuldt, R. J.: A dynamic model of wetland extent and peat accumulation: results for the Holocene, Biogeosciences, 9, 235-248, doi:10.5194/bg-9-235-2012, 2012.

Knorr, W. and Heimann, M.: Impact of drought stress and other factors on seasonal land biosphere $\mathrm{CO}_{2}$ exchange studied through an atmospheric tracer transport model, Tellus B, 47, 471-489, 1995. 
Kraft, N. J. B., Valencia, R., and Ackerly, D.: Functional traits and niche-based tree community assembly in an Amazonian forest, Science, 322, 580-582, 2008.

Kraft, N. J. B., Comita, L. S., Chase, J. M., Sanders, N. J., Swenson, N. G., Crist, T. O., Stegen, J. C., Vellend, M., Boyle, B., Anderson, M. J., Cornell, H. V., Davies, K. F., Freestone, A. L., Inouye, B. D., Harrison, S. P., and Myers, J. A.: Disentangling the drivers of diversity along latitudinal and elevational gradients, Science, 333, 1755-1758, 2011.

Kreft, H. and Jetz, W.: Global patterns and determinants of vascular plant diversity, P. Natl. Acad. Sci., 104, 5925-5930, 2007.

Krinner, G., Viovy, N., de Noblet-Ducoudré, N., Ogée, J., Polcher, J., Friedlingstein, P., Ciais, P., Sitch, S., and Prentice, I. C.: A dynamic global vegetation model for studies of the coupled atmosphere-biosphere system, Global Biogeochem. Cy., 19, 1-33, 2005.

Laughlin, D., Fulé, P., Huffman, D., Crouse, J., and Laliberté, E.: Climatic constraints on trait-based forest assembly, J. Ecol., 99, 1489-1499, 2011.

LeBauer, D. S. and Treseder, K. K.: Nitrogen limitation of net primary productivity in terrestrial ecosystems is globally distributed, Ecology, 89, 371-379, 2008.

Lee, E.: Impacts of meteorology-driven seed dispersal on plant migration: implications for future vegetation structure under changing climates, Ph.D. thesis, Massachusetts Institute of Technology, Cambridge, Massachusetts, 2011.

Lee, J.-E., Oliveira, R. S., Dawson, T. E., and Fung, I.: Root functioning modifies seasonal climate, P. Natl. Acad. Sci. USA, 102, 17576-17581, 2005.

Levis, S.: Modeling vegetation and land use in models of the Earth System, Wiley Interdisciplinary Reviews, Climate Change, 1, 840-856, doi:10.1002/wcc.83, 2010.

Liang, M. and Xie, Z.: Improving the vegetation dynamic simulation in a land surface model by using a statistical-dynamic canopy interception scheme, Adv. Atmos. Sci., 25, 610-618, 2008.

Litchman, E., Klausmeier, C. A., Schofield, O. M., and Falkowski, P. G.: The role of functional traits and trade-offs in structuring phytoplankton communities: scaling from cellular to ecosystem level, Ecol. Lett., 10, 1170-1181, 2007.

Litton, C. M. and Giardina, C.: Below-ground carbon flux and partitioning: global patterns and response to temperature, Funct. Ecol., 22, 941-954, 2008.

Litton, C. M., Raich, J. W., and Ryan, M. G.: Carbon allocation in forest ecosystems, Glob. Change Biol., 13, 2089-2109, 2007.

Loarie, S. R., Duffy, P. B., Hamilton, H., Asner, G. P., Field, C. B., and Ackerly, D.: The velocity of climate change, Nature, 462, 1052-1055, doi:10.1038/nature08649, 2009.

Loehle, C.: Height growth rate trade-offs determine northern and southern range limits for trees, J. Biogeogr., 25, 735-742, 1998.

Loreau, M.: Biodiversity and ecosystem functioning: current knowledge and future challenges, Science, 294, 804-808, 2001.

Luo, Y. Q., Randerson, J. T., Abramowitz, G., Bacour, C., Blyth, E., Carvalhais, N., Ciais, P., Dalmonech, D., Fisher, J. B., Fisher, R., Friedlingstein, P., Hibbard, K., Hoffman, F., Huntzinger, D., Jones, C. D., Koven, C., Lawrence, D., Li, D. J., Mahecha, M., Niu, S. L., Norby, R., Piao, S. L., Qi, X., Peylin, P., Prentice, I. C., Riley, W., Reichstein, M., Schwalm, C., Wang, Y. P., Xia, J. Y., Zaehle, S., and Zhou, X. H.: A framework for benchmarking land models, Biogeosciences, 9, 3857-3874, doi:10.5194/bg-9-38572012, 2012.

Luyssaert, S., Inglima, I., Jung, M., Richardson, A. D., Reichsteins, M., Papale, D., Piao, S. L., Schulzes, E. D., Wingate, L., Matteucci, G., Aragao, L., Aubinet, M., Beers, C., Bernhoffer, C., Black, K. G., Bonal, D., Bonnefond, J. M., Chambers, J., Ciais, P., Cook, B., Davis, K. J., Dolman, A. J., Gielen, B., Goulden, M., Grace, J., Granier, A., Grelle, A., Griffis, T., Gruenwald, T., Guidolotti, G., Hanson, P. J., Harding, R., Hollinger, D. Y., Hutyra, L. R., Kolar, P., Kruijt, B., Kutsch, W., Lagergren, F., Laurila, T., Law, B. E., Le Maire, G., Lindroth, A., Loustau, D., Malhi, Y., Mateus, J., Migliavacca, M., Misson, L., Montagnani, L., Moncrieff, J., Moors, E., Munger, J. W., Nikinmaa, E., Ollinger, S. V., Pita, G., Rebmann, C., Roupsard, O., Saigusa, N., Sanz, M. J., Seufert, G., Sierra, C., Smith, M. L., Tang, J., Valentini, R., Vesala, T., and Janssens, I. A.: $\mathrm{CO}_{2}$ balance of boreal, temperate, and tropical forests derived from a global database, Glob. Change Biol., 13, 2509-2537, 2007.

Mahecha, M. D., Reichstein, M., Carvalhais, N., Lasslop, G., Lange, H., Seneviratne, S. I., Vargas, R., Ammann, C., Arain, M. A., Cescatti, A., Janssens, I. A., Migliavacca, M., Montagnani, L., and Richardson, A. D.: Global convergence in the temperature sensitivity of respiration at ecosystem level, Science, 329, 838-840, 2010.

Malcolm, J., Markham, A., Neilson, R., and Garaci, M.: Estimated migration rates under scenarios of global climate change, J. Biogeogr., 29, 835-849, 2002.

Malhi, Y., Aragao, L. E. O. C., Metcalfe, D. B., Paiva, R., Quesada, C. A., Almeida, S., Anderson, L., Brando, P., Chambers, J. Q., da Costa, A. C. L., Hutyra, L. R., Oliveira, P., Patiño, S., Pyle, E. H., Robertson, A. L., and Teixeira, L. M.: Comprehensive assessment of carbon productivity, allocation and storage in three Amazonian forests, Glob. Change Biol., 15, 1255-1274, 2009.

Malhi, Y., Doughty, C., and Galbraith, D.: The allocation of ecosystem net primary productivity in tropical forests, Philos. T. R. Soc. B, 366, 3225-3245, 2011.

Marks, C. O.: The causes of variation in tree seedling traits: the roles of environmental selection versus chance, Evolution, 61, 455-469, 2007.

Marks, C. O. and Lechowicz, M. J.: A holistic tree seedling model for the investigation of functional trait diversity, Ecol. Model., 193, 141-181, 2006.

Masarie, K. A. and Tans, P. P.: Extension and integration of atmospheric carbon dioxide data into a globally consistent measurement record, J. Geophys. Res., 100, 11593-11610, 1995.

McCann, K. S.: The diversity-stability debate, Nature, 405, 228 233, 2000.

McCree, K.: An equation for the rate of respiration of white clover plants grown under controlled conditions, in: Productivity of Photosynthetic Systems; Models and Methods, edited by: Setlik, I., PUDOC, Wageningen, 221-229, 1970.

McGill, B. J., Enquist, B. J., Weiher, E., and Westoby, M.: Rebuilding community ecology from functional traits, Trends Ecol. Evol., 21, 178-185, 2006.

McGill, B. J., Etienne, R. S., Gray, J. S., Alonso, D., Anderson, M. J., Benecha, H. K., Dornelas, M., Enquist, B. J., Green, J. L., He, F., Hurlbert, A. H., Magurran, A. E., Marquet, P. A., Maurer, B. A., Ostling, A., Soykan, C. U., Ug- 
land, K. I., and White, E. P.: Species abundance distributions: moving beyond single prediction theories to integration within an ecological framework, Ecol. Lett., 10, 995-1015, 2007.

McKay, M., Conover, W., and Bechman, R.: A comparison of three methods for selecting values of input variables in the analysis of output from a computer code, Technometrics, 21, 239-245, 1979.

Medvigy, D., Wofsy, S. C., Munger, J. W., Hollinger, D. Y., and Moorcroft, P. R.: Mechanistic scaling of ecosystem function and dynamics in space and time: ecosystem demography model version 2, J. Geophys. Res.-Biogeo., 114, G01002, doi:10.1029/2008JG000812, 2009.

Mercado, L. M., Bellouin, N., Sitch, S., Boucher, O., Huntingford, C., Wild, M., and Cox, P.: Impact of changes in diffuse radiation on the global land carbon sink, Nature, 458, 1014-1017, 2009.

Millennium Ecosystem Assessment: Ecosystems and Human WellBeing: Synthesis, Island Press, Washington DC, 2005.

Monsi, M. and Saeki, T.: Über den Lichtfaktor in den Pflanzengesellschaften und seine Bedeutung für die Stoffproduktion, Jpn. J. Bot., 14, 22-52, 1953.

Moorcroft, P., Hurtt, G., and Pacala, S.: A method for scaling vegetation dynamics: the ecosystem demography model (ED), Ecol. Monogr., 71, 557-585, 2001.

Myneni, R., Hoffman, S., Knyazikhin, Y., Privette, J. L., Glassy, J., Tian, Y., Wang, Y., Song, X., Zhang, Y., Smith, G., Lotsch, A., Friedl, M., Morisette, J., Votava, P., Nemani, R. R., and Running, S.: Global products of vegetation leaf area and fraction absorbed PAR from year one of MODIS data, Remote Sens. Environ., 83, 214-231, 2002.

Myneni, R. B., Yang, W., Nemani, R. R., Huete, A. R., Dickinson, R. E., Knyazikhin, Y., Didan, K., Fu, R., Negrón Juárez, R. I., Saatchi, S. S., Hashimoto, H., Ichii, K., Shabanov, N. V., Tan, B., Ratana, P., Privette, J. L., Morisette, J. T., Vermote, E. F., Roy, D. P., Wolfe, R. E., Friedl, M. A., Running, S. W., Votava, P., El-Saleous, N., Devadiga, S., Su, Y., and Salomonson, V. V.: Large seasonal swings in leaf area of Amazon rainforests, P. Natl. Acad. Sci. USA, 104, 4820-4823, 2007.

Neilson, R., Pitelka, L., Solomon, A., Nathan, R., Midgley, G., Fragoso, J., Lischke, H., and Thompson, K.: Forecasting regional to global plant migration in response to climate change, Bioscience, 55, 749-759, 2005.

Norby, R., DeLucia, E., Gielen, B., Calfapietra, C., Giardina, C., King, J., Ledford, J., McCarthy, H., Moore, D., and Ceulemans, R.: Forest response to elevated $\mathrm{CO}_{2}$ is conserved across a broad range of productivity, P. Natl. Acad. Sci. USA, 102, 18052, 2005.

Ollinger, S. V., Richardson, A. D., Martin, M. E., Hollinger, D. Y., Frolking, S. E., Reich, P. B., Plourde, L. C., Katul, G. G., Munger, J. W., Oren, R., Smith, M. L., U, K. T. P., Bolstad, P. V., Cook, B. D., Day, M. C., Martin, T. A., Monson, R. K., and Schmid, H. P.: Canopy nitrogen, carbon assimilation, and albedo in temperate and boreal forests: functional relations and potential climate feedbacks, P. Natl. Acad. Sci. USA, 105, 19336-19341, 2008.

Olson, R. J., Scurlock, J. M. O., Prince, S. D., Zheng, D. L., and Johnson, K. R.: NPP Multi-Biome: NPP and Driver Data for Ecosystem Model-Data Intercomparison. Data set., Tech. rep., Environmental Sciences Division, Oak Ridge National Labora- tory, ORNL Distributed Active Archive Center for Biogeochemical Dynamics, Oak Ridge, TN USA, 2001.

O'Malley, M. A.: The nineteenth century roots of "everything is everywhere", Nat. Rev. Microbiol., 5, 647-651, 2007.

Page, S. E., Siegert, F., Rieley, J. O., Boehm, H.-D. V., Jaya, A., and Limin, S.: The amount of carbon released from peat and forest fires in Indonesia during 1997, Nature, 420, 61-65, 2002.

Pielou, E. C.: The measurement of diversity in different types of biological collections, J. Theor. Biol., 13, 131-144, 1966.

Potter, C., Randerson, J., Field, C., Matson, P., Vitousek, P., Mooney, H., and Klooster, S.: Terrestrial ecosystem production - a process model-based on global satellite and surface data, Global Biogeochem. Cy., 7, 811-841, 1993.

Prentice, I. C., Bondeau, A., Cramer, W., Harrison, S. P., Hickler, T., Lucht, W., Sitch, S., Smith, B., and Sykes, M. T.: Dynamic global vegetation modeling: quantifying terrestrial ecosystem responses to large-scale environmental change, in: Terrestrial Ecosystems in a Changing World, edited by: Canadell, J. G., Pataki, D. E., and Pitelka, L. F., Springer, Berlin, Heidelberg, 175-192, 2007.

Priestley, C. and Taylor, R.: On the assessment of surface heatflux and evaporation using large-scale parameters, Mon. Weather Rev., 100, 81-89, 1972.

Prieto, I., Armas, C., and Pugnaire, F. I.: Water release through plant roots: new insights into its consequences at the plant and ecosystem level, New Phytol., 193, 830-841, 2012.

Proulx, R., Wirth, C., Voigt, W., Weigelt, A., Roscher, C., Attinger, S., Baade, J., Barnard, R. L., Buchmann, N., Buscot, F., Eisenhauer, N., Fischer, M., Gleixner, G., Halle, S., Hildebrandt, A., Kowalski, E., Kuu, A., Lange, M., Milcu, A., Niklaus, P. A., Oelmann, Y., Rosenkranz, S., Sabais, A., Scherber, C., Scherer-Lorenzen, M., Scheu, S., Schulze, E.-D., Schumacher, J., Schwichtenberg, G., Soussana, J.-F., Temperton, V. M., Weisser, W. W., Wilcke, W., and Schmid, B.: Diversity promotes temporal stability across levels of ecosystem organization in experimental grasslands, PLoS one, 5, e13382, doi:10.1371/journal.pone.0013382, 2010.

Purves, D. and Pacala, S.: Predictive models of forest dynamics, Science, 320, 1452-1453, 2008.

Qian, T., Dai, A., Trenberth, K. E., and Oleson, K. W.: Simulation of global land surface conditions from 1948 to 2004. Part I: forcing data and evaluations, J. Hydrometeorol., 7, 953-975, 2006.

Quesada, C. A., Lloyd, J., Anderson, L. O., Fyllas, N. M., Schwarz, M., and Czimczik, C. I.: Soils of Amazonia with particular reference to the RAINFOR sites, Biogeosciences, 8, 1415-1440, doi:10.5194/bg-8-1415-2011, 2011.

Quetier, F., Thebault, A., and Lavorel, S.: Plant traits in a state and transition framework as markers of ecosystem response to landuse change, Ecol. Monogr., 77, 33-52, 2007.

Quillet, A., Peng, C., and Garneau, M.: Toward dynamic global vegetation models for simulating vegetation-climate interactions and feedbacks: recent developments, limitations, and future challenges, Environ. Rev., 18, 333-353, 2010.

Raddatz, T. J., Reick, C. H., Knorr, W., Kattge, J., Roeckner, E., Schnur, R., Schnitzler, K. G., Wetzel, P., and Jungclaus, J.: Will the tropical land biosphere dominate the climate-carbon cycle feedback during the twenty-first century?, Clim. Dynam., 29, 565-574, 2007.

Randerson, J. T., Hoffman, F. M., Thornton, P. E., Mahowald, N. M., Lindsay, K., Leee, Y.-H., Nevison, C. D., 
Doney, S., Bonan, G., Stoeckli, R., Covey, C., Running, S. W., and Fung, I. Y.: Systematic assessment of terrestrial biogeochemistry in coupled climate-carbon models, Glob. Change Biol., 15, 2462-2484, 2009.

Reich, P. B., and Oleksyn, J.: Global patterns of plant leaf N and P in relation to temperature and latitude, P. Natl. Acad. Sci. USA, 101, 11001-11006, 2004.

Reich, P. B., Walters, M. B., and Ellsworth, D. S.: From tropics to tundra: global convergence in plant functioning, P. Natl. Acad. Sci. USA, 94, 13730-13734, 1997.

Reich, P. B., Walters, M., Ellsworth, D., Vose, J., Volin, J., Gresham, C., and Bowman, W.: Relationships of leaf dark respiration to leaf nitrogen, specific leaf area and leaf life-span: a test across biomes and functional groups, Oecologia, 114, 471-482, 1998.

Reich, P. B., Hobbie, S. E., Lee, T., Ellsworth, D. S., West, J. B., Tilman, D., Knops, J. M. H., Naeem, S., and Trost, J.: Nitrogen limitation constrains sustainability of ecosystem response to $\mathrm{CO}_{2}$, Nature, 440, 922-925, 2006.

Reich, P. B., Wright, I. J., and Lusk, C. H.: Predicting leaf physiology from simple plant and climate attributes: a global GLOPNET analysis, Ecol. Appl., 17, 1982-1988, 2007.

Reiss, J., Bridle, J. R., Montoya, J. M., and Woodward, G.: Emerging horizons in biodiversity and ecosystem functioning research, Trends Ecol. Evol., 24, 505-514, 2009.

Reu, B., Proulx, R., Bohn, K., Dyke, J. G., Kleidon, A., Pavlick, R., and Schmidtlein, S.: The role of climate and plant functional trade-offs in shaping global biome and biodiversity patterns, Global Ecol. Biogeogr., 20, 570-581, 2010.

Reu, B., Zaehle, S., Proulx, R., Bohn, K., Kleidon, A., Pavlick, R., and Schmidtlein, S.: The role of plant functional trade-offs for biodiversity changes and biome shifts under scenarios of global climatic change, Biogeosciences, 8, 1255-1266, doi:10.5194/bg8-1255-2011, 2011.

Reu, B., Zaehle, S., Bohn, K., Pavlick, R., Schmidtlein, S. Williams, J. W., and Kleidon, A.: No-analogue vegetation types do not correspond to no-analogue climates in scenarios of global warming, Global Ecol. Biogeogr., accepted, 2013.

Robock, A.: The seasonal cycle of snow cover, sea ice and surface albedo, Mon. Weather Rev., 108, 267-285, 1980.

Roeckner, E., Arpe, K., Bengtsson, L., Christoph, M., Claussen, M., Dümenil, L., Esch, M., Giorgetta, M., Schlese, U., and Schulzweida, U.: The Atmospheric General Circulation Model ECHAM-4: Model Description and Simulation of Present-Day Climate, Max Planck Institute for Meteorology, Hamburg, Germany, 1996.

Ryan, M.: A simple method for estimating gross carbon budgets for vegetation in forest ecosystems, Tree Physiol., 9, 255-266, 1991.

Ryu, Y., Baldocchi, D., Kobayashi, H., van Ingen, C., Li, J., Black, T. A., Beringer, J., van Gorsel, E., Knohl, A., Law, B. E., and Roupsard, O.: Integration of MODIS land and atmosphere products with a coupled-process model to estimate gross primary productivity and evapotranspiration from $1 \mathrm{~km}$ to global, Global Biogeochem., 25, GB4017, doi:10.1029/2011GB004053, 2011.

Saatchi, S. S., Houghton, R. A., Alvala, R. C. D. S., Soares, J. V., and Yu, Y.: Distribution of aboveground live biomass in the Amazon Basin, Glob. Change Biol., 13, 816-837, 2007.

Saatchi, S. S., Harris, N. L., Brown, S., Lefsky, M., Mitchard, E. T., Salas, W., and Morel, A.: Benchmark map of forest carbon stocks in tropical regions across three continents, P. Natl. Acad. Sci. USA, 108, 9899-9904, 2011.

Samanta, A., Ganguly, S., Hashimoto, H., Devadiga, S., Vermote, E., Knyazikhin, Y., Nemani, R. R., and Myneni, R.: Amazon forests did not green-up during the 2005 drought, Geophys. Res. Lett., 37, L05401, doi:10.1029/2009GL042154, 2010.

Scheiter, S. and Higgins, S. L.: Impacts of climate change on the vegetation of Africa: an adaptive dynamic vegetation modelling approach, Glob. Change Biol., 15, 2224-2246, 2009.

Shinozaki, K., Yoda, K., Hozumi, K., and Kira, T.: A quantitative analysis of plant form - the pipe model theory, 1. basic analysis, Jpn. J. Ecol., 14, 97-105, 1964.

Shipley, B., Lechowicz, M., Wright, I. J., and Reich, P. B.: Fundamental trade-offs generating the worldwide leaf economics spectrum, Ecology, 87, 535-541, 2006a.

Shipley, B., Vile, D., and Garnier, E.: From plant traits to plant communities: a statistical mechanistic approach to biodiversity, Science, 314, 812-814, 2006b.

Sitch, S., Smith, B., Prentice, I. C., Arneth, A., Bondeau, A., Cramer, W., Kaplan, J. O., Levis, S., Lucht, W., Sykes, M. T., Thonicke, K., and Venevsky, S.: Evaluation of ecosystem dynamics, plant geography and terrestrial carbon cycling in the LPJ dynamic global vegetation model, Glob. Change Biol., 9, 161-185, 2003.

Sitch, S., Huntingford, C., Gedney, N., Levy, P. E., Lomas, M., Piao, S. L., Betts, R. A., Ciais, P., Cox, P., Friedlingstein, P., Jones, C. D., Prentice, I. C., and Woodward, F. I.: Evaluation of the terrestrial carbon cycle, future plant geography and climatecarbon cycle feedbacks using five Dynamic Global Vegetation Models (DGVMs), Glob. Change Biol., 14, 2015-2039, 2008.

Smith, T. and Huston, M.: A theory of the spatial and temporal dynamics of plant communities, Plant Ecol., 83, 49-69, 1989.

Sonnier, G., Shipley, B., and Navas, M.-L.: Plant traits, species pools and the prediction of relative abundance in plant communities: a maximum entropy approach, J. Veg. Sci., 21, 318-331, 2010.

Stoeckli, R., Lawrence, D. M., Niu, G. Y., Oleson, K. W., Thornton, P. E., Yang, Z. L., Bonan, G., Denning, A. S., and Running, S. W.: Use of FLUXNET in the community land model development, J. Geophys. Res.-Biogeo., 113, G01025, doi:10.1029/2007JG000562, 2008.

Swenson, N. G. and Weiser, M.: Plant geography upon the basis of functional traits: an example from Eastern North American trees, Ecology, 91, 2234-2241, 2010.

Taylor, K.: Summarizing multiple aspects of model performance in a single diagram, J. Geophys. Res.-Atmos., 106, 7183-7192, 2001.

Thonicke, K., Venevsky, S., Sitch, S., and Cramer, W.: The role of fire disturbance for global vegetation dynamics: coupling fire into a Dynamic Global Vegetation Model, Global Ecol. Biogeogr., 10, 661-677, 2008.

Thornley, J.: Respiration, growth and maintenance in plants, Nature, 227, 304-305, 1970.

Thornton, P. E., Lamarque, J.-F., Rosenbloom, N. A., and Mahowald, N. M.: Influence of carbon-nitrogen cycle coupling on land model response to $\mathrm{CO}_{2}$ fertilization and climate variability, Global Biogeochem. Cy., 21, GB4018, doi:10.1029/2006GB002868, 2007. 
Thum, T., Räisänen, P., Sevanto, S., Tuomi, M., Reick, C., Vesala, T., Raddatz, T., Aalto, T., Järvinen, H., Altimir, N., Pilegaard, K., Nagy, Z., Rambal, S., and Liski, J.: Soil carbon model alternatives for ECHAM5/JSBACH climate model: evaluation and impacts on global carbon cycle estimates, J. Geophys. Res., 116, G02028, doi:10.1029/2010JG001612, 2011.

Tilman, D., Reich, P. B., and Knops, J. M. H.: Biodiversity and ecosystem stability in a decade-long grassland experiment, Nature, 441, 629-632, 2006.

Van Bodegom, P. M., Douma, B., Witte, F. M., Ordoñez, J. C., Bartholomeus, R. P., and Aerts, R.: Going beyond limitations of plant functional types when predicting global ecosystem-atmosphere fluxes: exploring the merits of traitsbased approaches, Global Ecol. Biogeogr., 21, 625-636, doi:10.1111/j.1466-8238.2011.00717.x, 2011.

van der Werf, G. R., Randerson, J. T., Giglio, L., Collatz, G. J., Kasibhatla, P. S., and Arellano Jr., A. F.: Interannual variability in global biomass burning emissions from 1997 to 2004, Atmos. Chem. Phys., 6, 3423-3441, doi:10.5194/acp-6-3423-2006, 2006.

van der Werf, G. R., Dempewolf, J., Trigg, S. N., Randerson, J. T., Kasibhatla, P. S., Giglio, L., Murdiyarso, D., Peters, W., Morton, D. C., Collatz, G. J., Dolman, A. J., and DeFries, R. S.: Climate regulation of fire emissions and deforestation in equatorial Asia, P. Nal. Acad. Sci., 105, 20350-20355, 2008.

Verheijen, L. M., Brovkin, V., Aerts, R., Bönisch, G., Cornelissen, J. H. C., Kattge, J., Reich, P. B., Wright, I. J., and van Bodegom, P. M.: Impacts of trait variation through observed traitclimate relationships on performance of a representative Earth System model: a conceptual analysis, Biogeosciences Discuss., 9, 18907-18950, doi:10.5194/bgd-9-18907-2012, 2012.

Vieira, S., de Camargo, P. B., Selhorst, D., da Silva, R., Hutyra, L., Chambers, J. Q., Brown, I. F., Higuchi, N., dos Santos, J., Wofsy, S. C., Trumbore, S. E., and Martinelli, L. A.: Forest structure and carbon dynamics in Amazonian tropical rain forests, Oecologia, 140, 468-479, 2004.

Vile, D., Shipley, B., and Garnier, E.: Ecosystem productivity can be predicted from potential relative growth rate and species abundance, Ecol. Lett., 9, 1061-1067, 2006.

Wang, A. and Price, D. T.: Estimating global distribution of boreal, temperate, and tropical tree plant functional types using clustering techniques, J. Geophys. Res., 112, G01024, doi:10.1029/2006JG000252, 2007.
Webb, C. T., Hoeting, J. A., Ames, G. M., Pyne, M. I., and LeRoy Poff, N.: A structured and dynamic framework to advance traits-based theory and prediction in ecology, Ecol. Lett., 13, 267-283, 2010.

Westoby, M. and Wright, I. J.: Land-plant ecology on the basis of functional traits, Trends Ecol. Evol., 21, 261-268, 2006.

Westoby, M., Falster, D., Moles, A., Vesk, P., and Wright, I. J.: Plant ecological strategies: some leading dimensions of variation between species, Annu. Rev. Ecol. Syst., 33, 125-159, 2002.

Wigmosta, M., Vail, L., and Lettenmaier, D.: A distributed hydrology-vegetation model for complex terrain, Water Resour. Res., 30, 1665-1679, 1994.

Williams, J. W. and Jackson, S. T.: Novel climates, no-analog communities, and ecological surprises, Front. Ecol. Environ., 5, 475482, 2007.

Wolf, A., Field, C. B., and Berry, J. A.: Allometric growth and allocation in forests: a perspective from FLUXNET, Ecol. Appl., 21, 1546-1556, 2011.

Woodward, F. I., Lomas, M. R., Betts, R. A., Wagner, A., Mulligan, M., and Hewitt, C. N.: Vegetation-climate feedbacks in a greenhouse world, Philos. T. R. Soc. B, 353, 29-39, 1998.

Wright, I. J., Reich, P. B., Cornelissen, J. H. C., Falster, D. S., Garnier, E., Hikosaka, K., Lamont, B. B., Lee, W., Oleksyn, J., Osada, N., Poorter, H., Villar, R., Warton, D. I., and Westoby, M.: Assessing the generality of global leaf trait relationships, New Phytol., 166, 485-496, 2005.

Zaehle, S. and Friend, A. D.: Carbon and nitrogen cycle dynamics in the O-CN land surface model: 1. model description, site-scale evaluation, and sensitivity to parameter estimates, Global Biogeochem. Cy., 24, GB1005, doi:10.1029/2009GB003521, 2010.

Zaehle, S., Friend, A. D., Friedlingstein, P., Dentener, F., Peylin, P., and Schulz, M.: Carbon and nitrogen cycle dynamics in the O$\mathrm{CN}$ land surface model: 2. role of the nitrogen cycle in the historical terrestrial carbon balance, Global Biogeochem. Cy., 24, GB1006, doi:10.1029/2009GB003522, 2010.

Zhao, M., Heinsch, F., Nemani, R. R., and Running, S.: Improvements of the MODIS terrestrial gross and net primary production global data set, Remote Sens. Environ., 95, 164-176, 2005.

Zhao, M., Running, S. W., and Nemani, R. R.: Sensitivity of Moderate Resolution Imaging Spectroradiometer (MODIS) terrestrial primary production to the accuracy of meteorological reanalyses, J. Geophys. Res.-Biogeo., 111, G01002, doi:10.1029/2004JG000004, 2006. 